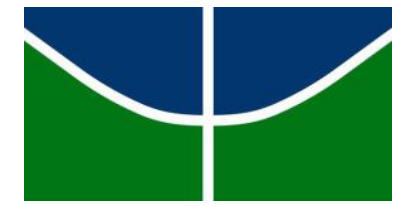

Universidade de Brasília

Departamento de Biologia Celular

Programa de Pós-graduação em Biologia Molecular

\title{
Identificação e caracterização do secretoma e celulossoma de um novo isolado de Clostridium thermocellum (B8) para a sacarificação de biomassas lignocelulósicas
}

\section{KAREN OFUJI OSIRO}




\section{KAREN OFUJI OSIRO}

\section{Identificação e caracterização do secretoma e celulossoma de um novo isolado de Clostridium thermocellum (B8) para a sacarificação de biomassas lignocelulósicas}

Orientadora: Prof. Drª. Eliane Ferreira Noronha

Dissertação apresentada ao Programa de Pós-graduação em Biologia Molecular da Universidade de Brasília como parte dos requisitos para obtenção do titulo de Mestre.

Brasilia/DF 


\section{BANCA EXAMINADORA}

$\checkmark$ Membro Interno: Prof. Dr. ․ Nádia Skorupa Parachin. Departamento de Biologia Celular/ Laboratório de Biologia Molecular da Universidade de Brasilia.

$\checkmark$ Membro Externo: Dr.ạ Elaine Nascimento Aquino. Laboratório de Microbiologia / Instituto Federal de Brasilia - Campus Gama.

$\checkmark$ Suplente: Prof. Dr. Edivaldo Ximenes Ferreira Filho. Departamento de Biologia Celular/ Laboratório de Enzimologia da Universidade de Brasilia.

Orientadora: Prof. Dr..$^{\text {a }}$ Eliane Ferreira Noronha

23 de Abril de 2015. 


\section{AGRADECIMENTOS}

À minha orientadora, Professora Eliane Ferreira Noronha, por ter me acolhido desde a iniciação científica, e por todo apoio, conselhos, orientação e muita paciência durante esta jornada. Será sempre uma referência e um exemplo de profissional, obrigada por todos esses anos.

À professora Nádia Skorupa Parachin, pelos conselhos e suporte. Obrigada por toda ajuda. À Elaine Nascimento, pela ajuda e amizade durante a pesquisa. Agradeço também por fazerem parte da minha banca de mestrado.

Ao professor Carlos Roberto Félix, por ser um exemplo de profissional com um coração enorme. Aos professores Edivaldo Ximenes, Ricardo Krüger e Tatsuya Nagata, pelo conhecimento compartilhado.

Às técnicas mais animadas e divertidas, Marísia e Margarete, por toda amizade, carinho e cafés.

À Jackeline Leite, por todos os ensinamentos e principalmente pela grande amizade. À Brenda Camargo por ter sido uma grande amiga, e que deu força em grande parte dos experimentos deste trabalho.

À Rachel Satomi, que estagiou comigo e me ajudou em vários experimentos, deixando eles mais divertidos.

Às amizades que fiz no laboratório, obrigada a todos da enzimologia. Cada um de vocês contribuiu de alguma forma para minha dissertação e crescimento pessoal, seja com um conselho, tirando dúvidas, ou até mesmo pela companhia e amizade quando precisei. Agradeço por todos os momentos de confraternização, congressos, happy hours, e El Paso juntos.

À Leonora e a Débora, por terem me ajudado no experimento de HPLC e à Mary-Ann e Amanda pela ajuda no DLS.

Ao meu companheiro e melhor amigo Caio, que acompanhou de perto desde a minha entrada na UnB até este momento. Seu amor e cuidado foram essenciais para que eu chegasse até aqui, te amo.

Aos meus amigos Raul, Mila e Fernando Hiro, vocês são pra vida toda.

Aos meus amigos biólogos, Thaís, Tamara, Thales e Ana. Sem vocês eu não seria a mesma bióloga, vocês fazem parte de tudo isso e me ajudaram a manter o sorriso mesmo nas situações mais difíceis.

Agradeço em especial à minha família, por serem à base de tudo. 


\section{APOIO FINANCEIRO}

Este projeto foi realizado por meio do apoio financeiro das agências de fomento CNPq (Conselho Nacional de Desenvolvimento), FAPDF (Fundação de Apoio à Pesquisa do Distrito Federal) e com a concessão de bolsa de estudos fornecida pela CAPES (Coordenação de Aperfeiçoamento de Pessoal de Nível Superior). 


\section{RESUMO}

O presente trabalho tem como propósito a purificação de celulossomas, sua caracterização e do secretoma de um novo isolado de Clostridium thermocellum B8, obtido do rúmen de caprino. Para obtenção das amostras proteicas $C$. thermocellum foi cultivada em meio líquido contendo celulose como fonte de carbono. O secretoma que constitui a amostra de Proteínas Ligadas á Celulose (PLC) foi eluído a partir da celulose residual da cultura. As frações cromatográficas do principal pico de proteína resultante do fracionamento da amostra PLC em uma cromatografia de exclusão molecular (Superdex S-200) compõe a amostra de Celulossomas Parcialmente Purificados (CPP). Ambas as amostras apresentaram atividades enzimáticas celulolíticas e xilanolíticas. As análises de SDS-PAGE, DLS e espectrometria de massa confirmaram que a amostra CPP se trata de um complexo celulossomal, com uma massa molecular estimada de 11,3 MDa \pm 4,4 MDa. As proteínas constituintes de CPP foram identificadas por espectrometria de massa LC-MS/MS, levando a identificação de: proteína estrutural (CipA), glicosil hidrolases das famílias 5, 8, 9, 10 e 48 e transportadores do tipo ABC. $\mathrm{Na}$ amostra PLC foram identificadas principalmente proteínas envolvidas no catabolismo de polissacarídeos, além de proteínas relacionadas com 0 mecanismo de transporte de moléculas e processos metabólicos. Dentre as proteínas que têm a função no catabolismo de polissacarídeos, foram identificados glicosil hidrolases das famílias 5, 8, 9, 10, 11, 26, 30, 43 e 53, com atividades de endoglucanase, celobiohidrolases, endoxilanases, endoxilanases com esterase feruloil e acetil com função de xilana esterase, xiloglucanases, arabinoxilanase, glucoxilana xilanahidrolase, arabinofuranosidase, exogalactanase, endogalactanase (arabinogalactana), quitinase, mananase. CPP e PLC apresentaram atividade máxima no intervalo de temperatura entre $60^{\circ} \mathrm{C}-70^{\circ} \mathrm{C}, \mathrm{pH} 5.0$, e estabilidade térmica a 50,60 e $70^{\circ} \mathrm{C}$, principalmente, no que diz respeito a amostra de PLC. As atividades holocelulolíticas de PLC foram inibidas por compostos fenólicos, enquanto que CPP apresentou um aumento nas atividades de CMCase e xilanase na presença de vários fenóis. A partir dos resultados da sacarificação dos substratos de celulose, palha de cana e piolho de algodão por PLC e CPP, foi observado maiores quantidades de açúcares liberados principalmente a $50^{\circ} \mathrm{C}$, em comparação com os dados de $60^{\circ} \mathrm{C}$, após 10 dias de incubação. Entretanto, foi observado que após o segundo dia de sacarificação, que os produtos obtidos pela desconstrução de materiais lignocelulósicos, acabam por interferir na velocidade de hidrólise das enzimas de C. thermocellum B8. Em conclusão, este estudo demonstrou potencial para utilização de ambas as amostras (CPP e PLC) de C. thermocellum B8 para hidrolisar biomassas lignocelulósicas, destacando-se 0 aumento da atividade celulolítica e xilanolítica de CPP na presença de compostos fenólicos, além da termoestabilidade de PLC.

Palavras chaves: celulossoma, Clostridium thermocellum, fenóis e sacarificação. 


\begin{abstract}
The present work aimed the purification and characterization of the secretome produced by Clostridium thermocellum B8, a novel isolate obtained from goat rumen, after growth on liquid medium containing cellulose as carbon source. The secretome were eluted from the residual substrate, constituting the Protein Linked on Cellulose (PLC) sample. The main protein peak of PLC fractionation onto a molecular exclusion (Superdex S-200) composes the Cellulosomes Partially Purified (CPP) sample. Both samples presented enzymatic activities of cellulases and xylanases. It was elucidated through SDSPAGE, DLS and mass spectrometry that CPP sample is a cellulosome complex, with an estimated mass of 11,3 MDa \pm 4,4 MDa. CPP's constituting proteins were identified by mass spectrometry LC-MS/MS leading the identification of: scaffolding protein (CipA), glycoside hydrolase proteins classified on the families 5, 8, 9, 10 and 48 and $A B C$ transporter substrate-binding protein. In the PLC sample were identified mostly proteins involved in the catabolism of polysaccharides, besides proteins related to the transport mechanism molecules and metabolic processes. Among the proteins which have catabolism of polysaccharides function, were identified glycosyl hydrolase families 5, 8, 9, $10,11,26,30,43$ and 53 with endoglucanase activity, cellobiohydrolases, endoxylanases, endoxylanases with feruloil esterase and acetyl xylan esterase function, xyloglucanases, arabinoxylanase, glucoxylana xylanhydrolase, arabinofuranosidase, exogalactanase, endogalactanase (arabinogalactan), chitinase, mannanase. CPP and PLC presented maximal activity in the range of $60^{\circ}$ to $70^{\circ} \mathrm{C}$ and $\mathrm{pH} 5.0$, and also those samples have a high thermostability at 50,60 and $70^{\circ} \mathrm{C}$ mainly for PLC sample. PLC holocelullolytic activities were inhibited by phenolic compounds, while CPP showed improvement or was less inhibited on its xylanase and CMCase activity in phenols presence. Saccharification results of cellulose, sugarcane straw and cotton gin waste by PLC and CPP, showed highest amounts of sugar released mostly at $50^{\circ} \mathrm{C}$ in comparison to $60^{\circ} \mathrm{C}$ and after 10 days of incubation. In summary, this research demonstrated the potential of using CPP and PLC samples of $C$. thermocellum B8 to hydrolyze lignocellulosic biomasses, with the ability of CPP increase its holocelullolytic activities in the presence of phenolic compounds, and the interesting thermostability of PLC sample, both being valuable for second generation production of biofuels.
\end{abstract}

Key words: cellulosome, Clostridium thermocellum, phenols and saccharification. 


\section{LISTA DE FIGURAS}

igura 1. Esquema ilustrativo de possíveis produtos de uma biorrefinaria baseada em materiais lignocelulósicos. Extraído e adaptado de Kamm and Kamm (2004).

Figura 2. Estrutura da biomassa lignocelulósica. Dentre os principais componentes da parede celular vegetal, a estrutura da celulose cristalina é a mais abundante, situada na parte mais interna da microfibrila. A hemicelulose, juntamente com a lignina, está localizada em volta da celulose, formando uma estrutura organizada, a qual confere rigidez e estabilidade para planta. Modificado de Rubin, E. M. (2008). 7

Figura 3. Estrutura molecular da celulose e mecanismo de ação de endoglucanases, exoglucanases e $\beta$-glicosidases. Neste exemplo, a partir da extremidade redutora liberada pela endoglucanase, a exoglucanase gera um dissacarídeo, em que este será posteriormente catalizado por $\beta$ glicosidases. Extraído e adaptado de Kumar, Singh e Singh (2008) e Held (2012).

Figura 4. Estrutura da xilana com ramificações laterais e suas enzimas hidrolíticas. Extraído e adaptado de Shallom e Shoham (2003).

Figura 5. Esquema ilustrativos dos componentes de celulossomas. Interação entre os domínios coesinas e doquerinas tipo I e a ilustração das estruturas de doquerina tipo II e CBM, ambos pertencentes à escafoldina. Adaptado de Fontes e Gilbert (2010). 16

Figura 6. Estrutura ilustrativo dos componentes de policelulossomas. Interação entre as proteínas S-Layers dos celulossomas na parede celular (SdbA, OlpB e Orf2) e no meio extracelular (Cthe 0736) com a proteína estrutural (CipA). Adaptado de Fontes e Gillbert (2010). 17 
Figura 7. Esquema da metodologia para produção das amostras PLC e CPP, seguido dos experimentos de caracterização, identificação por nanoUPLC-MS(E), teste de fenóis e sacarificação, com o objetivo de comparação entre as amostras.

Figura 8. Perfil cromatográfico $(280 \mathrm{~nm})$ em mAU após o fracionamento da amostra PLC na coluna High-Load Superdex 200 e as atividades enzimáticas (xilanase e CMCase) (A), medidas pelo ensaio colorimétrico (DNS) e normalizadas por meio da unidade internacional (UI) estabelecida como ( $\mu$ mol.L-1 de açúcar redutor.min-1.mL-1). As figuras $(B)$ e (C) representam géis de SDS-PAGE (12\%) dos picos da cromatografia, PI e PII. (B) MM: marcadores de massa molecular e frações PI de 13 a 20; (C) MM: marcadores de massa molecular e frações PII de 30 até 34. 33

Figura 9. Análise da amostra CPP por meio da técnica de espalhamento de luz dinâmica (DLS) sem o tratamento com Tween80 (A), com Tween 0,1\% (B) e Tween $1 \%(C)$. 34

Figura 10. Atividades celulolítica e xilanolítica obtidos nas amostras PLC e CPP $\left({ }^{*} p \leq 0,05\right)$. 35

Figura 11. Proteínas identificadas da amostra PLC por espectrometria de massa e categorizadas por suas funções. 36

Figura 12. Proteínas identificadas da amostra CPP por espectrometria de massa e categorizadas por suas funções.

Figura 13. Efeito de temperatura $(A)$ e $\mathrm{pH}(B)$ sob as atividades de CMCase e xilanase nas amostras PLC e CPP. (A) Teste da temperatura sob as atividades de CMCase e xilanase das amostras de PLC e CPP, no intervalo de temperaturas de $40^{\circ} \mathrm{C}, 50^{\circ} \mathrm{C}, 60^{\circ} \mathrm{C}, 65^{\circ} \mathrm{C}, 70^{\circ} \mathrm{C}, 80^{\circ} \mathrm{C}$. (B) Efeito do $\mathrm{pH}$ sob as atividades de $\mathrm{CMCase}$ e xilanase das amostras de 
PLC e CPP para os $\mathrm{pH}$ 3, 4, 5, 6, 7, 8 e 9. A barra de erro representa o desvio padrão de replicatas técnicas. Na figura 13A, (*) P $\leq 0,05$ entre PLC e CPP para a atividade de CMCase $(\diamond)$ e $p \leq 0,05$ entre PLC e CPP para atividade de xilanase.

Figura 14. Avaliação da termoestabilidade com relação às atividades de CMCase e xilanase da amostra PLC a $50^{\circ} \mathrm{C}$ e $60^{\circ} \mathrm{C}(\mathrm{A})$, CPP a $50^{\circ} \mathrm{C}$ e $60^{\circ} \mathrm{C}(\mathrm{B})$, PLC a $70^{\circ} \mathrm{C}(\mathrm{C})$ e CPP a $70^{\circ} \mathrm{C}$ (D). A barra de erro representa o desvio padrão de replicatas técnicas.

Figura 15. Efeito dos compostos fenólicos (vanilina (V), ácido tânico (AT), ácido ferúlico $(A F)$, ácido cinâmico $(A C)$, ácido p-cumárico $(A P C)$ e 4-hidroxibenzóico $(4 \mathrm{HB}))$ nas atividades de CMCase e xilanase das amostras PLC e CPP. Atividade de xilanase das amostras PLC e CPP durante a presença de fenóis $(A)$. ( $\bullet p \leq 0,05$ para comparação entre PLC e CPP com relação à atividade de xilanase com adição de fenóis. Atividade de CMCase das amostras PLC e CPP durante a presença de fenóis (B). ( $\left.{ }^{*}\right)$ P $\leq 0,05$ para comparação entre PLC e CPP com relação à atividade de CMCase com adição de fenóis. $p \leq 0,05$ entre os padrões (atividade enzimática sem fenóis) quando comparado as amostras PLC e CPP na presença de AT, AF, AC, a APC e 4HB, para xilanase e atividades CMCase. A barra de erro representa o desvio padrão de replicatas técnicas.

Figura 16. Quantidade de açúcar liberado durante a sacarificação por PLC (A) e CPP (B) dos substratos de celulose, palha de cana-de-açúcar e piolho algodão a $50^{\circ} \mathrm{C}$ e $60^{\circ} \mathrm{C}$, com agitação a $180 \mathrm{rpm}$ durante 10 dias. Os açúcares redutores liberados foram detectados por meio de um ensaio colorimétrico (DNS)

Figura 17. Cinética da sacarificação. Quantidade de açúcar liberado durante a sacarificação por tempo de incubação pelas amostras de PLC (A) e CPP (B) a partir dos substratos de celulose, palha de cana-de-açúcar e piolho algodão a $50^{\circ} \mathrm{C}$ e $60^{\circ} \mathrm{C}$ 52 


\section{LISTA DE TABELAS}

Tabela 1. Atividades e atividades específicas das amostras PLC e CPP.

Tabela 2. Quantidade em nanogramas (ngram) de xilanases, engoglucanases e exoglucanases nas amostras PLC e CPP identificadas por espectrometria de massa e normalizadas pela adição de Fosforilase - P00489 PHS2_COELHO.

Tabela 3. Proteínas identificadas da amostra PLC por nanoUPLC-MS(E). 39

Tabela 4. Proteínas identificadas da amostra CPP por nanoUPLC-MS(E) 45

Tabela 5. Análise de açúcares obtidos durante a hidrólise enzimática da celulose a $50^{\circ} \mathrm{C}$ e $60^{\circ} \mathrm{C}$

Tabela 6. Análise de açúcares obtidos durante a hidrólise enzimática de piolho de algodão a $50^{\circ} \mathrm{C}$ e $60^{\circ} \mathrm{C}$

Tabela 7. Análise dos açúcares obtidos durante a hidrólise enzimática da palha de cana de açúcar a $50^{\circ} \mathrm{C}$ e $60^{\circ} \mathrm{C}$ 


\section{LISTA DE SIGLAS E ABREVIATURAS}

BSA: Bovine Serum albumini/albumina sérica bovina

Cazy: Carbohydrate-Active Enzymes

CBM: Carbohydrate Binding Module / Módulos de Ligação ao Carboidrato

CBP: Consolidated Bioprocessing / Bioprocesso Consolidado

CMC: Carboximetilcelulose

CPP: Celulossomas Parcialmente Purificados

DLS: Dynamic light scattering / Espalhamento de luz dinâmico

DNS: Ácido 3,5-dinitrosalicílico

Fmol: Fentomol

FPase: Atividade em papel de filtro

FWHM: Full-width half-maximum /

Largura à meia altura

GH: Glicosil Hidrolases

HMF: 5-hidroximetilfurfural

HPLC: High Performance Pressure

Liquide Chromatography /

Cromatografia Líquida de Alta

Eficiência

kDa: Quilodalton
NCBI: National Center for Biotechnology Information / Centro Nacional de Informações sobre Biotecnologia

nm: Nanômetros

pH: Potencial de hidrogênio

PLC: Proteínas Ligadas à Celulose PLGS: ProteinLynx Global Server / Servidor Global ProteinLinx

pNP: p-nitrofenol

pNPG: p-nitrofenil- $\beta$-D-

glicopiranosídeo

PVDF: Fluoreto de Polivinilideno

rpm: Rotação por Minuto

SDS: Sodium dodecy/ sulfate/ Dodecil sulfato de sódio

SDS-PAGE: SDS- polyacrylamide gel electrophoresis/ eletroforese em gel de poliacrilamida

SHF: Separate Hydrolysis and Fermentation / Hidrólise e Fermentação em etapas Separadas

SSF: Simultaneous Saccharification and Fermentation / Sacarificação e Fermentação Simultânea 
LC-MSE: Liquid chromatographymass spectrometry / Cromatografia liquida acoplada a espectrometria de masas

MDa: Megadalton

MM: Marcador Molecular

mg: Miligramas

mL: Mililitros

MS: Mass Spectrometry /

Espectrometria de massa

nanoUPLC: nano ultra performance liquid chromatography / nano alta resolução de cromatografia líquida
SSSF: Semi-Simultaneous

Saccharification and Fermentation / Sacarificação e Fermentação Semi Simultânea

TCA: Ácido tricloroacético

TOF: Time of flight / tempo de vôo

UI: Unidade internacional

$\mu \mathrm{g}$ : Microgramas

$\mu \mathrm{L}:$ Microlitros 


\section{SUMÁRIO}

1. INTRODUÇÃO

1.1. Combustíveis Fósseis, Bioetanol e Biorrefinaria...................................... 1

1.2. Estruturas da biomassa lignocelulósica e Enzimas hidrolíticas ...............5

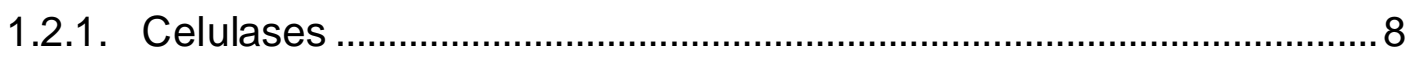

1.2.2. Hemicelulases .......................................................................... 9

1.2.3. Pectinases e Enzimas lignolíticas ................................................... 9

1.3. Produção de bioetanol de segunda geração .......................................10

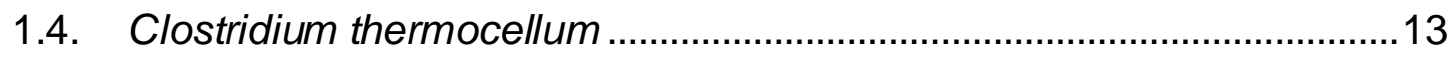

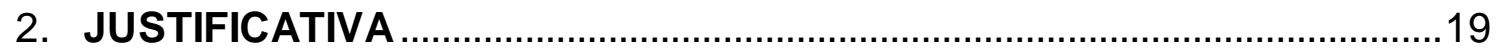

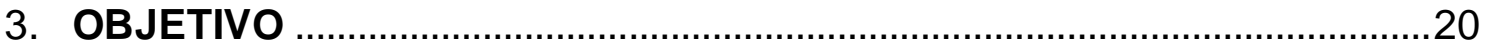

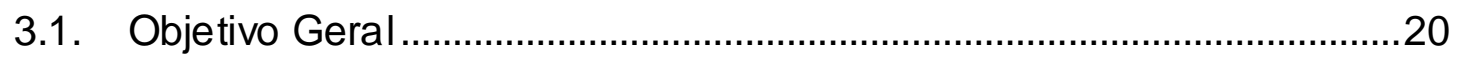

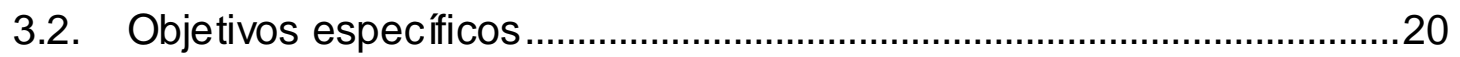

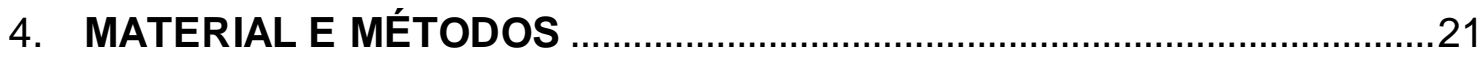

4.1. Cultivo e isolamento de $C$. thermocellum .............................................21

4.2. Preparação das amostras enzimáticas..................................................23

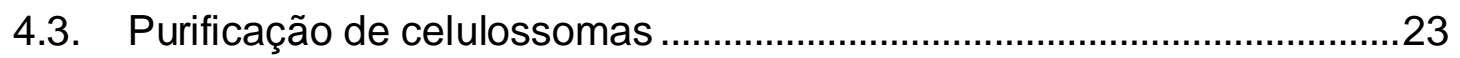

4.4. Determinação da atividade enzimática e quantificação de proteínas ..24

4.5. Análise eletroforética (SDS-PAGE) ..................................................25

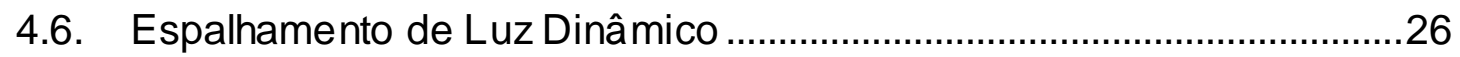

4.7. Efeito do $\mathrm{pH}$ e da temperatura nas atividades enzimáticas ..................26

4.8. Efeito dos compostos fenólicos nas atividades de CMCase e

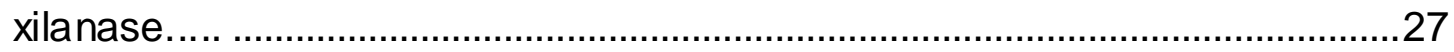

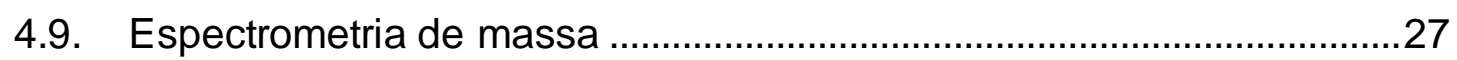


4.10. Experimentos de sacarificação de biomassas lignocelulósicas

4.11. Quantificação dos açúcares produzidos nos experimentos de sacarificação

4.12. Análises estatísticas .............................................................................

5. RESULTADOS

5.1. Purificação do celulossoma e análise de DLS..........................................32

5.2. Atividades enzimáticas e análise por espectrometria utilizando

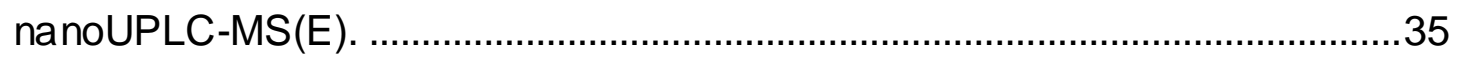

5.3. Efeito de $\mathrm{pH}$ e temperatura nas amostras de PLC e CPP.........................45

5.4. Efeito dos compostos fenólicos nas atividades de CMCases e xilanases das amostras PLC e CPP ............................................................................4 48

5.5. Sacarificação de materiais lignocelulósicos por PLC e CPP …………....50

5.6. Identificação de açúcares liberados no processo de sacarificação por

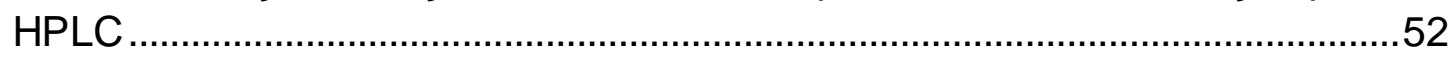

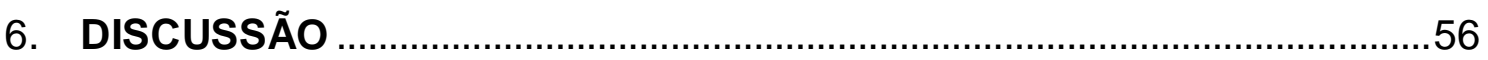

7. CONCLUSÕES

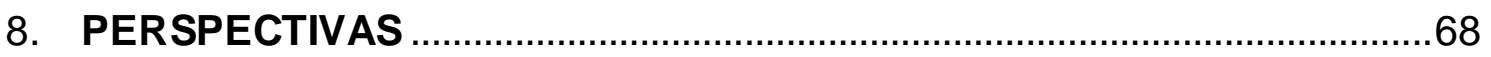

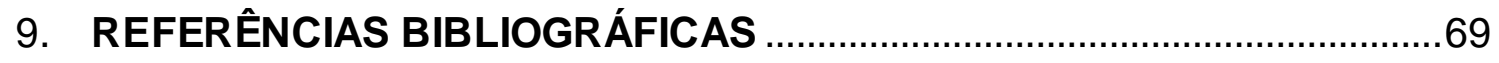




\section{INTRODUÇÃO}

\subsection{Combustíveis Fósseis, Bioetanol e Biorrefinaria}

Combustíveis fósseis primários, como o carvão, gás natural e petróleo, ainda são mundialmente utilizados como fonte de energia em nossa sociedade. Entretanto, alternativas ao carvão e ao gás natural já foram desenvolvidas (energia solar, hidrelétrica, eólica ou energia nuclear) no que corresponde à produção de eletricidade e calor (Dale, 2008). O petróleo, por sua vez, possui cerca de $90 \%$ do consumo destinado para geração de mobilidade, calor e eletricidade, com apenas $10 \%$ voltado para indústria química. O transporte é o setor mais vinculado ao uso do petróleo, o que proporciona um impacto negativo devido à alta emissão de dióxido de carbono na atmosfera (Carlsson, 2009). Portanto, a dependência do petróleo está relacionada ao consumo exacerbado de uma fonte energética limitada, o que enfatiza a necessidade de alternativas que satisfaçam de forma sustentável esta alta demanda por combustíveis (Greene, 2004).

No Brasil, desde a década de 70 , o etanol vem sendo utilizado como combustível em prol da diminuição da dependência política e econômica do petróleo. Em função da crise mundial no setor, o País iniciou, em 1975, o Programa Nacional do Álcool (Pró-Álcool), com intuito de produzir biocombustíveis para substituição da gasolina. Desta forma, parte da produção de açúcar obtido a partir da cana-de-açúcar foi redirecionada para gerar etanol (Soccol et al., 2010). Este programa impulsionou no decorrer dos anos o desenvolvimento de usinas sucroalcooleiras, que de acordo com os dados fornecidos pela Companhia Nacional de Abastecimento (Conab), em 2013, chegaram ao número de mais de 400 usinas instaladas pelo país.

Os Estados Unidos e o Brasil são os maiores produtores de etanol, sendo responsáveis por cerca de $60 \%$ da produção mundial. Enquanto a produção brasileira possui o açúcar da cana-de-açúcar como principal matériaprima para obtenção do bioetanol, os Estados Unidos utilizam o amido de milho. Além dessas fontes, o etanol de primeira geração pode ser produzido por fermentação de carboidratos disponíveis a partir de outras culturas, como 
cevada, aveia, arroz, trigo, beterraba e sorgo (Kim e Dale, 2004; Soccol et al., 2010; Kung, Runguphan e Keasling, 2012). Em 2004, o custo do litro do etanol brasileiro era competitivo com o da gasolina, o que impulsionou o cultivo da cana-de-açúcar no Brasil, destacando-a economicamente em relação aos demais tipos de cultivos (Goldemberg, 2007). No entanto, a utilização destas matérias-primas para produção do etanol, compete tanto com o setor alimentício, quanto com o setor agrário, pois para o aumento de sua produtividade torna-se necessário a expansão da área de cultivo (Lynd, 1996; Gnansounou, 2010; Martin, 2010).

Visando contornar os problemas relacionados à produção do etanol de primeira geração, o etanol de segunda geração surge com a proposta de aproveitamento dos resíduos agrícolas e industriais de origem lignocelulósica. Neste caso, o objetivo é realizar a hidrólise dos polímeros constituintes da parede celular vegetal para geração de açúcares fermentáveis, que podem posteriormente, serem fermentados a etanol. Esta estratégia tem ganhado espaço por ser mais sustentável e pela possibilidade de aumento da produção de biocombustíveis, sem haver a necessidade de uma expansão agrícola (Lynd e Wang, 2003; Kung, Runguphan e Keasling, 2012). Assim, o acúmulo em larga escala de resíduos de biomassa lignocelulósica pela atividade agroindustrial, proporciona um baixo custo de matéria-prima, devido a sua grande disponibilidade, o que permite uma amplitude macroeconômica (Kim e Dale, 2004; Cardona e Sánchez, 2007).

De acordo com dados fornecidos do Balanço Energético Nacional (BEN) 2014 - ano base 2013, a contribuição de fontes renováveis na Matriz Energética Brasileira foi entorno de $40 \%$ do total da energia utilizada, e classificada entre as mais elevadas do mundo. Dentre as energias renováveis, a biomassa da cana-de-açúcar é a fonte renovável que possui maior oferta, representando $16 \%$, a hidráulica com $12 \%$, lenha e carvão vegetal com $8 \%$ e lixívia e outras renováveis com 4\% (Epe, 2014).

Por ser o maior produtor mundial de cana-de-açúcar, o Brasil acumula grande quantidade destes resíduos, como a palha e o bagaço. Foram estimados, na safra de 2012/2013 mais de 600 milhões de toneladas de cana- 
de-açúcar processada pelas indústrias sucroalcooleiras, resultando na produção dos resíduos de palha e bagaço de cana-de-açúcar (Conab., 2012). A palha é composta pela parte superior do colmo, e por folhas secas e frescas, já o bagaço é obtido após a moagem do colmo para obtenção do suco da cana. Contudo, grande parte dessa biomassa, 90\% da parcela do bagaço da cana, é queimada em caldeiras para a geração de energia termoelétrica a partir do vapor (Conab, 2011), o que promove emissão de poluentes. O bagaço é constituído por 38.4-45.5\% de celulose, 22.7-27.0\% de hemicelulose e 19.1$32.4 \%$ de lignina, possuindo maior teor de celulose quando comparado com a palha, que possui entre $33.3-36.1 \%$ de celulose, $18.4-28.9 \%$ hemicelulose e $25.8-40.7 \%$ de lignina, além de cinzas e extrativos presente em ambos os substratos (Canilha et al., 2011).

Outra matéria-prima que tem sido considerada para a produção do bioetanol de segunda geração são os rejeitos de algodão. Só no ano de 2010, foram produzidas quase 3 millhões toneladas de algodão, que resultou em mais de 500 mil toneladas de resíduos (Dias et al., 2012). Um dos resíduos do algodão é o piolho do algodão, definido como uma mistura de caroços, fragmentos de cascas e de outras substâncias eliminadas durante 0 descaroçamento (Ima, Portaria n 630, de 30 de Março de 2004). Em média, entre $80 \%$ e $90 \%$ dos carboidratos em piolho de algodão é composto por polímeros de glucana e xilana, possuindo em menor proporção mananas, arabinanas e galactanas (Agblevor, Batz e Trumbo, 2003).

Portanto, pode-se observar que há uma grande disponibilidade de matéria-prima sustentável como fonte de carbono para o desenvolvimento não apenas de biocombustíveis, como também se torna possível à produção de outros bioprodutos, sendo este, o princípio da biorrefinaria (Figura 1). 0 conceito da biorrefinaria é análogo à atual refinaria de petróleo, que visa o aproveitamento máximo de materiais lignocelulósicos, a fim de adquirir diversos produtos químicos, da mesma maneira como procede à indústria petroquímica, a qual tem como base o uso de hidrocarbonetos, obtidos por meio do processo de craqueamento do petróleo, para gerar solventes, lubrificantes, plásticos, borrachas sintéticas, fibras, detergentes, entre outros (Ohara, 2003; Kamm e Kamm, 2004; Carlsson, 2009; Cherubini, 2010). 


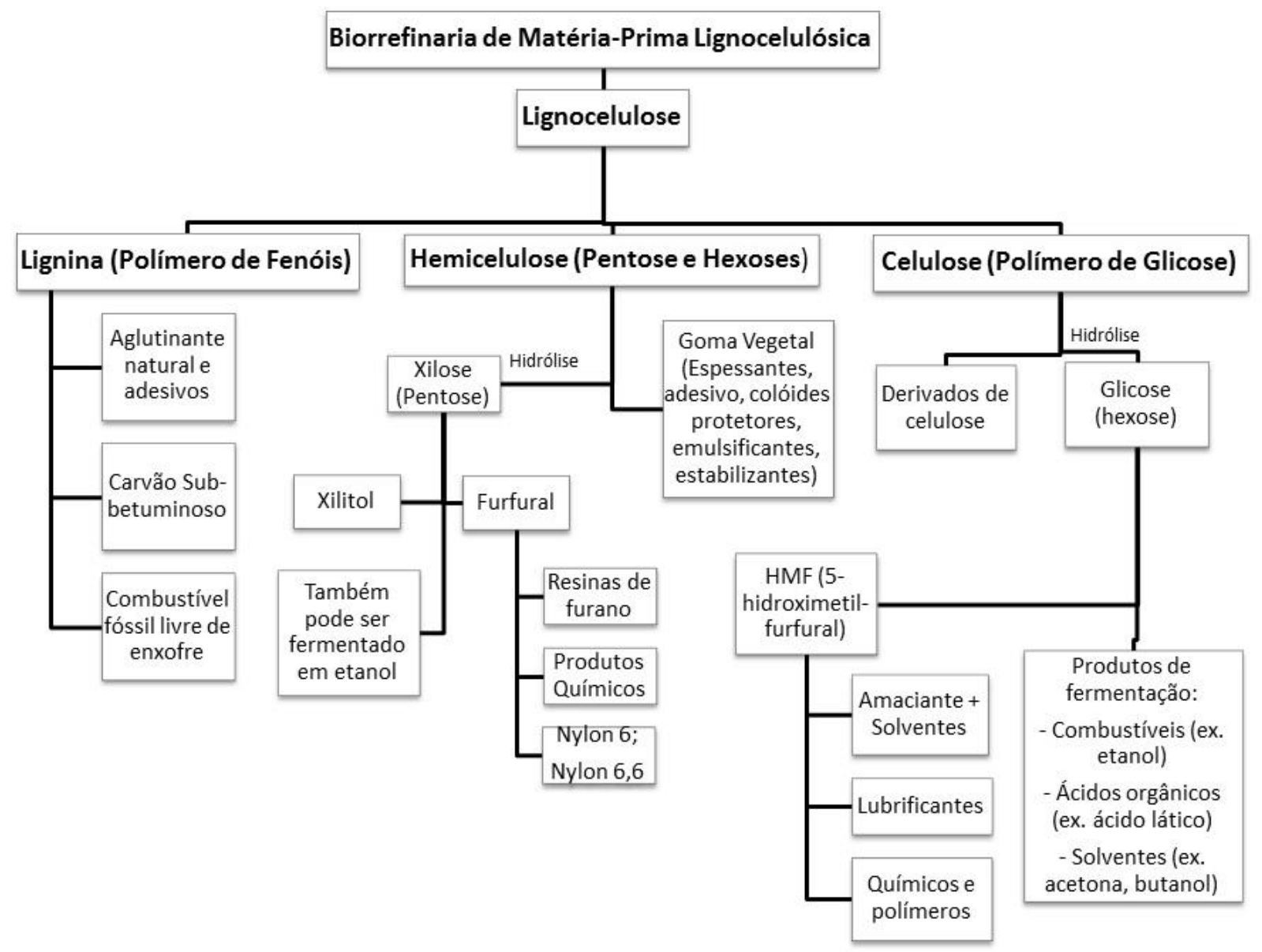

Figura 1. Esquema ilustrativo de possíveis produtos de uma biorrefinaria baseada em materiais lignocelulósicos. Extraído e adaptado de Kamm and Kamm (2004).

Os principais produtos para o fornecimento de energia que podem ser obtidos pelo processamento de biomassas lignocelulósicas em biorrefinarias são: biocombustíveis gasosos (biogás, singás, hidrogênio, biometano), sólidos (pellets, ligninas, carvão vegetal) e líquidos (bioetanol, biodiesel, FTcombustíveis, bio-óleo). Além disto, podem ser produzidos da mesma fonte de carbono, produtos químicos (química fina, blocos de construção, produtos químicos a larga escala), ácidos orgânicos (succínico, láctico, itacónico e outros derivados de açúcar), polímeros e resinas (plásticos à base de amido, resinas de fenol, resinas de furano) (Kamm e Kamm, 2004).

A cadeia produtiva para obtenção destes compostos depende da descontrução dos materiais lignocelulósicos. Contudo, pode-se gerar nesse processo tanto açúcares de interesse, como compostos que venham a interferir na catálise enzimática e na fermentação, como no caso dos fenóis (Chen e 
Dixon, 2007; Ruiz-Dueñas e Martínez, 2009; Ximenes et al., 2010b). Assim, tecnologias que promovam uma eficiente degradação de tais materiais com menor produção de inibidores, são de interesse para melhoria da cadeia produtiva de derivados de lignocelulose com potencial aplicação biotecnológica.

Nesse contexto, a busca por enzimas capazes de hidrolisar matériasprimas lignocelulósicas são fundamentais para que haja uma otimização desse processo. A desconstrução desses materiais por enzimas apresenta maior especificidade aos substratos, auxiliando a etapa de pré-tratamento com uma hidrólise menos poluente e com menor consumo de energia (Sarrouh et al., 2012). Além disso, existem etapas no processo de produção do etanol que demandam temperaturas mais elevadas, tornando-se relevante a presença de enzimas termoestáveis para conseguir atuar com eficiência nessas temperaturas (Turner, Mamo e Karlsson, 2007). A obtenção de enzimas industriais, geralmente é proveniente de fungos e bactérias (Sarrouh et al., 2012), sendo importante o estudo desses microrganismos para identificação de potenciais celulases e hemicelulases que consigam tolerar a maioria dos inibidores, resultantes da hidrólise de lignina e hemicelulose, e altas temperaturas, verificando também, as melhores condições de temperatura e pH para o desempenho nas atividades enzimáticas.

\subsection{Estruturas da biomassa lignocelulósica e Enzimas hidrolíticas}

A biomassa lignocelulósica possui uma estrutura recalcitrante, conferida pela organização dos polímeros constituintes da parede celular vegetal, que oferece resistência mecânica natural e dificulta a atuação microbiana e enzimática para sua degradação. A parede celular vegetal é constituída por celulose, hemicelulose, pectina, lignina e proteínas, podendo variar sua composição específica dependendo da planta considerada (Figura 2) (Heredia, Jiménez e Guillén, 1994; Sun e Cheng, 2002; Himmel et al., 2007). 


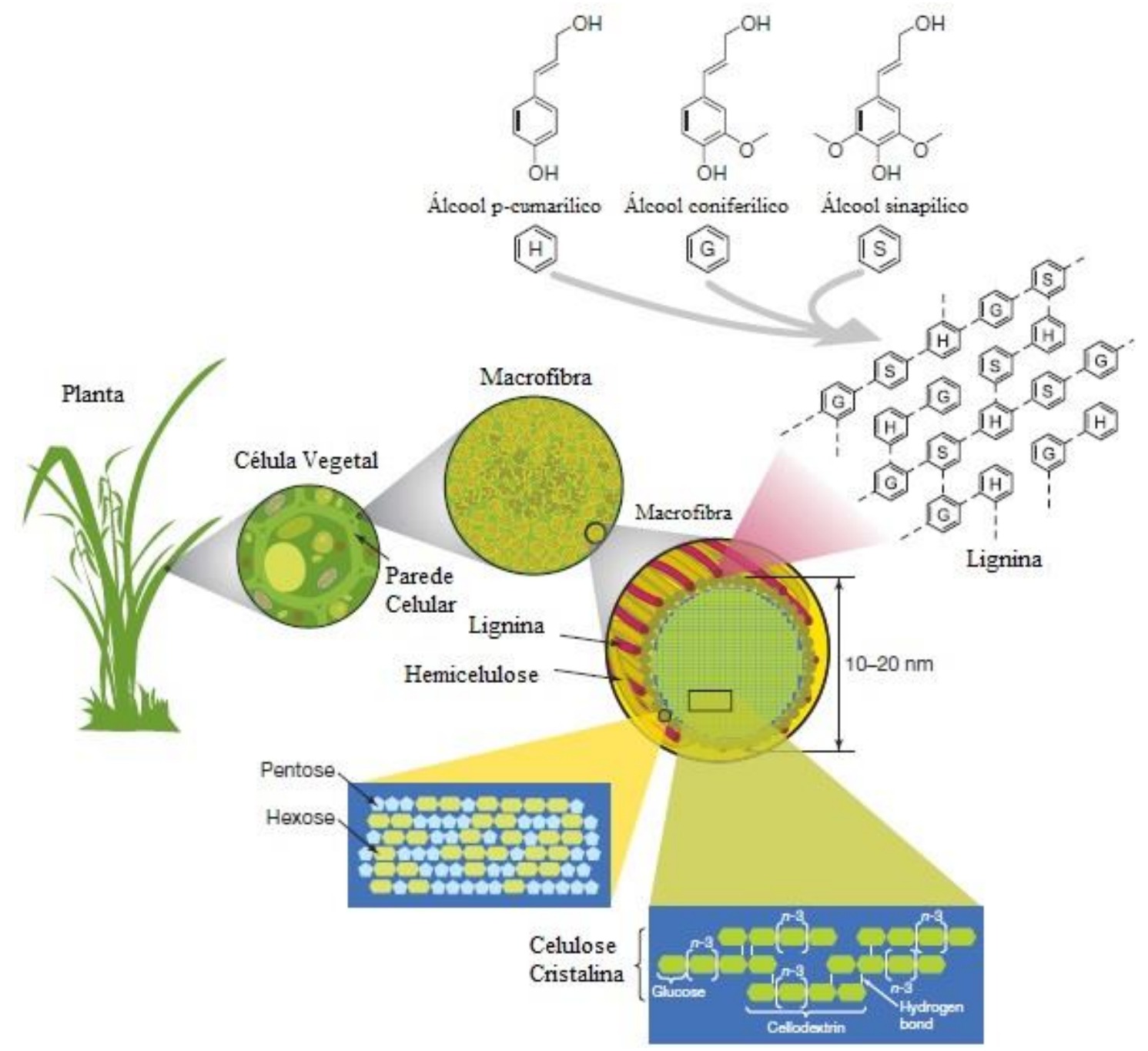

Figura 2. Estrutura da biomassa lignocelulósica. Dentre os principais componentes da parede celular vegetal, a estrutura da celulose cristalina é a mais abundante, situada na parte mais interna da microfibrila. A hemicelulose, juntamente com a lignina, está localizada em volta da celulose, formando uma estrutura organizada, a qual confere rigidez e estabilidade para planta. Modificado de Rubin, E. M. (2008).

A celulose é formada por unidades de glicose vinculadas com ligações do tipo $\beta 1 \rightarrow 4$. Esta estrutura bem organizada e de cadeia longa possui associações laterais por meio de ligações de hidrogênio, conferindo deste modo, arranjos paralelos de uma microfibrila cristalina (Lynd, 1996; Horn et al., 2012). Esse biopolímero é o principal componente de matéria vegetal e o polissacarídeo mais abundante da terra (Bayer, Chanzy, et al., 1998). Uma característica marcante dessa estrutura é a presença de regiões ordenadas e aparentemente mais compactas, e de regiões denominadas de amorfas, as 
quais apresentam uma maior interação com moléculas de água devido a sua conformação (Lynd, 1996; Khazraji e Robert, 2013).

A hemicelulose é um polímero situado ao redor da celulose, interagindo covalentemente a lignina, e que possui um grupo heterogêneo de polissacarídeos, incluindo xiloglucanas, xilanas, mananas e glucomananas, e $\beta$ - $(1 \rightarrow 3,1 \rightarrow 4)$-glucanos em sua composição. A xilana é principal cadeial da hemicelulose, integrada por unidades de $D$-xilose com ligações do tipo $\beta(1 \rightarrow 4)$, sendo a mais abundante dentro da classificação das angiospermas. A estrutura de xilana é envolvida por diversas ligações com outros compostos, sendo estas, ramificações laterais de resíduos 4-O-metil-D-glucurônico, ácido glicurônico, D-galactose, L-arabinose, ácido ferúlico, ácido p-cumárico e ácido acético (ligação éster) (Lynd, 1996; Scheller e Ulvskov, 2010).

A pectina é um polissacarídeo estruturado principalmente pela molécula $\alpha$-D-galactopiranosilurônico, conectadas por ligações $\alpha(1 \rightarrow 4)$, dando origem a cadeia de homogalacturonana. A associação de alguns resíduos, tais como, L-arabinofuranosil, D-galactopiranosil, D-glucuronosil L-arabinosil, Dgalactosil, D-xilosil, L-ramnosil ou L-fucosil, ácido ferúlico, ácido cumárico, além de alguns ácidos metil-esterificados e acetilações, tendo como resultado as cadeias de ramnogalacturonana I e Il, e xilogalacturonana. Essa estrutura é encontrada em apenas algumas plantas, como no caso do algodão (Ridley, O'neill e Mohnen, 2001). Contudo, a pectina não é identificada na constituição da parede vegetal da cana de açúcar (Chen e Chou, 1993; Mohnen, 2008).

A lignina é definida pela disposição de monoligóis especificamente sintetizados pelos álcoois $p$-coumaril, coniferi e sinapil, os quais dão origem às unidades de p-hidroxifenil $(H)$, guaiacil $(L)$ e siringil $(S)$ fenilpropanóides, respectivamente (Freudenberg, 1959; Brosse, M. e Rahim, 2011). Todos os polímeros constituintes da parede celular vegetal possuem uma estrutura química complexa. No entanto, a lignina está entre os que mais conferem a propriedade de recalcitrância à biomassa lignocelulósica, podendo liberar compostos fenólicos capazes de inibir enzimas e microrganismos durante a hidrólise e o processo de fermentação (Chen e Dixon, 2007; Ruiz-Dueñas e Martínez, 2009; Ximenes et al., 2010b). 


\subsubsection{Celulases}

A completa degradação do polímero de celulose inclui três principais enzimas (Figura 3): as endoglicanases (EC 3.2.1.4), as exoglicanases ou celobiohidrolases 1 e 2 (EC 3.2.1.91 e EC 3.2.1.74) e $\beta$-glicosidases (EC 3.2.1.21). As endoglicanases catalisam a hidrólise de ligações do tipo $\beta(1 \rightarrow 4)$ internamente e randomicamente no polímero de celulose, liberando extremidades redutoras para atuação das exoglicanases. As exoglicanases catalisam a hidrólise de do tipo $\beta(1 \rightarrow 4)$ em extremidades redutoras e não redutoras, gerando tetrassacarídeos (glicanohidrolases) ou dissacarídeos (celobiohidrolase) como produtos finais. Por último, as $\beta$-glicosidases desempenham a função de degradação da celobiose em duas moléculas de glicose. (Schwarz, 2001; Dashtban et al., 2010). A atuação conjunta dos três tipos de celulases resulta em uma maior atividade do que a ação isolada dessas enzimas, devido ao sinergismo existente entre elas. Contudo, o grau do sinergismo depende de alguns fatores, como por exemplo, o tipo de substrato (Woodward, 1991; Ganner et al., 2012).

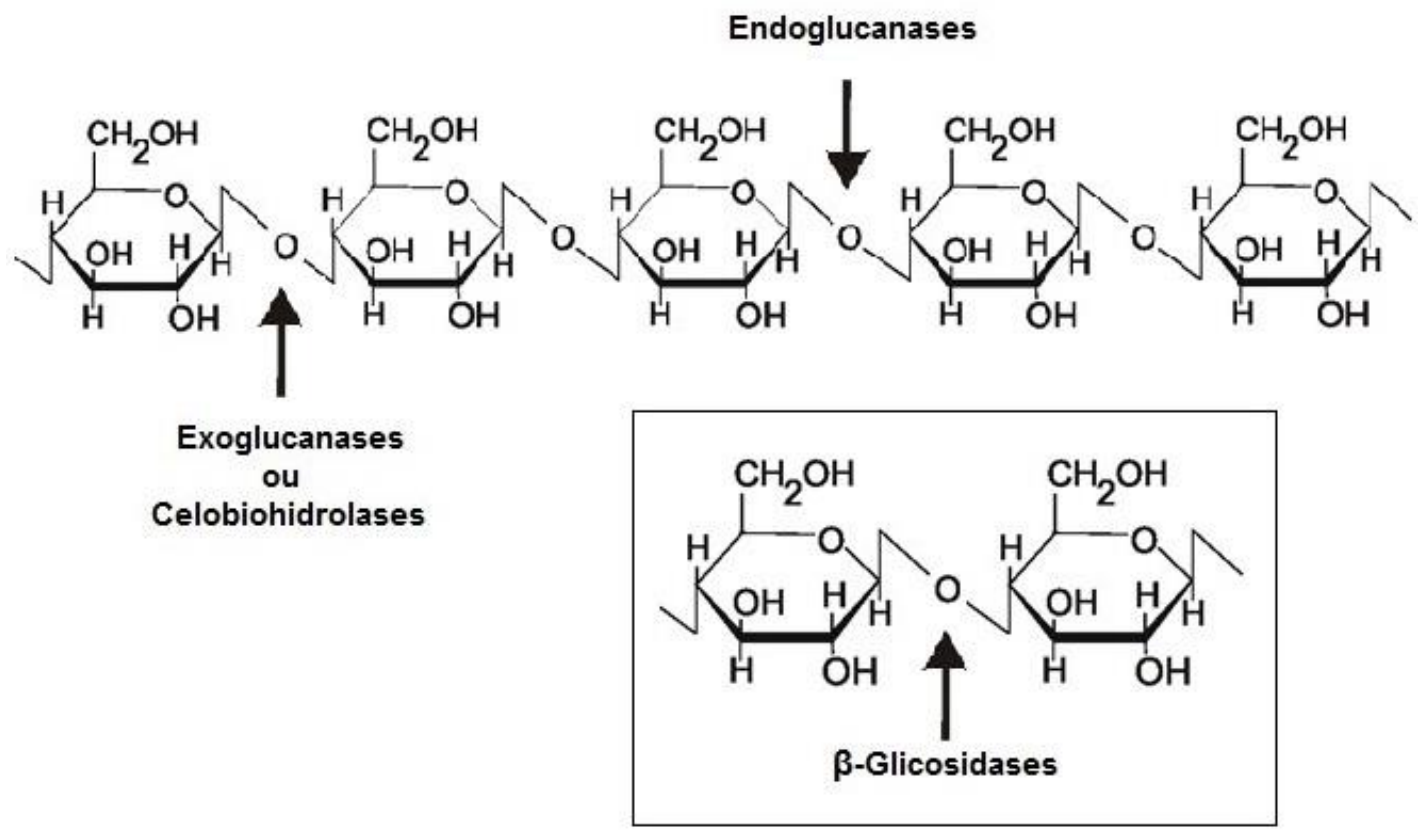

Figura 3. Estrutura molecular da celulose e mecanismo de ação de endoglucanases, exoglucanases e $\beta$-glicosidases. Neste exemplo, a partir da extremidade redutora liberada pela endoglucanase, a exoglucanase gera um dissacarídeo, em que este será posteriormente catalizado por $\beta$-glicosidases. Extraído e adaptado de Kumar, Singh e Singh (2008) e Held (2012). 


\subsubsection{Hemicelulases}

Para obter uma desconstrução total da hemicelulose, é necessária a atuação sinérgica de múltiplas enzimas devido à complexidade de sua estrutura, requerendo a participação de endo-1,4- $\beta$-xilanases (E.C.3.2.1.8), $\beta$ -

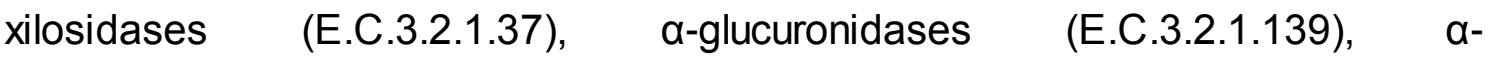
arabinofuranosidases (E.C.3.2.1.55), arabinases (E.C. 3.2.1.99), acetil xilana esterases (E.C.3.1.1.72), feruloil xilana esterases (E.C.3.1.1.73), endo-1.4- $\beta$ mananase (EC 3.2.178), $\beta$-manosidase (EC 3.2.1.25), e $\beta$-glicosidase (EC 3.2.1.21), com a representação das principais enzimas na figura abaixo (Figura 4) (Beg et al., 2001; Shallom e Shoham, 2003; Moreira e Filho, 2008; Scheller e Ulvskov, 2010; Juturu e Wu, 2013).

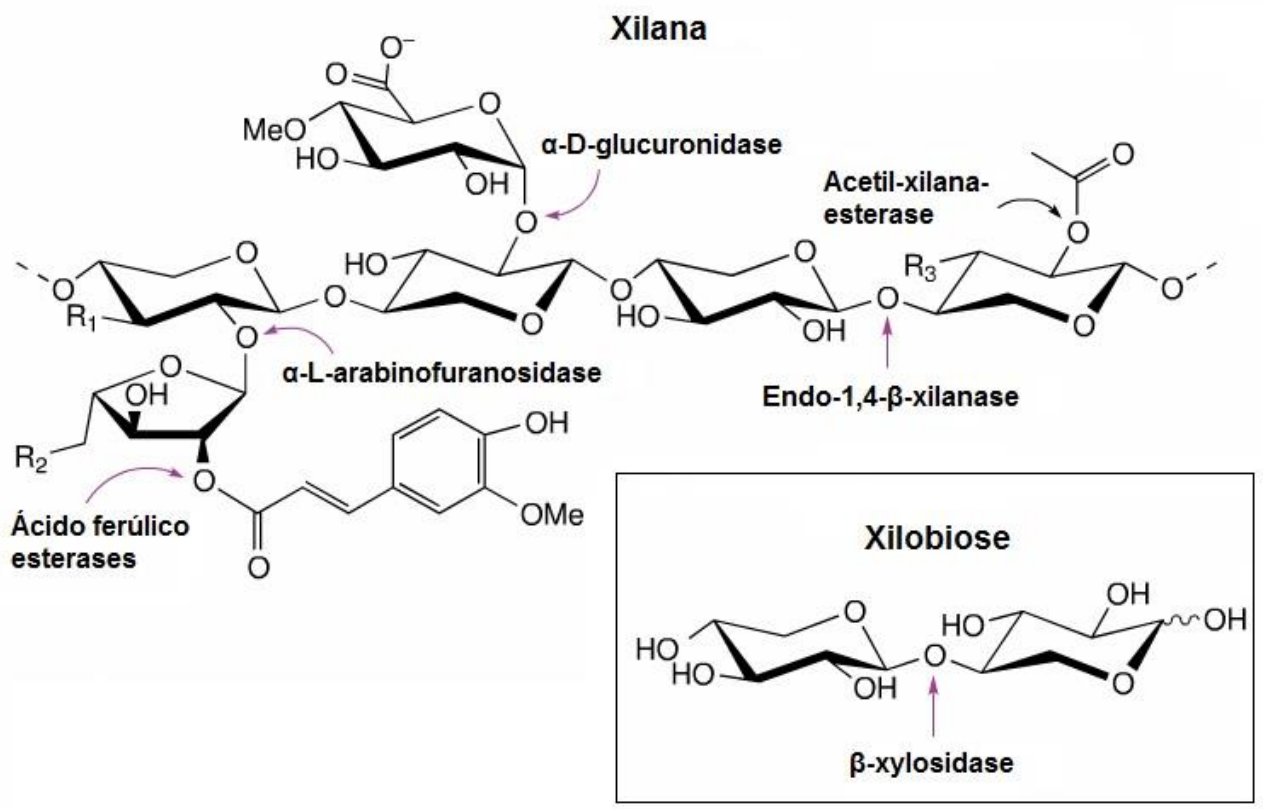

Figura 4. Estrutura da xilana com ramificações laterais e suas enzimas hidrolíticas. Extraído e adaptado de Shallom e Shoham (2003).

\subsubsection{Pectinases e Enzimas lignolíticas}

As principais enzimas envolvidas no processo de hidrólise da pectina estão divididas entre liases e hidrolases, dentre elas estão: as pectinas liases (EC 4.2.2.10), pectato liases (EC 4.2.2.2), e poligalacturonases (EC 3.2.1.15 e EC 3.2.1.67) (Devries e Visser, 2001). 
A degradação da lignina requer a participação de enzimas como a lacase (Lac), lignina peroxidase (LiP) e manganês peroxidase $(\mathrm{MnP})$. A lacase atua na oxidação das unidades de fenóis presentes na lignina. Já a lignina peroxidase catalisa a oxidação da lignina por transferência de elétron e atua na clivagem de várias ligações e na abertura do anel aromático. E a enzima manganês peroxidase pertence ao grupo heme, tendo o manganês como cofator (Chen et al., 2011).

\subsection{Produção de bioetanol de segunda geração}

A produção de etanol de segunda geração requer pelo menos 4 etapas distintas: o pré-tratamento, a hidrólise, a fermentação e a separação/destilação do produto (Balat, 2011). O pré-tratamento é uma etapa crucial que visa à diminuição da recalcitrância da biomassa lignocelulósica podendo levar ao fracionamento dos três principais componentes desse material (celulose, hemicelulose e lignina) ou na remoção parcial da hemicelulose ou lignina. Este tratamento, portanto, favorece um maior acesso das enzimas ao substrato (Chum et al., 1985; Brodeur et al., 2011).

Existem diferentes tipos de pré-tratamentos, dentre os quais podem ser citados: o biológico, o físico, o químico e o físico-químico. A escolha do prétratamento depende da constituição de cada tipo de biomassa vegetal e das enzimas que serão utilizadas em seguida no processo de sacarificação (Alvira et al., 2010). Apesar da necessidade da utilização do pré-tratamento para diminuir a recalcitrância da biomassa, esta etapa pode influenciar na redução da taxa de produção final do etanol, devido à liberação de fenóis constituintes da lignina durante o processo de deslignificação, tendo por consequência à inibição de algumas enzimas utilizadas na etapa de sacarificação e no processo de fermentação. Pré-tratamentos que agem sobre a hemicelulose, principalmente nas ramificações do polímero de xilana, também podem gerar inibidores como furfural, ácido fórmico, ácido acético, ácido urônico, ácido levulínico e 5-hidroximetilfurfural (HMF) (Brodeur et al., 2011; Hu e Ragauskas, 2012). 
Seguido do pré-tratamento, têm-se a sacarificação da biomassa por enzimas hidrolíticas, que convertem carboidratos complexos em simples monômeros de açúcares. No caso, a degradação da celulose gera a glicose, enquanto que a hemicelulose fornece uma variedade de pentoses e hexoses. Tais enzimas são produzidas por diversos gêneros de microrganismos como Clostridium, Cellulomonas, Thermonospora, Bacillus, Bacteriodes, Ruminococcus, Erwina, Acetovibrio, Microbispora, Streptomyces, incluindo os fungos, que são bem conhecidos por serem produtores de celulases, dentre eles o Trichoderma, Penicillium, Fusarium, Phanerochaete, Humicola, Schizophillum sp. (Sarkar et al., 2012). No entanto, para obter a eficiência máxima de hidrólise, é necessário a compreensão das melhores condições enzimáticas, ressaltando a importância de se avaliar fatores como temperatura, meia-vida, pH, carga de enzimas e a concentração do substrato (Canilha et al., 2011).

Após as etapas de pré-tratamento e sacarificação enzimática é realizado o processo de fermentação a partir dos monômeros de açúcares obtidos, sendo comumente utilizado a Saccharomyces cerevisiae para transformar esses açúcares em etanol, principalmente por esta levedura já ser muito bem estudada e estabelecida industrialmente, além de ser capaz de tolerar o seu produto final. Entretanto, a $S$. cerevisiae tem o consumo restrito somente a glicose para fermentação (Hahn-Hägerdal et al., 2007).

Assim, para o máximo de aproveitamento dos açúcares provenientes da hidrólise vegetal (pentoses e hexoses), necessita também, de organismos que utilizem outros açúcares, além da glicose, como fonte de carbono para fermentação. Bactérias e leveduras como Clostridium acetobutilicum, Clostridium thermocellum, Escherichia coli, Pichia stipitis, Candida shehatae e Pachysolen tannophilus, são capazes de utilizar naturalmente xilose no processo fermentativo (Skoog e Hahn-Hägerdal, 1988; Balat, Balat e Öz, 2008).

Todavia, estes microrganismos possuem limitações em condições industriais, por não apresentarem a eficiência requerida em níveis osmóticos elevados, em ambiente anaeróbio estrito e na presença inibidores. (Rudolf et 
al., 2008). Por conseguinte, até o instante não se sabe de fato, qual seria 0 microrganismo ideal para executar a fermentação de múltiplos açúcares.

Diferentes processos têm sido desenvolvidos para melhor o rendimento na produção do etanol. Contudo, existem fatores que precisam ser levados em consideração, ao analisar a escolha do microrganismo fermentador e as enzimas mais adequadas para hidrólise, como por exemplo, as possíveis combinações entre as etapas de processamento, que podem ocorrer simultaneamente ou separado (Holtzapple et al., 1990; Abdel-Banat et al., 2010).

O processo no qual a hidrólise e a fermentação ocorram separadamente (SHF) permite que cada etapa aconteça em suas condições de temperatura e $\mathrm{pH}$ ótimos, embora contribua com a inibição de celulases, devido ao acúmulo de glicose e celobiose durante a hidrólise enzimática (Paulová et al., 2014). As enzimas hidrolíticas geralmente atuam melhor na faixa de $50^{\circ} \mathrm{C}$ a $60^{\circ} \mathrm{C}$, enquanto que os organismos fermentadores tem a produção do etanol realizada em temperaturas mais baixas, entre $28^{\circ} \mathrm{C}$ e $37^{\circ} \mathrm{C}$ (Paulová et al., 2014).

A sacarificação e a fermentação simultânea (SSF) origina-se com o objetivo de resolver a questão da repressão catabólica, que decorre no processo de SHF. Contudo, deve-se estabelecer a mesma temperatura e $\mathrm{pH}$ para ambos os procedimentos, havendo uma dificuldade de conciliação, sem que haja perda no rendimento em pelo menos uma das etapas. Mesmo com este problema, já é demonstrado que SSF possui um melhor rendimento do que SHF (Ballesteros et al., 1993; Wingren, Galbe e Zacchi, 2003; Kádár, Szengyel e Réczey, 2004).

Há também, a possibilidade de integração da SSF e SHF, onde se mantém as vantagens de cada processo, resultando no método semisimultâneo de sacarificação e fermentação (SSSF). O SSSF consiste em duas fases: pré-hidrólise enzimática em sua temperatura ótima por um período, seguido da diminuição da temperatura para a condição de SSF. Foi observada uma melhor produtividade com 24 horas de pré-hidrólise (Shen e Agblevor, 2010). 
Outra abordagem que está crescendo, é o bioprocesso consolidado (CBP), tendo como objetivo tanto a produção de enzimas para sacarificação, a hidrólise e a fermentação de todos os tipos de monossacarídeos, realizadas em um único processo. CBP tem o potencial de reduzir o custo de produção se houver um microrganismo que realize a maior parte desses requerimentos, além de aumentar as taxas de hidrólise, devido ao sinergismo entre as enzimas e a célula microbiana, bem como a possibilidade de se utilizar um organismo termofilico (Lynd et al., 2005).

Neste caso, a bactéria anaeróbica e termoflica, Clostridium thermocellum, é candidata para aplicação em CBP e como fonte de enzimas para sacarificação de biomassa celulósica, devido à produção de um complexo enzimático capaz de realizar a desconstrução da biomassa lignocelulósica em altas temperaturas, o que coincide com a temperatura ótima de crescimento da bactéria, estabelecida entre $50^{\circ} \mathrm{C}$ e $68^{\circ} \mathrm{C}$. Além disso, a $\mathrm{C}$. thermocellum consegue utilizar a celulose, celobiose, xilose e hemiceluloses como fonte de carbono para seu crescimento (Mcbee, 1954; Akinosho et al., 2014). O processo de produção de bioetanol em altas temperaturas beneficia não somente a atividade enzimática com o aumento na difusão e na reação termodinâmica, como também evita contaminações e reduz o custo associado ao resfriamento para etapa seguinte (fermentação), principalmente em países tropicais (Schwarz, 2001; Abdel-Banat et al., 2010)

\subsection{Clostridium thermocellum}

A bactéria Clostridium thermocellum é caracterizada por ser anaeróbica, gram-positiva, produtora de esporos e termofilica, devido ao seu crescimento em temperaturas mais elevadas (em torno de $58^{\circ} \mathrm{C}$ a $61^{\circ} \mathrm{C}$ ), possuindo alto potencial em aplicações biotecnológicas por sua capacidade hidrolítica e fermentativa (Mcbee, 1954; Ng, Weimer e Zeikus, 1977; Freier, Mothershed e Wiegel, 1988; Schwarz, 2001).

Em virtude de seu potencial, estudos na caracterização do genoma, transcriptoma, proteoma e perfis metabolômicos de $C$. thermocellum tem 
atraído interesse, para melhor compreensão das reações de hidrólise e fermentação de materiais lignocelulósicos por esta bactéria. O sequenciamento do genoma de $C$. thermocellum é disponível em seis cepas, incluindo ATCC 27405, YS, LQRI, JW20, BC1, e DSM 1313, contendo 3,8 Mb previsto para codificar 3.163 genes, com relação à linhagem ATCC 27405 (Brown et al., 2007; Akinosho et al., 2014). A partir dessa análise, foram identificados três proteínas GlyR1, GlyR2, e GlyR3 (anteriormente denominadas de CelR1, CelR2, e CelR3, respectivamente), homólogas a Lacl de E. coli, sugerindo que essas proteínas fazem parte da família Lacl, exercendo um papel no controle negativo na presença de laminaribiose (Demain, Newcomb e Wu, 2005).

A natureza celulolítica e etanogênica desta bactéria a torna uma candidata a ser utilizada na produção de etanol celulósico em um único passo, reunindo as etapas de sacarificação e fermentação. Além do mais, a peculiaridade de ser termófila traz algumas vantagens relacionadas ao custo de produção, principalmente devido à presença de enzimas termoestáveis, o que não exige o resfriamento do processo para realizar a sacarificação, bem como facilita na recuperação do etanol e evita possíveis contaminações (Demain, Newcomb e Wu, 2005; Verardi et al., 2012).

C. thermocellum é caracterizada também, por degradar celulose utilizando um complexo enzimático denominado celulossoma, que contém múltiplas subunidades e domínios funcionais. A primeira evidência da existência deste complexo enzimático celulolítico foi observada em $C$. thermocellum, em função de sua adesão à celulose, sendo inicialmente chamado de Fator Ligante à Celulose ou "Celulose-Binding Fator" (CBF). Posteriormente, foi demonstrado que se tratava de um complexo proteico, constituído por diferentes celulases, que o conferia alta eficiência na degradação de celulose (Lamed, Setter e Bayer, 1983).

Este complexo de alta massa molecular, em torno de 2,0 $\mathrm{MDa}$, tem como uma das principais características, a presença da proteína estrutural ou escafoldina (Cellulosome Integrating Protein - CipA), que o difere de outros complexos ou agregados (Bayer, Morag e Lamed, 1994; Morag et al., 1995). A escafoldina ou proteína estrutural tem massa molecular de $210 \mathrm{kDa}$ e ancora 
as subunidades catalíticas, organizando o complexo enzimático e sendo portanto, uma das principais estruturas celulossomais (Bayer, Morag e Lamed, 1994; Bayer et al., 2007).

A proteína estrutural do celulossoma de $C$. thermocellum, a CipA, é constituída, em geral, por mais de 4 domínios denominados coesina do tipo I, podendo variar entre 1 a 11 domínios; um domínio denominado doquerina do tipo II e um único domínio de aminoácidos que media a ligação à celulose denominado Módulo de Ligação à Carboidratos, ou "Carbohydrate-Binding Modules" (CBM) (Figura 5) (Shoham, Lamed e Bayer, 1999; Fontes e Gilbert, 2010). Os CBMs são classificados segundo o critério utilizado de similaridade de sequências de aminoácidos utilizado para classificação de famílias de glicosil hidrolases. Segundo este critério de classificação os CBMs já foram dividido em 39 famílias. Alternativamente, os CBMs também podem ser classificados de acordo com sua afinidade ao carboidrato ligante, sendo classificados em tipo $A$ quando se ligam a estruturas de polissacarídeos, as cadeias de glicanas (tipo B) ou a mono-, di- ou tri-sacarídeos (tipo C) (Boraston et al., 2004; Cai, Zheng e Dong, 2011).

As enzimas celulossomais, subunidades catalíticas, possuem uma sequência de aminoácidos repetitiva que corresponde ao domínio doquerina tipo I, e que interage especificamente com o domínio coesina tipo I da escafoldina. Estabelecendo desta maneira, uma ligação das enzimas com a proteína estrutural, em que por meio do domínio doquerina tipo ॥, a CipA também se associa às proteínas S-Layers situadas na superfície celular bacteriana (SdbA, OlpB e Orf2) ou até mesmo no meio extracelular (Cthe 0736), promovendo deste modo, a ligação entre o complexo celulossomal e a célula bacteriana (Figura 6) (Lamed, Setter e Bayer, 1983; Fujino, Béguin e Aubert, 1993; Shoham, Lamed e Bayer, 1999).

Essa organização celulossomal, posiciona as unidades catalíticas em uma orientação, que proporciona uma proximidade espacial entre as enzimas e também das enzimas com o substrato. Desta maneira, a aproximação das enzimas potencia as interações sinérgicas, que ainda são aumentadas, devido à ligação do CBM com o substrato e à flexibilidade pelo tamanho do complexo, 
quando comparado com enzimas livres (Shoham, Lamed e Bayer, 1999; Fontes e Gillbert, 2010).

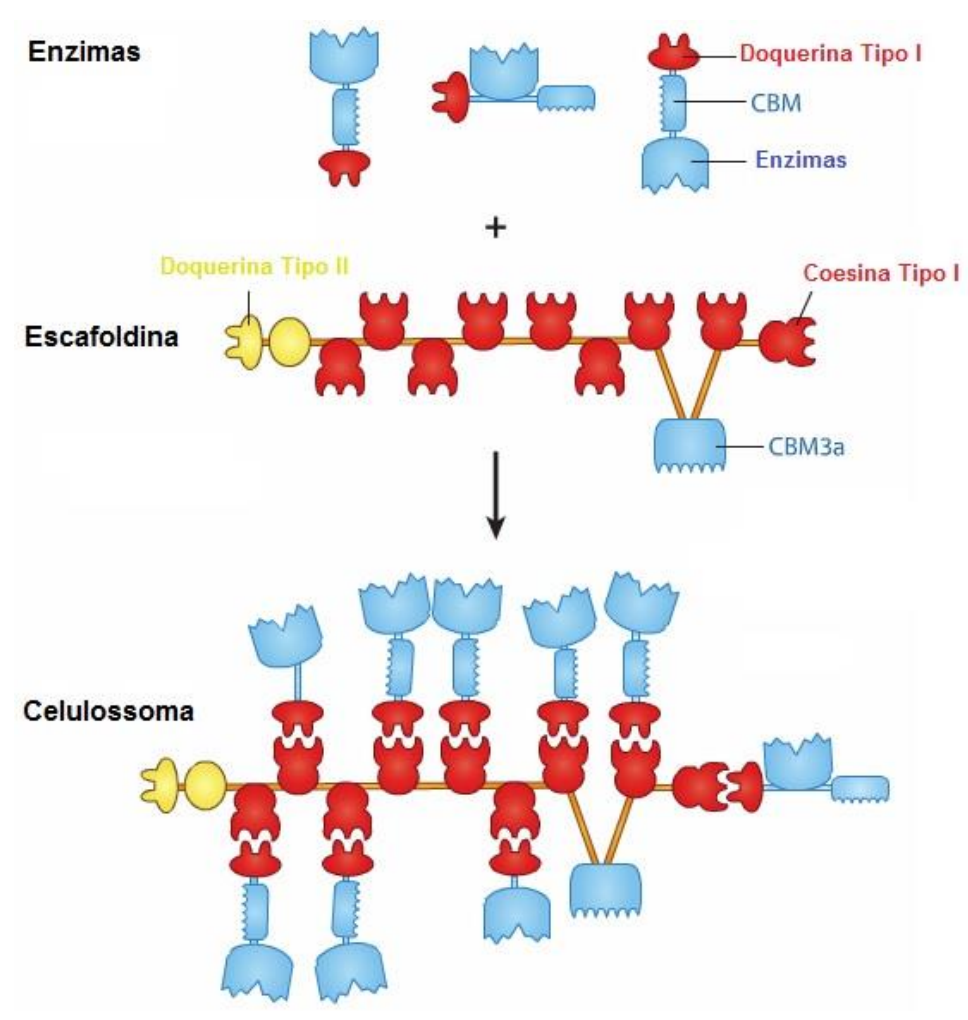

Figura 5. Esquema ilustrativos dos componentes de celulossomas. Interação entre os domínios coesinas e doquerinas tipo I e a ilustração das estruturas de doquerina tipo II e CBM, ambos pertencentes à escafoldina. Adaptado de Fontes e Gillbert (2010).

As enzimas celulossomais contêm os mesmos tipos de domínios catalíticos encontrados em enzimas "livres" (não ligadas ao complexo), diferindo somente pelo domínio doquerina registrado somente em enzimas celulossomais. Enzimas celulossomais apresentam massa molecular variando entre $40 \mathrm{kDa}$ a $180 \mathrm{kDa}$, e pertencem a diferentes famílias de glicosil hidrolases. Dentre essas enzimas, a CelA, CelB, CelD, CelE, CelF, CelG, CelH, CelN, e CelP representam as atividades de endoglucanases, e as enzimas CbhA, CelK, CelO, CelS exibem atividade de exoglucanases, destacando-se principalmente a CelS, uma glicosil hidrolase pertencente à família 48 (GH48), pois geralmente é identificada em maior quantidade no complexo. No caso, a atividade xilanolítica é constituída por XynA, XynB, XynV, XynY e XynZ que pode conter simultaneamente atividade de esterase (ácido ferúlico esterase ou acetil xilana esterase), proporcionando tanto a hidrólise da principal cadeia de hemicelulose (xilana), como também de suas cadeias laterais, desvinculando 
deste modo, da lignina (Bayer, Shimon, et al., 1998; Lynd et al., 2002; Demain, Newcomb e Wu, 2005).

Como as proteínas de ancoragem (tanto as de superfície celular quanto as extracelulares) apresentam mais de um domínio de coesina do tipo Il, vários celulossomas podem se ligar a estas proteínas, levando à formação de um policelulossomas com massa molecular estimada por volta de $100 \mathrm{MDa}$ (Mayer et al., 1987). Outra possibilidade, é a aderência direta de enzimas celulossomais (doquerina tipo I) às proteínas de ancoragem OlpA e OlpC que contém o domínio coesina tipo I, possibilitando a ligação direta destas enzimas na superficial da célula bacteriana (Figura 6) (Fontes e Gilbert, 2010).

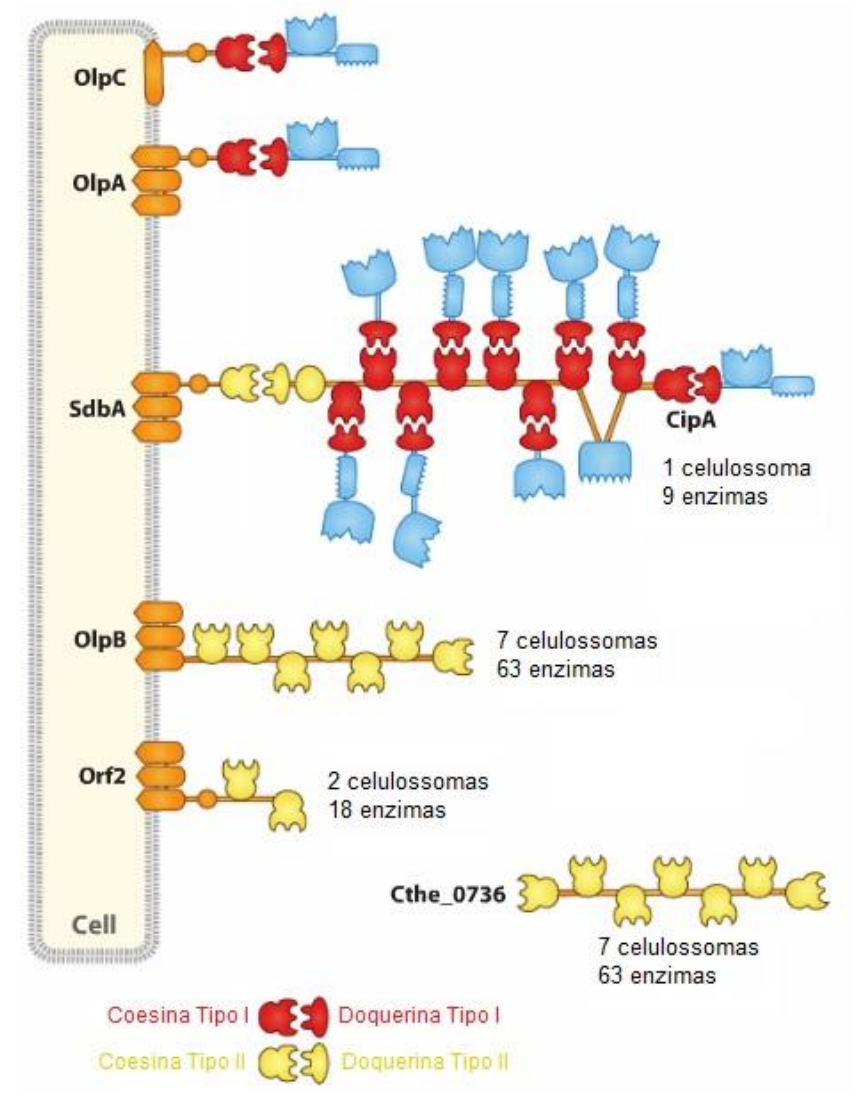

Figura 6. Estrutura ilustrativo dos componentes de policelulossomas. Interação entre as proteínas S-Layers dos celulossomas na parede celular (SdbA, OlpB e Orf2) e no meio extracelular (Cthe 0736) com a proteína estrutural (CipA). Adaptado de Fontes e Gilbert (2010).

Atualmente, existem outras bactérias descritas na literatura que também possuem complexos enzimáticos similares a celulossomas, como Clostridium cellulovorans, Clostridium cellulolyticum, Clostridium acetobutylicum, 
Clostridium josui, Clostridium papyrosolvens, Acetivibrio cellulolyticus, Bacteroides cellulosolvens, Ruminococcus albus e Ruminococcus flavefaciens, mas ainda sendo o celulossoma de $C$. thermocellum, o melhor caracterizado até o momento (Fontes e Gilbert, 2010).

No entanto, a estrutura e composição do celulossoma podem variar não apenas entre diferentes bactérias ou isolados de uma mesma espécie, pois já foi observado que a expressão gênica de $C$. thermocellum também se difere conforme o substrato que for utilizado para o cultivo. Análises transcriptômicas revelaram que há variação significativa no nível de expressão de 348 genes em resposta a utilização de celulose ou celobiose como fonte de carbono no crescimento de $C$. thermocellum. Houve uma redução da expressão de 78 genes e um aumento de 95 genes na presença de celobiose, o que sugere que esta bactéria é capaz de responder a estímulos externos com relação à disponibilidade de nutrientes (Akinosho et al., 2014). A proteômica de celulossomas confirma essa diferença, quando a bactéria é cultivada nos substratos de celulose, celobiose e gramíneas pré-tratadas, possuindo uma alta incidência de GH9 em celulose microcristalina e em gramíneas prétratadas, enquanto que o aumento de GH5 ocorre especificamente em celulose amorfa ou cristalina. Além disso, foi observado uma maior expressão da CelS, procedida do crescimento de $C$. thermocellum em avicel, quando comparada a celobiose (Gold e Martin, 2007).

Apesar de todo esse conhecimento de genômica, transcriptômica e proteômica de $C$. thermocellum, há poucos estudos quanto ao uso de celulossomas na sacarificação de complexos materiais lignocelulósicos, tendo a maior parte dos dados voltados à hidrólise da celulose microcristalina (Johnson et al., 1982; Morag et al., 1995; Prawitwong et al., 2013), e apenas alguns com relação à palha de trigo e palha de arroz como substrato (Moraïs et al., 2012; Tachaapaikoon et al., 2012; Waeonukul et al., 2012). Até o momento, não houve relatos de sacarificação de biomassas como palha de cana de açúcar e piolho de algodão por celulossomas de $C$. thermocellum. 


\section{JUSTIFICATIVA}

A biomassa vegetal lignocelulósica fornece uma grande disponibilidade de fonte de carbono que pode ser aproveitada por diversos organismos para produção de energia, combustível, entre outras moléculas de interesse comercial. Microrganismos produtores de enzimas holocelulolíticas são promissores na hidrólise desta biomassa para produção de açúcares fermentáveis, e consequentemente na produção de bioetanol celulósico. Nesse contexto, é de suma importância pesquisas que contribuam para o melhor entendimento desses organismos e a identificação de suas enzimas, visando a sua aplicação no desenvolvimento de produtos a partir da sacarificação de materiais lignocelulósicos e, portanto, no desenvolvimento de biorrefinarias.

Neste trabalho propomos o estudo de um novo isolado da bactéria $C$. thermocellum, isolado $\mathrm{B} 8$, obtido do rúmem de um caprino da raça Moxotó. $\mathrm{A}$ principal meta é contribuir para a caracterização dos celulossomas produzidos por este isolado e avaliar o potencial de sua aplicação na hidrólise de resíduos agrícolas para produção de compostos de interesse biotecnológico. E desta forma, contribuir para melhoria da cadeia produtiva de bioetanol e outros derivados da hidrólise de biomassa lignocelulósica. 


\section{OBJETIVO}

\subsection{Objetivo Geral}

Purificar, identificar e caracterizar as atividades celulolíticas e xilanolíticas secretadas por $C$. thermocellum isolado B8, assim como avaliar a sua capacidade de hidrolisar resíduos agrícolas, tais como palha de cana e piolho de algodão.

\subsection{Objetivos específicos}

- Purificar celulossomas de C. thermocellum isolado B8 quando cultivado em celulose como fonte de carbono;

- Determinar a atividade de carboximetilcelulase (CMCase), FPAse, avicelase e xilanase secretadas por este isolado;

- Analisar se a amostra purificada é um complexo enzimático utilizando análise eletroforética (SDS-PAGE) e Espalhamento de Luz Dinâmico.

- Identificar as proteínas secretadas pelo isolado B8 quando cultivado em celulose como fonte de carbono;

- Avaliar o efeito do efeito de $\mathrm{pH}$, temperatura e de compostos fenólicos na atividade de celulases e xilanases secretadas pelo isolado B8.

- Realizar a sacarificação de celulose, palha de cana e pilho de algodão utilizando os celulossomas purificados e a fração de proteínas ligantes ao substrato secretadas pelo isolado $\mathrm{B} 8$;

- Quantificar os açúcares produzidos obtidos pela sacarificação dos substratos acima mencionados. 


\section{MATERIAL E MÉTODOS}

\subsection{Cultivo e isolamento de C. thermocellum}

Bactérias anaeróbicas foram isoladas de amostras sólidas e líquidas do rúmen de um caprino endêmico no nordeste do Brasil, da raça Moxotó, utilizando condições de crescimento anaeróbio, conforme descrito por Freier et al. em 1988. Um total de 10 bactérias isoladas foram inoculadas em meio de cultura redutor (extrato de levedura $\left(3 \mathrm{~g} . \mathrm{L}^{-1}\right), \mathrm{NH}_{2} \mathrm{PO}_{4}\left(5 \mathrm{~g} . \mathrm{L}^{-1}\right), \mathrm{Na}_{2} \mathrm{HPO}_{4}(2.5$ g. $\left.\mathrm{L}^{-1}\right), \mathrm{NH}_{4} \mathrm{Cl}\left(0.5 \mathrm{~g} . \mathrm{L}^{-1}\right),\left(\mathrm{NH}_{4}\right)_{2} \mathrm{SO}_{4}\left(0.5 \mathrm{~g} \cdot \mathrm{L}^{-1}\right), \mathrm{NaHCO}_{3}\left(0.5 \mathrm{~g} \cdot \mathrm{L}^{-1}\right), \mathrm{MgCl}_{2}(0.09$ g. $\left.\mathrm{L}^{-1}\right)$, solução mineral $(5.0 \mathrm{~mL})$, solução de vitaminas $(0.5 \mathrm{~mL}), \mathrm{NaOH}(0.04$ g. $\left.\mathrm{L}^{-1}\right), \mathrm{Na}_{2} \mathrm{~S}_{9} \mathrm{H}_{2} \mathrm{O}\left(0.125 \mathrm{~g} . \mathrm{L}^{-1}\right)$, cisteína $\left(0.05 \mathrm{~g} . \mathrm{L}^{-1}\right)$ suplementado com $1 \%$ de celulose microcristalina $(\mathrm{m} / \mathrm{v})$ como fonte de carbono, e incubadas a $60^{\circ} \mathrm{C}$ durante 48 horas. Dentre estes, um único isolado apresentou crescimento em celulose, e posteriormente foi identificado como da espécie Clostridum thermocellum utilizando análise da sequência 16SrDNA e comparação de genomas. Este isolado, denominado $C$. thermocellum B8, foi capaz de crescer sob estas condições e utilizar a celulose como fonte de carbono, assim esta bactéria anaeróbica termofilica foi escolhida para posterior análise. Culturas líquidas de C. thermocellum foram mantidas a $4^{\circ} \mathrm{C}$ e $-80^{\circ} \mathrm{C}$ com repiques semanais e a cada 6 meses, respectivamente. 


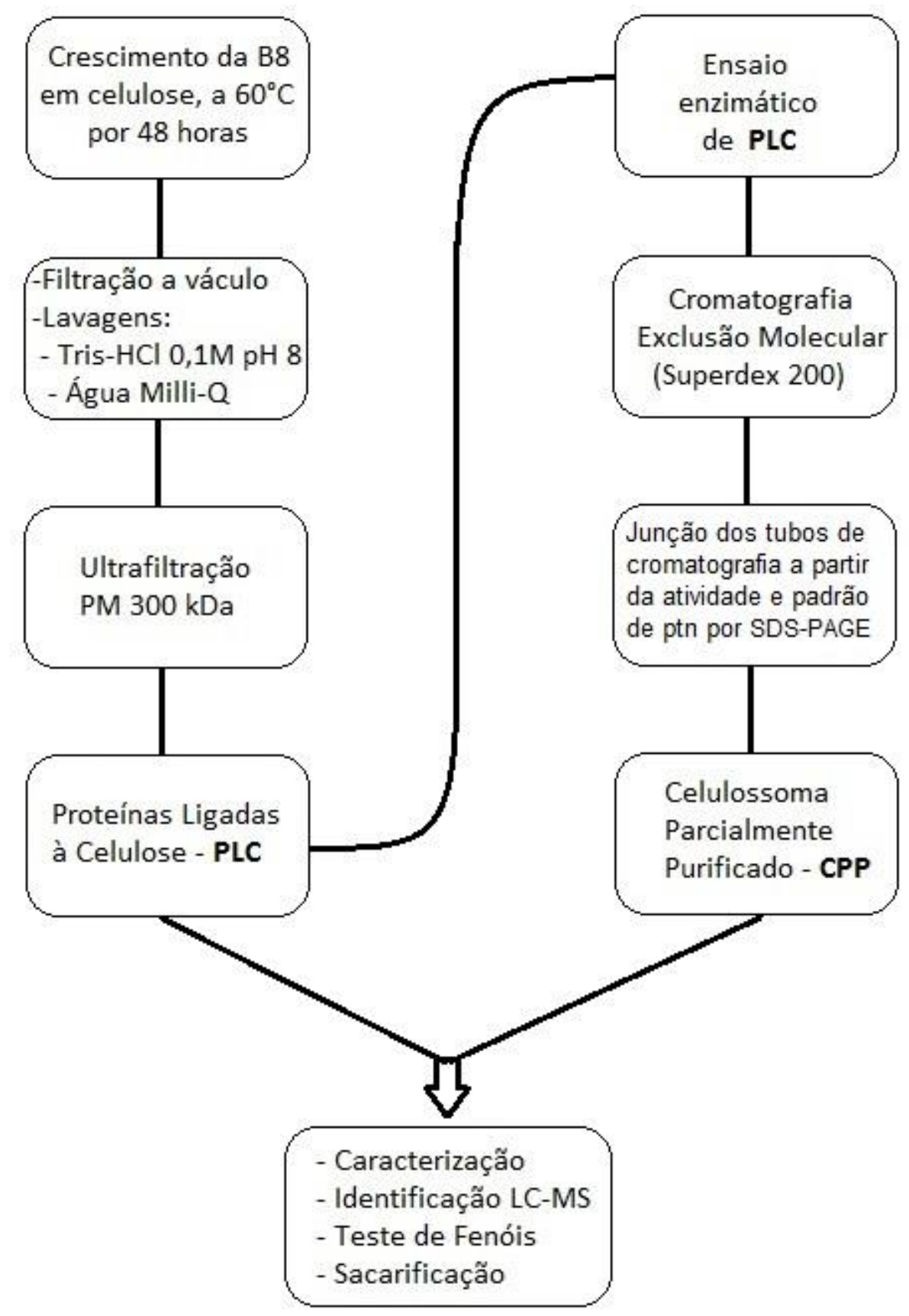

Figura 7. Esquema da metodologia para produção das amostras PLC e CPP, seguido dos experimentos de caracterização, identificação por nanoUPLC-MS(E), teste de fenóis e sacarificação, com o objetivo de comparação entre as amostras. 


\subsection{Preparação das amostras enzimáticas}

Para a obtenção de celulossomas, o crescimento da $C$. thermocellum B8 foi realizado em condições anaeróbias, utilizando o meio líquido de cultura redutor (Freier, Mothershed e Wiegel, 1988) suplementado com 1\% de celulose cristalina $(\mathrm{m} / \mathrm{v})$ como fonte de carbono e incubado a $60^{\circ} \mathrm{C}$, como descrito anteriormente. Após 48 horas de crescimento, as culturas foram filtradas a vácuo (papel de filtro Whatman $n^{\circ} 5$ ) de modo a separar a celulose cristalina do sobrenadante, para posterior uso do substrato residual na extração de Proteínas Ligadas à Celulose (PLC), incluindo os cellulossomas.

A obtenção da fração de proteínas ligantes à celulose, PLC, é realizada a partir da lavagem do substrato residual com o tampão Tris- $\mathrm{HCl} 0,1 \mathrm{M} \mathrm{pH} \mathrm{8,0}$ (lavagem com $90 \mathrm{~mL}$ de tampão para cada 2 frascos contendo $100 \mathrm{~mL}$ de meio de cultura) com o objetivo de remover proteínas que não estão ligadas especificamente ao substrato. Em seguida a celulose foi lavada com água ultrapura (água Milli Q), recuperando proteínas que estão fortemente ligadas ao substrato, dentre elas, o celulossoma (Ljungdahl et al., 1983). A amostra correspondente a PLC foi concentrada 10x por ultrafiltração em um sistema Amicon, sendo utilizada uma membrana com faixa de exclusão de $300 \mathrm{kDa}$ (Millipore Co., MA, USA). Desta forma, PLC concentrada é constituída por proteínas com massa molecular acima de $300 \mathrm{kDa}$. Esta amostra foi utilizada como fonte de proteínas para os experimentos de caracterização de xilanases e celulases e para purificação de celulossomas (Figura 7).

\subsection{Purificação de celulossomas}

A purificação dos celulossomas foi realizada de forma automatizada utilizando o equipamento Äkta purifier e software Unicorn 5.1 system (GE, Uppsala, Sweden). Foram aplicados $5 \mathrm{~mL}$ da amostra PLC em uma coluna de cromatografia de exclusão molecular (HiLoad 16/60 Superdex S-200-GE). A eluição das proteínas foi realizada utilizando-se fluxo de $0,8 \mathrm{~mL} / \mathrm{min}$, tendo como fase móvel o tampão Tris- $\mathrm{HCl} 0,1 \mathrm{M} \mathrm{pH} \mathrm{8,0}$ adicionado de $150 \mathrm{mM}$ de $\mathrm{NaCl}$ e $2 \mathrm{mM}$ de $\mathrm{CaCl}_{2}$ coletando $4 \mathrm{~mL}$ por fração. O Blue dextran (2MDa) foi 
utilizado como marcador de massa molecular para determinar o volume vazio da coluna (Figura 7).

As frações com massa molecular em torno de 2MDa e que apresentaram atividades de xilanase e CMCase foram analisadas em gel SDSPAGE. As frações que apresentaram o mesmo perfil de proteínas foram reunidas constituindo a amostra denominada de Celulossoma Parcialmente Purificado (CPP). As amostras PLC e CPP foram utilizadas nos experimentos de espectrometria de massa e sacarificação de biomassas lignocelulósicas, além de avaliadas quanto ao efeito de temperatura, $\mathrm{pH}$ e fenóis.

\subsection{Determinação da atividade enzimática e quantificação de proteínas}

As atividades enzimáticas foram determinadas pelo método de Miller, que utiliza o ácido 3,5-dinitrosalicílico (DNS) para detecção de açúcares redutores, liberados após a hidrólise de polissacarídeos, que são utilizados como substratos nos ensaios enzimáticos (Miller, 1959). Os ensaios enzimáticos foram realizados utilizando como substrato: carboximetilcelulose $(\mathrm{CMC})$, avicel e xilana oat spelts na concentração de $2 \%(\mathrm{~m} / \mathrm{v})$ e na proporção volumétrica de 1:2 de amostra enzimática e substrato. Para as atividades de CMCase foi utilizado o tampão acetato de sódio $100 \mathrm{mM}$ pH 5,0 e para determinação das atividades de xilanase e avicelase, o tampão fosfato de sódio $100 \mathrm{mM}$ pH 6,0. Após 30 minutos de reação a $65^{\circ} \mathrm{C}$, (com exceção para atividade de avicelase, que é incubada por 2 horas), $300 \mu \mathrm{L}$ do reagente de DNS foram adicionados para interromper a reação em cada tubo de ensaio, estes foram fervidos durante 10 minutos para detecção dos açúcares redutores liberados. A absorbância foi medida a $540 \mathrm{~nm}$. Uma unidade de atividade enzimática foi definida como a quantidade de enzima necessária para obter um micromol de açúcar redutor por minuto de reação.

Para o ensaio de papel de filtro (FPase), utilizou-se uma tira de papel Whatman $\mathrm{n}^{\circ} 1(1 \times 6 \mathrm{~cm})$ como substrato e incubado por 1 hora a $65^{\circ} \mathrm{C}$ com 150 $\mu \mathrm{L}$ de amostra enzimática, seguido da adição de $300 \mu \mathrm{L}$ do reagente de DNS. O ensaio foi fervido por 10 minutos, e adicionado $500 \mu \mathrm{L}$ de água destilada 
para leitura a $540 \mathrm{~nm}$, possuindo a mesma unidade definida para as atividades descritas anteriormente.

A atividade de $\beta$-glicosidase foi determinada utilizando $p$-nitrofenil- $\beta$-Dglucosídeo (pNPG) 10 mM como substrato, com a proporção volumétrica de $2: 1$ de enzima. Após o ensaio ser incubado durante 30 minutos a $65^{\circ} \mathrm{C}$, foi adicionado $1 \mathrm{~mL}$ de $\mathrm{Na}_{2} \mathrm{CO}_{3} 1 \mathrm{M}$ para quebrar a ligação entre o pNPG e as moléculas de glicose, desta forma, o produto resultante da hidrólise foi detectado a $410 \mathrm{~nm}$. Uma unidade de atividade enzimática foi definida como a quantidade de enzima necessária para obter um micromol de pNP por minuto de reação.

Glicose, xilose e PNP foram utilizados como padrão para a determinação das atividades enzimáticas de CMCase, avicelase e FPase; xilanase e $\beta$-glicosidase, respectivamente. Todos os testes foram realizados em triplicata. A atividade específica foi calculada a partir da atividade enzimática pela quantidade de proteína de cada amostra $(\mathrm{mg} / \mathrm{mL})$.

A concentração de proteínas nas amostras foi determinando utilizando o kit Quick Start Bradford (BioRad, EUA, 1976), tal como recomendado em suas instruções. A absorbância da mistura foi determinada a $595 \mathrm{~nm}$ e utilizando BSA (albumina de soro bovino) como padrão (Bradford, 1976).

\subsection{Análise eletroforética (SDS-PAGE)}

Proteínas das frações cromatográficas $(500 \mu \mathrm{L})$ foram precipitadas com ácido tricloroacético, TCA, 10\% (v/v). Após incubação por 1 hora a $4^{\circ} \mathrm{C}$, as amostras foram centrifugadas a $14000 \mathrm{rpm}$, a $4^{\circ} \mathrm{C}$ por 15 minutos, 0 sobrenadante foi descartado e o precipitado lavado duas vezes com acetona PA gelada, com centrifugação nas mesmas condições anteriormente descritas (Damerval et al., 1986). A eletroforese foi realizada em gel de poliacrilamida a $12 \%(\mathrm{~m} / \mathrm{v})$ em condições desnaturantes, SDS-PAGE (Laemmli, 1970). As amostras foram ressuspendidas em $16 \mu \mathrm{L}$ de água ultrapura Milli $\mathrm{Q}$ e $4 \mu \mathrm{L}$ de tampão de amostra contendo tris-HCl 125 mM, pH 6,8; SDS 2,0\% (v/v); azul de bromofenol 0,05\% (m/v); glicerol 20\% (v/v) e $\beta$-mercaptoetanol 5,0\% (v/v) e 
fervidas por 5 minutos. A corrida foi realizada em corrente elétrica fixa de 25 mA. Os géis foram corados com prata de acordo com Blum et al, 1987. "PageRuler Unstained Broad Range Protein Ladder" foi utilizado como marcador de massa molecular (MM), contendo proteínas de com massa molecular entre 5 e $250 \mathrm{kDa}$ (Thermo Scientific, EUA).

\subsection{Espalhamento de Luz Dinâmico}

A amostra CPP foi analisada pelo método de espalhamento de luz dinâmico, do inglês "Dynamic Light Scattering" (DLS), utilizando o equipamento Zetasizer Nanoseries (Malvern, Londres, Reino Unido). Os parâmetros utilizados foram: emissão de laser no comprimento de onda de $633 \mathrm{~nm}$ a $25^{\circ} \mathrm{C}$ e a captura do laser em uma angulação de $173^{\circ}$. O tamanho em nanômetros da amostra CPP foi estimado de acordo com o método acumulado (Z-average) e foram realizadas três medições com número de corridas em modo automático. O diâmetro hidrodinâmico, o número e o volume de CPP foram estimados pela intensidade de espalhamento de luz (Wilson, 2003). Foram analisadas amostras de celulossoma não tratada (CPP) e tratadas com Tween 80 (Sigma-Aldrich Co., MO, EUA), em concentrações de 0,1\% e 1\%, com o objetivo de observar a dissociação das proteínas dos complexos celulossomais.

\subsection{Efeito do pH e da temperatura nas atividades enzimáticas}

O efeito do $\mathrm{pH}$ nas atividades de CMCase e xilanase das amostras PLC e CPP foi avaliado utilizando os ensaios enzimáticos descritos no item 4.4., nos

pHs 3, 4, 5, 6, 7, 8 e 9 em três diferentes tipos de tampão: acetato de sódio (para os valores de $\mathrm{pH} 3,4$ e 5), citrato de sódio (para os valores de 5, 6 e pH 7) e Tris- $\mathrm{HCl}$ (para os valores de $\mathrm{pH} 7,8$ e 9) a $100 \mathrm{mM}$. O efeito da temperatura sobre estas atividades enzimáticas foi avaliado utilizando os ensaios enzimáticos descritos no item 4.4., em temperaturas variando de $40^{\circ} \mathrm{C}$ a $80^{\circ} \mathrm{C}$. A estabilidade térmica de PLC foi avaliada pela sua pré-incubação a $50^{\circ} \mathrm{C}$ e $60^{\circ} \mathrm{C}$, com retiradas a cada 5 dias até o máximo de 20 dias, e a $70^{\circ} \mathrm{C}$ 
foram retiradas alíquotas a cada 24 horas até o máximo de 5 dias (120 horas). As atividades residuais foram determinadas de acordo com os ensaios enzimáticos, realizados como descrito no item 4.4. A atividade foi expressa em atividade relativa, considerando $100 \%$ a maior atividade detectada.

\subsection{Efeito dos compostos fenólicos nas atividades de CMCase e xilanase}

O efeito de compostos fenólicos nas atividades de CMCase e de xilanase das amostras PLC e CPP foi analisado na presença de vanilina, ácido tânico, ácido ferúlico, ácido cinâmico, ácido p-cumárico e ácido ácido-4-hidroxibenzóico (sendo os dois primeiros diluídos em água e os demais em etanol) em uma concentração final de $1 \mathrm{mg} / \mathrm{mL}$. (Ximenes, 2010). As amostras foram incubadas a $25^{\circ} \mathrm{C}$ tanto na presença quanto na ausência (controle) de cada composto fenólico durante 24 horas, seguido do ensaio enzimático descrito no item 4.4. Dependendo da diluição de cada composto, ao controle foi adicionado água ou etanol. Atividade enzimática foi expressa em atividade relativa considerando $100 \%$ a atividade da do controle de cada amostra.

\subsection{Espectrometria de massa}

A preparação da amostra, a análise por NanoUPLC-MSE, o processamento de dados e a identificação das proteínas foram realizados de acordo com Murad e Rech, 2012. A amostra PLC foi dialisada, liofilizada e filtrada em filtro de Membrana Fluoreto Polivinidileno (PVDF) de 0,22 mm (Merck Millipore, MA, EUA). A amostra CPP foi dialisada e liofilizada. Ambas utilizadas como fonte de proteínas para análise por espectrometria de massa.

Um total de $50 \mu \mathrm{L}$ de cada amostra (concentração final de proteína de 1 $\mu \mathrm{g}$ de proteína $\mu \mathrm{L}^{-1}$ ) foram adicionados a $10 \mathrm{~mL}$ de bicarbonato de amônio 50 mM. Em seguida, $25 \mathrm{~mL}$ de RapiGESTTM (Waters, EUA) $(0,2 \% \mathrm{v} / \mathrm{v})$ foram adicionados, e as amostras foram agitadas e incubadas num banho seco a $80^{\circ} \mathrm{C}$ durante 15 minutos. As amostras foram reduzidas, alquiladas e digeridas 
com tripsina, como descrito em Murad e Rech, 2012. Após as etapas de digestão e limpeza, os sobrenadantes foram transferidos para frascos de Waters Total Recovery vials (Waters, USA), onde $5 \mu \mathrm{l}$ de Fosforilase B de coelho (Waters, número de peça 186002326) (com $1 \mathrm{~mL}$ contendo $3 \%$ de acetonitrila e $0,1 \%$ de ácido fórmico) e $85 \mathrm{~mL}$ de acetonitrila a 3\% e solução de ácido fórmico a $0,1 \%$ foram adicionados. A concentração final das amostras foi de $250 \mathrm{ng} \cdot \mathrm{LL}^{-1}$, e a concentração final de Fosforilase $B$ foi $25 \mathrm{fmol} . \mu \mathrm{L}^{-1} \mathrm{em}$ um volume final de $200 \mu \mathrm{L}$ (Murad et al., 2011; Murad e Rech, 2012).

Um sistema nanoACQUITYTM ${ }^{\text {TM }}$ (Waters Corp., EUA) com a tecnologia de diluição 2D, equipado com a pré-coluna Symmetry C18 $5 \mu \mathrm{m}, 5 \mathrm{~mm} \times 300 \mu \mathrm{m}$ e a coluna analítica de fase reversa nanoEaseTM BEH130 C18 $1.7 \mu \mathrm{m}, 100 \mu \mathrm{m}$ x $100 \mathrm{~mm}$ (Waters, EUA) para a separação LC nanoscale de peptídeos trípticos de TPS. As amostras foram inicialmente transferidas para a pré-coluna, utilizando uma solução aquosa de ácido fórmico a 0,1\%. A fase móvel $A$ consiste em ácido fórmico a 0,1\% em água, e a fase móvel $B$ consiste em ácido fórmico a $0,1 \%$ em acetonitrila. Os peptídeos foram separados utilizando um gradiente de $3 \%-40 \%$ de fase móvel B durante 200 minutos, com um fluxo de

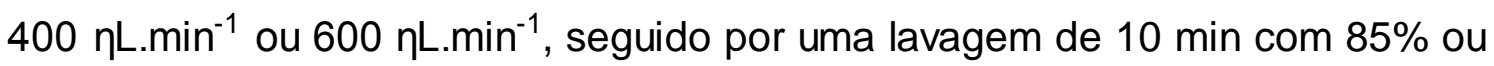
$90 \%$, respectivamente, de fase móvel B. A coluna foi reequilibrada para as condições iniciais durante 20 minutos. A temperatura da coluna foi mantida a $35^{\circ} \mathrm{C}$. Todas as amostras foram analisadas em três repetições.

Peptídeos trípticos foram analisados utilizando o espectrômetro de massa SYNAPT G2 HDMSTM (Waters, Manchester, Reino Unido) com uma geometria de tempo de vôo (oa-TOF) de um hibrido quadrupolo/mobilidade iônica/aceleração ortogonal. Para todas as medições, o espectrômetro de massa foi operado em modo sensível de análise com um típico poder de resolução de pelo menos 10000 full-width half-maximum (FWHM). Todas as análises realizadas utilizaram os parâmetros descritos por Murad e Rech, 2012 e Murad, Souza et al, 2011. O processamento de dados e a identificação de proteínas foram feitas utilizando ProteinLynx Global Server (PLGS) versão 3.0 (Waters, Manchester, Reino Unido) processados e com os dados MS pesquisados, os quais foram obtidos a partir da análise LC-MSE. As proteínas foram identificadas com o algoritmo de contabilidade de íon incorporado no 
software, e a pesquisa pelo banco de dados de Clostridium spp do UniProt com os padrões de digestão MassPREP (MPDs) e com sequências UniProtKB/Swiss-Prot (Fosforilase - P00489 - PHS2_COELHO, Hemoglobina Bovina - P02070 - HBB_BOVIN, ADH - P00330 - ADH1_YEAST, BSA - P02769

- ALBU_ BOVIN) acrescentados ao banco de dados. Identificações e as embalagens de dados quantitativos foram gerados usando algoritmos dedicados e uma pesquisa contra um banco de dados espécies-específico do UniProt (para referência futura, por favor consulte Murad e Rech, 2012). Os parâmetros de pesquisa incluem a modificação fixa de carbamidometil-C, as modificações variáveis de acetilação do terminal- $\mathrm{N}$, de desamidação de $\mathrm{N}$, desamidação de $\mathrm{Q}$ oxidação de $\mathrm{M}$ e a permissão de uma clivagem perdida. Os componentes foram tipicamente agrupado com uma precisão de massa 10 ppm e uma tolerância de tempo 0,25 minutos contra o banco de dado gerado teórico de peptídeos íon massa com um mínimo de um peptídeo correspondido. Os critérios de identificação de proteínas também incluem a detecção de pelo menos três fragmentos de íon por peptídeo, 6 fragmentos por proteína e a determinação de pelo menos um peptídeo por proteína. A identificação da proteína permitida com um máximo de $4 \%$ de taxa de detecção de falsos positivos em pelo menos três injeções de replicadas técnicas. Informações adicionais como gene, tipo de CBM e informações mais detalhada da proteína foram complementadas com o auxílio de bancos de dados do National Center for Biotechnology Information (NCBI) e Carbohydrate Active Enzymes (Cazy).

\subsection{Experimentos de sacarificação de biomassas lignocelulósicas}

As sacarificações de celulose, palha de cana e piolho de algodão pelas amostras PLC e CPP foram executadas em duas temperaturas, $50^{\circ} \mathrm{C}$ e $60^{\circ} \mathrm{C}$, e a produção de açúcares redutores foi monitorada durante 10 dias. Os substratos foram previamente submetidos a um pré-tratamento alcalino de acordo com protocolo prescrito por Zhang et al., 2011. O experimento de sacarificação foi realizado em agitação constante a $180 \mathrm{rpm}$, cada ensaio continha $2 \mu \mathrm{g}$ de proteínas de cada uma das amostras para cada miligrama de 
substrato (0,5\% wt/vol) equilibrada em tampão de acetato de sódio $250 \mathrm{mM}, \mathrm{pH}$ 5,0 com $5 \mathrm{mM}$ de $\mathrm{CaCl}_{2}$ (Tachaapaikoon et al., 2012). A cada dois dias de incubação com agitação e nas temperaturas de 50 ou $60^{\circ} \mathrm{C}$ foram retiradas alíquotas, volume máximo total da coleta de apenas $10 \%$ do volume final, e estas utilizadas para determinação da concentração $(\mathrm{mg} / \mathrm{ml})$ de açúcar redutor liberado, utilizando o reagente DNS (Miller, 1959), e a identificação dos produtos por HPLC. O experimento foi realizado em triplicata e as alíquotas conservadas $\mathrm{a}-20^{\circ} \mathrm{C}$.

\subsection{Quantificação dos açúcares produzidos nos experimentos de sacarificação}

Os açúcares liberados durante a sacarificação das biomassas foram identificados e quantificados utilizando coluna aniônica forte, específica para cromatografia de oligossacarídeos, no sistema Dionex ICS 3000 DC, acoplado ao detector eletroquímico ED40 (Dionex). As alíquotas retiradas no experimento de sacarificação para análises em HPLC (100 $\mu \mathrm{L})$ foram filtradas em um filtro de PVDF 0,22 mm (Merck Millipore, MA, EUA) e diluídas cinco vezes em água ultrapura (Milli-Q) (volume final de $500 \mu \mathrm{L}$ ). Foram injetados 10 $\mu \mathrm{L}$ de amostra por injeção automática, auto sampler AS40 (Dionex), e estas fracionadas utilizando a pré-coluna CarboPac Guard e a coluna CarboPac PA100 (Dionex Corporation, Sunnyvale, CA, EUA). A eluição dos açúcares foi realizada com lavagem com o tampão de acetato de sódio $(0,5 \mathrm{M})$ contendo hidróxido de sódio $(0,1 \mathrm{M})$ (Dionex) em um fluxo de $15 \mathrm{~mL} / \mathrm{h}$, a $20^{\circ} \mathrm{C}$, durante 80 min. O software Chromeleon 6,8 SR8 (Dionex) foi utilizado para a análise dos dados. Três curvas de calibração foram realizadas, uma para cada tipo de açúcar (xilose, glicose e manose), com uma mistura de oligossacarídeos variando entre uma a seis unidades de carbono de cada açúcar. Assim foram obtidas: uma curva de D-xilose e seus derivados (xilose, xilobiose, xilotriose, xylotetraose, xylopentaose, e xylohexaose), D-manose e seus derivados (manose, mannobiose, mannotriose, mannotetraose, manopentaose e mannohexaose) e de D-glicose e seus derivados (glicose, celobiose, celotriose, cellotetraose, cellopentaose e cellohexaose). Para cada curva foram utilizadas 
6 concentrações com variações entre: $0,01 \mathrm{mg} / \mathrm{mL}, 0,02 \mathrm{mg} / \mathrm{mL}, 0,03 \mathrm{mg} / \mathrm{mL}$, $0,04 \mathrm{mg} / \mathrm{mL}, 0,05 \mathrm{mg} / \mathrm{mL}$ e $0,1 \mathrm{mg} / \mathrm{mL}$ (Corporação Megazyme, Wicklow, Irlanda).

\subsection{Análises estatísticas}

Diferenças estatísticas foram avaliadas por meio do teste t de Student com o objetivo de analisar as diferenças entre as atividades das amostras PLC e CPP obtidas nos experimentos de caracterização bioquímica (efeito da temperatura e do $\mathrm{pH}$, termoestabilidade, fenóis e sacarificação). A significância estatística foi definida como $p<0,05$. 


\section{RESULTADOS}

C. thermocellum foi capaz de crescer em meio líquido contendo celulose cristalina como fonte de carbono, apresentando crescimento máximo após 48 horas a $60^{\circ} \mathrm{C}$ (resultado não mostrado). Além disso, secretou enzimas com atividade holocelulolítica como mostrado pelas atividades detectadas na amostra PLC. Nesta amostra foram detectadas atividades de xilanase $(0,9$ $\mathrm{U} / \mathrm{mL})$, CMCase $(0,6 \mathrm{U} / \mathrm{mL})$, FPase $(0,2 \mathrm{U} / \mathrm{mL})$ e Avicelase $(0,01 \mathrm{U} / \mathrm{mL})$ (Tabela 1). No entanto, o maior valor de atividade foi detectado para a atividade xilanolítica.

Tabela 1. Atividades e atividades específicas das amostras PLC e CPP.

\begin{tabular}{cccc}
\hline & Atividades & PLC & CPP \\
\hline & Xilanase & $0,962 \pm 0,0505$ & $0,167 \pm 0,0065$ \\
Atividades & CMCase & $0,609 \pm 0,0037$ & $0,140 \pm 0,0068$ \\
$($ UV/mL $)$ & FPase & $0,241 \pm 0,1004$ & $0,045 \pm 0,0239$ \\
& Avicelase & $0,018 \pm 0,0002$ & $0,005 \pm 0,0004$ \\
\hline \multirow{2}{*}{ Atividades } & Xilanase & 2,70 & 6,99 \\
espećficas & CMCase & 1,71 & 5,85 \\
(mg/mL) & FPase & 3,00 & 1,14 \\
& Avicelase & 0,05 & 0,21 \\
\hline
\end{tabular}

\subsection{Purificação do celulossoma e análise de DLS}

Dois picos de proteínas, PI e Pll, foram detectados após o fracionamento de PLC na coluna cromatográfica High-Load Superdex 200 (Figura 8). O pico $\mathrm{PI}$, com massa molecular estimada de $2 \mathrm{MDa}$, apresentou atividades de xilanase e CMCase (Figura 8A). O perfil de proteínas de PI, correspondente as frações cromatográficas de 13 a 20 , é muito similar, sendo visualizadas proteínas com massa molecular entre 40 e 250 kDa, destacando-se principalmente proteínas de alta massa molecular (Figura 8B). De outro modo, foram visualizadas nas frações correspondentes ao Pll, proteínas com massa molecular abaixo de $70 \mathrm{kDa}$, e estas não apresentaram atividades de CMCase ou xilanase, como é retratado nas figuras $8 \mathrm{~A}$ e $8 \mathrm{C}$. 


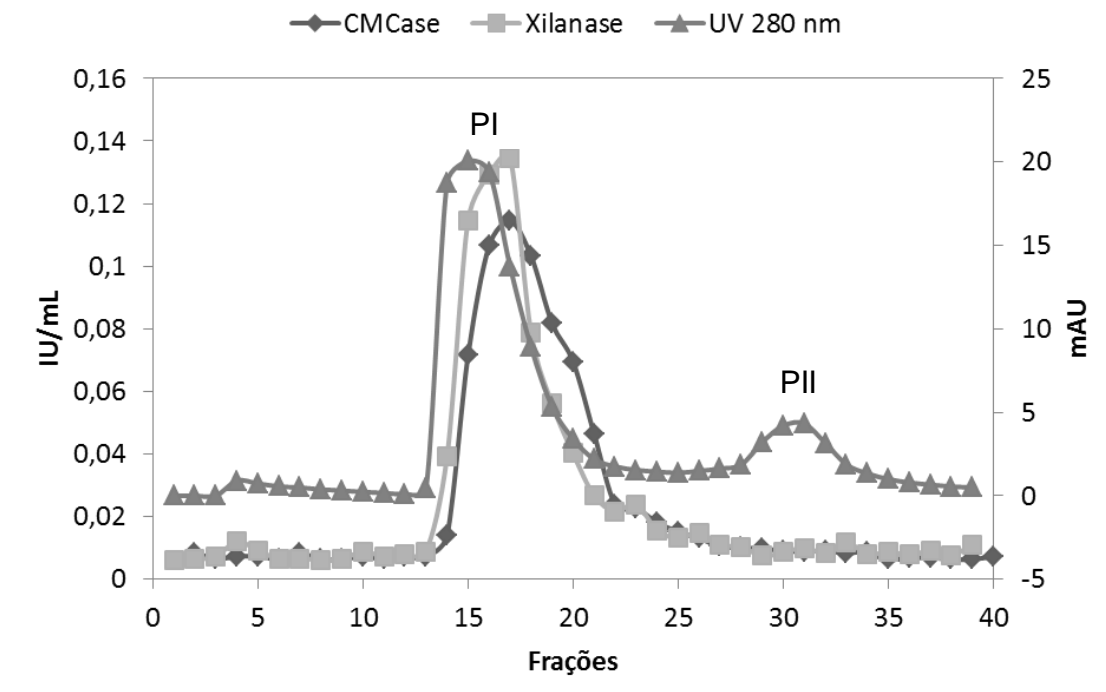

(A)
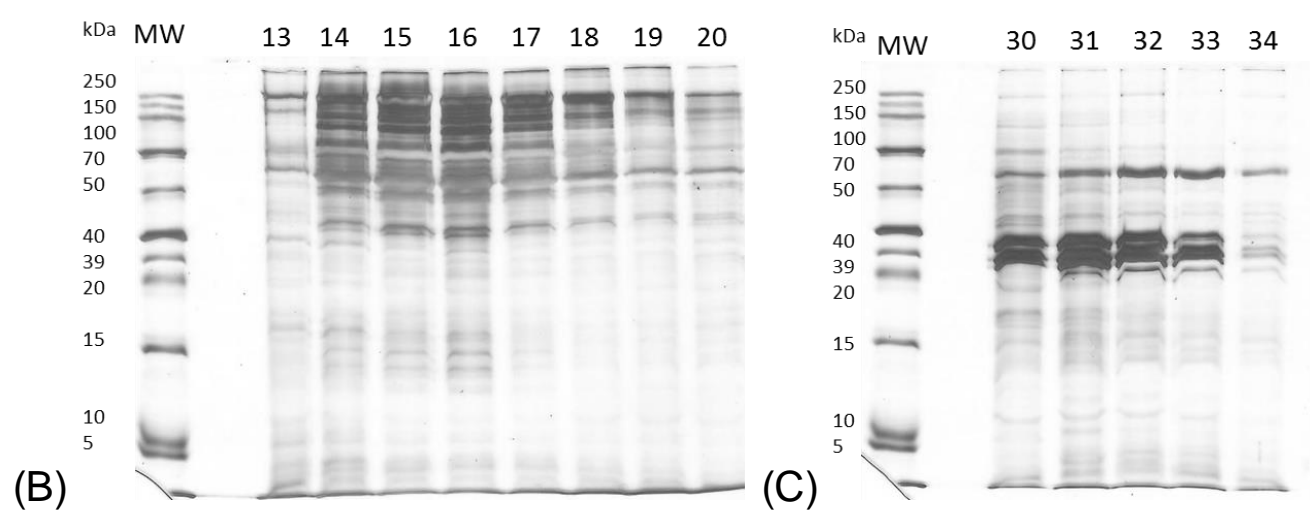

Figura 8. Perfil cromatográfico $(280 \mathrm{~nm})$ em mAU após o fracionamento da amostra PLC na coluna High-Load Superdex 200 e as atividades enzimáticas (xilanase e CMCase) (A), medidas pelo ensaio colorimétrico (DNS) e normalizadas por meio da unidade internacional (UI) estabelecida como ( $\mu$ mol.L-1 de açúcar redutor.min-1.mL-1). As figuras (B) e (C) representam géis de SDS-PAGE (12\%) dos picos da cromatografia, PI e Pll. (B) MM: marcadores de massa molecular e frações PI de 13 a 20; (C) MM: marcadores de massa molecular e frações Pll de 30 até 34.

$\mathrm{Na}$ análise pela técnica de espalhamento de luz dinâmico (DLS), a amostra CPP, pool das frações 13 a 20 que é correspondente a $\mathrm{Pl}$, apresentou dois picos de intensidade (pi1 e pi2), polidispersos e com tamanho estimado de $64,34 \pm 19,17 \mathrm{~nm}(11,3 \mathrm{MDa} \pm 4,4 \mathrm{MDa})$ e $481,7 \pm 186,9 \mathrm{~nm}(1260 \mathrm{MDa} \pm$ $375 \mathrm{MDa})$, respectivamente. No entanto, pi1 abrange a população de proteínas predominante na amostra (Figura 9A). CPP tratada com 0,1\% de Tween 80 (Figura 9B) apresentou um pico adicional, pi3, também polidisperso contendo proteínas com tamanho estimado de 10,64 $\pm 2,46 \mathrm{~nm}(168,2 \mathrm{KDa} \pm 75,8 \mathrm{KDa})$. 
Além disto, para esta amostra, pi3 predomina em número em comparação a pi1 (Figura 9B). O aumento na concentração de Tween, para 1\%, levou a não deteç̧ão dos picos pi1 e pi2 no perfil de DLS, e observa-se apenas a predominância de pi3 (Figura 9C).
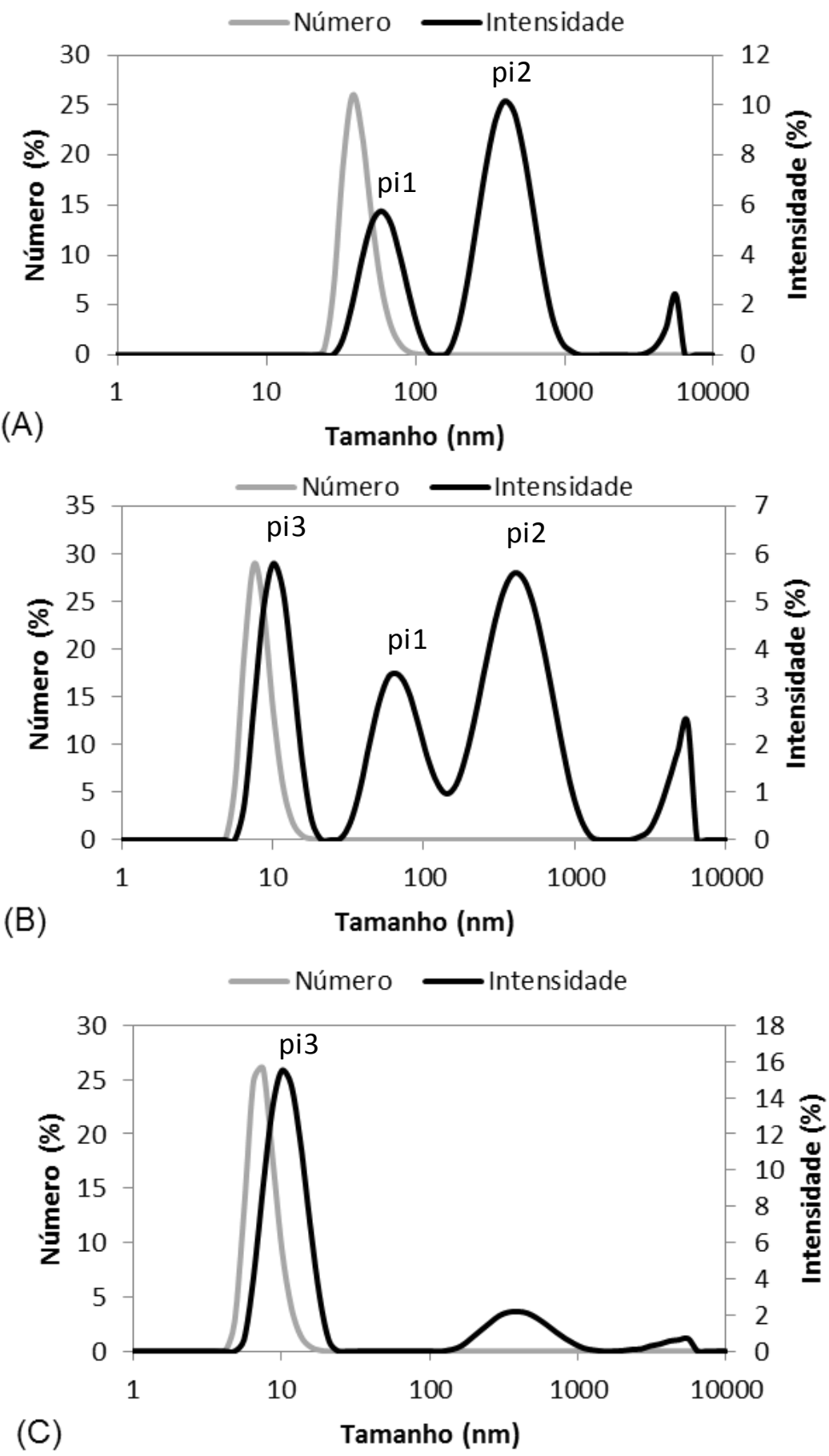

Figura 9. Análise da amostra CPP por meio da técnica de espalhamento de luz dinâmica (DLS) sem o tratamento com Tween80 (A), com Tween 0,1\% (B) e Tween $1 \%(C)$. 


\subsection{Atividades enzimáticas e análise por espectrometria utilizando nanoUPLC-MS(E).}

As amostras PLC e CPP apresentaram atividades celulolíticas (CMCase e FPase) e xilanolíticas, sendo que os maiores valores foram detectados para a amostra PLC (Figura 10). No entanto, CPP apresentou maior atividade específica para xilanase $(6,99 \mathrm{mg} / \mathrm{mL})$, CMCase $(5,85 \mathrm{mg} / \mathrm{mL})$ e avicelase $(0,21 \mathrm{mg} / \mathrm{mL})$ do que a amostra PLC, contendo $2,70 \mathrm{mg} / \mathrm{mL}$ de atividade específica para xilanase, $1,71 \mathrm{mg} / \mathrm{mL}$ de CMCase e $0,05 \mathrm{mg} / \mathrm{mL}$ de avicelase. O que não foi observado para a atividade de FPase, visto que atividade específica de PLC $(3,00 \mathrm{mg} / \mathrm{mL})$ para este ensaio foi quase três vezes maior que a determinada para CPP $(1,14 \mathrm{mg} / \mathrm{mL}$ ) (Tabela 1$)$. Não foi detectado atividade de $\beta$-glicosidase em nenhuma das duas amostras.

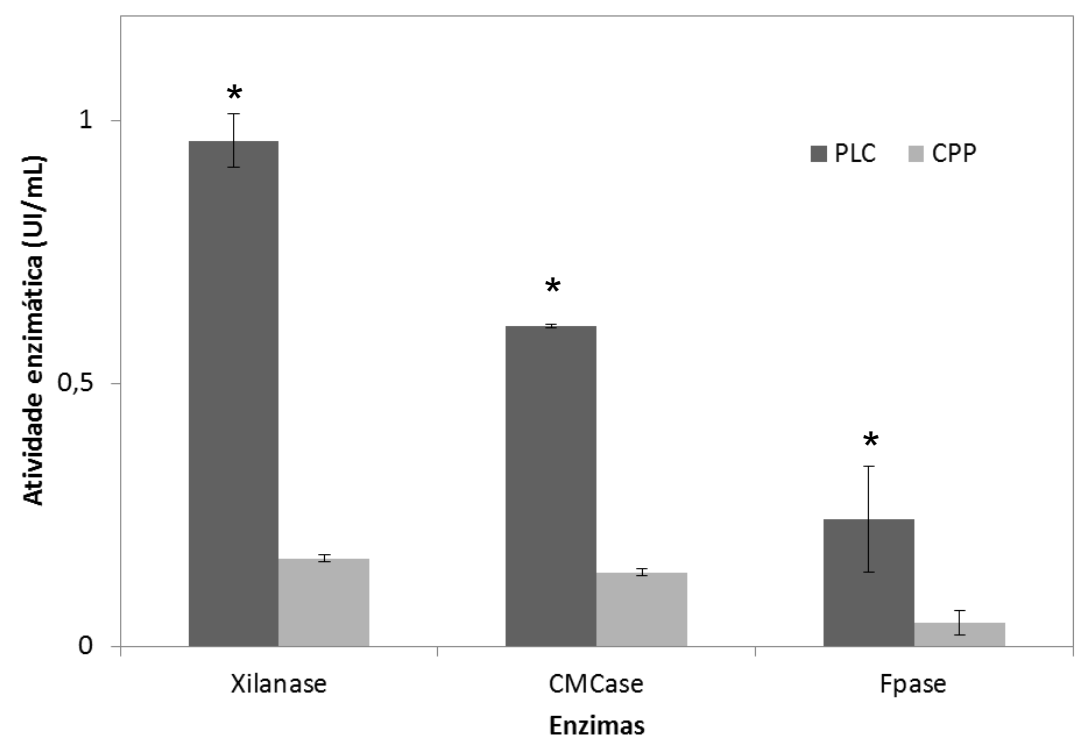

Figura 10. Atividades celulolítica e xilanolítica obtidos nas amostras PLC e CPP $\left({ }^{*} p \leq 0,05\right)$.

$\mathrm{Na}$ amostra PLC foram identificadas em sua maioria proteínas envolvidas no catabolismo de polissacarídeos (93\%). Dentro desta função majoritária, as glicosil hidrolases da família 9, 48 e a CipA, constituem 34\%, $27 \%$ e $19 \%$ dessa categoria, respectivamente. O percentual restante, $7 \%$, inclui: proteínas relacionadas com o mecanismo de transporte de moléculas (3\%) e a outros processos metabólicos (4\%), como fosforilação, sistema imune adaptativo, condensação do cromossomo, splicing de proteínas, biossíntese e 
enovelamento de proteínas, resposta ao estresse oxidativo, motilidade celular, tradução, moléculas de transporte $\mathrm{e}$ alguns deles possuem função desconhecida (Tabela 2 e Figura 11). Dentre as proteínas que possuem função correspondente ao catabolismo de polissacarídeos foram identificadas glicosil hidrolases das famílias $5,8,9,10,11,26,30,43$ e 53, todas contendo o domínio de aminoácidos doquerina tipo I, que as identifica como proteínas pertencentes ao celulossoma. Estas famílias incluem as enzimas: endoglucanases, celobiohidrolases, endoxilanases, endoxilanases com função de feruloil esterase e de acetil xilana esterase, xiloglucanases, arabinoxilanase, glucoxilana xilanohidrolase, arabinofuranosidase, exogalactanase, endogalactanase (arabinogalactana), quitinases, mananase $e$ fator de coagulação 58. Nessa mesma amostra, as exoglucanases (509,6 ngram) foram identificadas em maior quantidade entre as enzimas hidrolíticas, seguida das endoglucanases (392,4 ngram) e xilanases (102,3 ngram) como indicado na tabela 2.

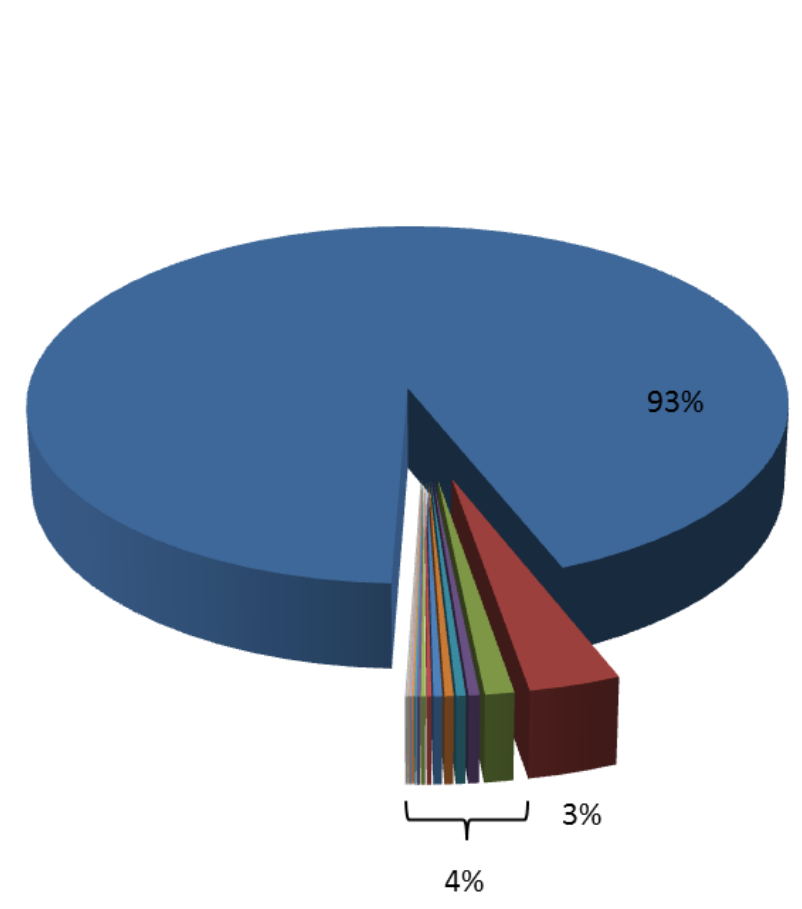

\footnotetext{
- Catabolismo de polissacarídeos

- Moléculas de transporte

- Processo de oxirredução

Enovelamento de proteinas

- Processo glicolítico

- Função desconhecida

- Sistema Imunológico Adaptativo

- Metabolismo ATP

- Fosforilação

- Processo metabólico

- Condensação do cromossomo

Splicing proteína

Motilidade celular

Biossíntese de proteínas

$\square$ Resposta ao estresse oxidativo

Tradução
}

Figura 11. Proteínas identificadas da amostra PLC por espectrometria de massa categorizadas por suas funções. 
Um menor número de categorias funcionais de proteínas foi detectado na amostra CPP. Quase que o total das proteínas identificadas participam no catabolismo de polissacarídeos (99\%), incluindo a proteína estrutural (CipA) e glicosil hidrolases das famílias 5, 8, 9, 10 e 48, que possuem atividades de endoglucanase, celobiohidrolase e xilanase. A família 48 (CelS) destaca-se entre as glicosil hidrolases identificadas, com predominância de $34,9 \%$ na amostra, junto com a CipA, a qual representa $29,9 \%$ do total de proteínas. $O$ $1 \%$ restante é referente à proteína transportadora do tipo $A B C$, classificada como não celulossomal dentre proteínas identificas na amostra CPP. As glicosil hidrolases da familia 5 identificadas incluem: duas endo- $\beta$-1,4-glucanases, CelB e CelG. Apenas a CelA (endo- $\beta-1,4$-glucanase) foi represente da GH8. A GH9 foi a familia com maior quantidade de enzimas identificadas, possuindo 9 enzimas no total, contendo celobiohidrolases (CbhA e CelK), e endo- $\beta-1,4-$ glucanases (CelF, CeIN, CelQ, CelR, CelT, CelU e CelW), onde a CelK (10,5\%) é classificada como a terceira proteína mais abundante da amostra, sendo a principal das GH9. As xilanases da amostra de CPP são a XynC e a XynY, pertencentes a GH10. A XynY, além de apresentar a atividade xilanolítica, ela também possui a atividade de carboidrato esterase. Outra enzima presente, é a CelJ que faz parte tanto da família 9 quanto da 44 das glicosil hidrolases, exibindo atividade de endoglucanase e a capacidade de degradação de xiloglucanos. A CipA presente na amostra CPP contém coesinas tipo I e II, com CBM 3A. Uma observação a ser feita é que todas as famílias de glicosil hidrolases presentes na amostra possuem doquerina tipo I, o que sugere que estas, sejam proteínas pertencentes ao complexo celulossomal (Tabela 3 e Figura 12). No caso da amostra CPP, também foi observado uma maior predominância de exoglucanases (184,6 ngram), seguida das endoglucanases (72,1 ngram) e xilanases (12,3 ngram) como indicado na tabela 2. 


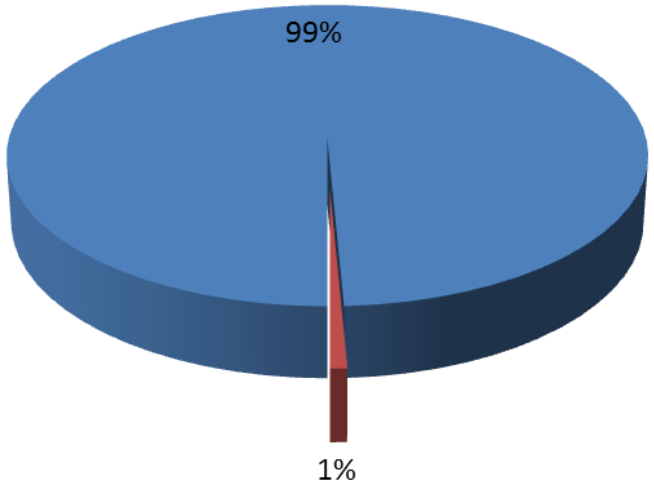

- Catabolismo de

polissacarídeos

- Transporte molecular

Figura 12. Proteínas identificadas da amostra CPP por espectrometria de massa e categorizadas por suas funções.

Tabela 2. Quantidade em nanogramas (ngram) de xilanases, engoglucanases e exoglucanases nas amostras PLC e CPP identificadas por espectrometria de massa e normalizadas pela adição de Fosforilase - P00489 - PHS2_COELHO.

\begin{tabular}{cccc}
\hline & $\begin{array}{c}\text { Xilanases } \\
\text { (ngram) }\end{array}$ & $\begin{array}{c}\text { Endoglucanases } \\
\text { (ngram) }\end{array}$ & $\begin{array}{c}\text { Exoglucanases } \\
\text { (ngram) }\end{array}$ \\
\hline PLC & 102,3 & 392,4 & 509,6 \\
CPP & 12,3 & 72,1 & 184,6 \\
\hline
\end{tabular}


Tabela 3. Proteínas identificadas da amostra PLC por nanoUPLC-MS(E).

\begin{tabular}{|c|c|c|c|c|c|c|c|c|c|c|c|c|}
\hline Gene & $\begin{array}{l}\text { Código } \\
\text { Uniprote }\end{array}$ & CBM & Descrição da Proteína & Função & MW & $\begin{array}{l}\text { Score } \\
\text { AVG }\end{array}$ & $\begin{array}{l}\text { Produtos } \\
\text { AVG }\end{array}$ & $\begin{array}{l}\text { Peptídeos } \\
\text { AVG }\end{array}$ & $\begin{array}{c}\text { Fmol } \\
\text { CV }\end{array}$ & $\begin{array}{l}\text { ngram } \\
\text { AVG }\end{array}$ & $\begin{array}{l}\text { Taxa de } \\
\text { repetição }\end{array}$ & $\begin{array}{l}\% \text { de } \\
\text { TSP }\end{array}$ \\
\hline \multicolumn{13}{|c|}{ CipA } \\
\hline \multirow{11}{*}{ CipA } & D1NJA2 & - & Coesina tipo I & $\begin{array}{l}\text { Catabolismo de } \\
\text { Polissacarídeos }\end{array}$ & 68676,5 & 447,6 & 70,4 & 16,1 & 3,0 & 0,3 & 9,0 & 0,02 \\
\hline & H8ED53 & - & Coesina tipo I & $\begin{array}{l}\text { Catabolismo de } \\
\text { Polissacarídeos }\end{array}$ & 68732,6 & 445,6 & 70,3 & 16,2 & 0,5 & 1,6 & 9,0 & 0,1 \\
\hline & D1NHZ0 & 3 & Coesina tipo I & $\begin{array}{l}\text { Catabolismo de } \\
\text { Polissacarídeos }\end{array}$ & 178367,9 & 75477,8 & 568,3 & 46,3 & 1,5 & 86,1 & 9,0 & 6,2 \\
\hline & E6UU82 & 3 & Coesina tipo I & $\begin{array}{l}\text { Catabolismo de } \\
\text { Polissacarídeos }\end{array}$ & 143945,2 & 75473,9 & 566,8 & 46,2 & 0,8 & 129,8 & 9,0 & 9,3 \\
\hline & H8EAE8 & 3 & Coesina tipo I & $\begin{array}{l}\text { Catabolismo de } \\
\text { Polissacarídeos }\end{array}$ & 36765,6 & 18454,9 & 178,9 & 14,7 & 3,0 & 3,7 & 9,0 & 0,3 \\
\hline & H8EGI0 & - & Coesina tipo I & $\begin{array}{l}\text { Catabolismo de } \\
\text { Polissacarídeos }\end{array}$ & 48331,8 & 402,5 & 37,1 & 11,3 & 0,5 & 1,0 & 8,0 & 0,1 \\
\hline & D1NMl8 & 3 & Coesina tipo I & $\begin{array}{l}\text { Catabolismo de } \\
\text { Polissacarídeos }\end{array}$ & 140645,7 & 1440,5 & 214,3 & 39,8 & 3,0 & 1,1 & 9,0 & 0,1 \\
\hline & H8EFU0 & 3 & Coesina tipo I & $\begin{array}{l}\text { Catabolismo de } \\
\text { Polissacarídeos }\end{array}$ & 140645,7 & 1440,5 & 214,3 & 39,8 & 0,4 & 8,0 & 9,0 & 0,6 \\
\hline & D1NHZ1 & - & Coesina tipo I & $\begin{array}{l}\text { Catabolismo de } \\
\text { Polissacarídeos }\end{array}$ & 192072,7 & 2220,0 & 72,4 & 13,3 & 3,0 & 1,8 & 9,0 & 0,1 \\
\hline & E6UU83 & - & Coesina tipo I & $\begin{array}{l}\text { Catabolismo de } \\
\text { Polissacarídeos }\end{array}$ & 173103,0 & 2219,5 & 72,2 & 13,1 & 0,5 & 8,4 & 9,0 & 0,6 \\
\hline & H8EGH9 & - & Coesina tipo I & $\begin{array}{l}\text { Catabolismo de } \\
\text { Polissacarídeos }\end{array}$ & 75028,2 & 918,0 & 44,5 & 9,3 & 0,6 & 2,8 & 8,0 & 0,2 \\
\hline \multicolumn{13}{|c|}{ Glicosil Hidrolase da Família 5} \\
\hline CelB & H8EBB4 & - & $\begin{array}{l}\text { Endo- } \beta-1,4-\text { glucanase, } \\
\text { Doquerina tipo I }\end{array}$ & $\begin{array}{l}\text { Catabolismo de } \\
\text { Polissacarídeos }\end{array}$ & 64157,2 & 3641,8 & 161,2 & 19,6 & 0,2 & 18,7 & 9,0 & 1,3 \\
\hline \multirow{2}{*}{ CelG } & D1NQT1 & - & $\begin{array}{l}\text { Endo- } \beta-1,4-\text { glucanase, } \\
\text { Doquerina tipo I }\end{array}$ & $\begin{array}{l}\text { Catabolismo de } \\
\text { Polissacarídeos }\end{array}$ & 63655,5 & 7141,9 & 189,2 & 20,3 & 1,2 & 14,9 & 9,0 & 1,1 \\
\hline & H8EI72 & - & $\begin{array}{l}\text { Endo- } \beta-1,4-\text { glucanase, } \\
\text { Doquerina tipo I }\end{array}$ & $\begin{array}{l}\text { Catabolismo de } \\
\text { Polissacarídeos }\end{array}$ & 63641,5 & 6742,0 & 182,1 & 19,9 & 1,0 & 18,0 & 9,0 & 1,3 \\
\hline CelL & H8EGT5 & - & $\begin{array}{c}\text { Endo- } \beta-1,4-\text { glucanase, } \\
\text { Doquerina tipo I }\end{array}$ & $\begin{array}{l}\text { Catabolismo de } \\
\text { Polissacarídeos }\end{array}$ & 60338,2 & 2591,3 & 94,0 & 16,7 & 0,2 & 5,8 & 9,0 & 0,4 \\
\hline CtMan5A & H8ECW7 & 32 & $\begin{array}{c}\text { Fator de coagulação 58, } \\
\text { Dockerin type I }\end{array}$ & $\begin{array}{l}\text { Catabolismo de } \\
\text { Polissacarídeos }\end{array}$ & 63338,2 & 1125,0 & 63,0 & 12,8 & 0,4 & 2,6 & 9,0 & 0,2 \\
\hline \multirow{2}{*}{ Xyl5A } & D1NNT8 & 6,13 e 62 & $\begin{array}{c}\text { Arabinoxilana específica, } \\
\text { Doquerina tipo I }\end{array}$ & $\begin{array}{l}\text { Catabolismo de } \\
\text { Polissacarídeos }\end{array}$ & 103411,1 & 2262,5 & 171,0 & 26,7 & 0,6 & 11,4 & 9,0 & 0,8 \\
\hline & H8EB41 & 6,13 e 62 & $\begin{array}{c}\text { Arabinoxilana específica, } \\
\text { Doquerina tipo I }\end{array}$ & $\begin{array}{l}\text { Catabolismo de } \\
\text { Polissacarídeos }\end{array}$ & 103351,0 & 2126,4 & 163,8 & 25,9 & 2,1 & 2,9 & 9,0 & 0,2 \\
\hline
\end{tabular}


Glicosil Hidrolase da Família 8

\begin{tabular}{|c|c|c|c|c|c|c|c|c|c|c|c|c|}
\hline CelA & C7HGK4 & - & $\begin{array}{c}\text { Endo- } \beta-1,4-\text { glucanase } \\
\text { Doquerina tipo I }\end{array}$ & & 51657,5 & 32209,7 & 352,9 & 27,4 & 0,2 & 61,6 & 9,0 & 4,4 \\
\hline \multicolumn{13}{|c|}{ Glicosil Hidrolase da Família 9} \\
\hline \multirow{3}{*}{ CbhA } & C7HIJ7 & 3 e 4 & $\begin{array}{l}\text { Celobiohidrolase, Doquerina } \\
\text { tipo I, domínio CenC }\end{array}$ & $\begin{array}{l}\text { Catabolismo de } \\
\text { Polissacarídeos }\end{array}$ & 138625,6 & 40640,3 & 705,1 & 85,0 & 3,0 & 3,0 & 9,0 & 0,2 \\
\hline & D1NLS3 & 3 e 4 & $\begin{array}{l}\text { Celobiohidrolase, Doquerina } \\
\text { tipo I, domínio CenC }\end{array}$ & $\begin{array}{l}\text { Catabolismo de } \\
\text { Polissacarídeos }\end{array}$ & 137914,9 & 40639,9 & 705,6 & 85,1 & 0,4 & 21,9 & 9,0 & 1,6 \\
\hline & Q59325 & 3 e 4 & $\begin{array}{l}\text { Celobiohidrolase, Doquerina } \\
\text { tipo I, domínio CenC }\end{array}$ & $\begin{array}{l}\text { Catabolismo de } \\
\text { Polissacarídeos }\end{array}$ & 138933,9 & 40324,6 & 651,3 & 77,1 & 3,0 & 16,8 & 9,0 & 1,2 \\
\hline Cel9A/CelD & H8ECW5 & - & $\begin{array}{l}\text { Endo- } \beta-1,4 \text {-glucanase, } \\
\text { Doquerina tipo I }\end{array}$ & $\begin{array}{l}\text { Catabolismo de } \\
\text { Polissacarídeos }\end{array}$ & 72700,6 & 650,4 & 60,9 & 15,7 & 0,2 & 3,7 & 9,0 & 0,3 \\
\hline Cel9B/CelF & H8EBA7 & 3 & $\begin{array}{l}\text { Endo- } \beta-1,4-\text { glucanase, } \\
\text { Doquerina tipo I }\end{array}$ & $\begin{array}{l}\text { Catabolismo de } \\
\text { Polissacarídeos }\end{array}$ & 82431,2 & 2409,2 & 152,9 & 23,1 & 0,2 & 6,9 & 9,0 & 0,5 \\
\hline \multirow{2}{*}{ CelK } & C7HHU0 & 4 & $\begin{array}{c}\text { Celobiohidrolase, Doquerina } \\
\text { tipo I, CenC-like }\end{array}$ & $\begin{array}{l}\text { Catabolismo de } \\
\text { Polissacarídeos }\end{array}$ & 101249,4 & 69096,6 & 675,7 & 60,4 & 1,3 & 0,8 & 9,0 & 0,1 \\
\hline & D1NLS2 & 4 & $\begin{array}{l}\text { Celobiohidrolase, Doquerina } \\
\text { tipo I, CenC-like }\end{array}$ & $\begin{array}{l}\text { Catabolismo de } \\
\text { Polissacarídeos }\end{array}$ & 101339,4 & 83013,5 & 837,0 & 75,7 & 0,2 & 112,2 & 9,0 & 8,0 \\
\hline \multirow{2}{*}{ CelN } & H8El14 & 3 & $\begin{array}{l}\text { Endo- } \beta-1,4-g l u c a n a s e \\
\text { Doquerina tipo I }\end{array}$ & $\begin{array}{l}\text { Catabolismo de } \\
\text { Polissacarídeos }\end{array}$ & 82538,4 & 1428,9 & 102,3 & 18,4 & 0,2 & 4,2 & 9,0 & 0,3 \\
\hline & Q9L3J5 & 3 & $\begin{array}{l}\text { Endo- } \beta-1,4 \text {-glucanase, } \\
\text { Doquerina tipo I }\end{array}$ & $\begin{array}{l}\text { Catabolismo de } \\
\text { Polissacarídeos }\end{array}$ & 82580,5 & 1230,2 & 84,3 & 16,4 & 3,0 & 0,6 & 9,0 & 0,04 \\
\hline \multirow{2}{*}{ CelP } & D1NLD7 & - & $\begin{array}{c}\text { Endo- } \beta-1,4-\text { glucanase, } \\
\text { Doquerina tipo I, CenC-like }\end{array}$ & $\begin{array}{l}\text { Catabolismo de } \\
\text { Polissacarídeos }\end{array}$ & 63176,1 & 972,2 & 77,4 & 14,4 & 3,0 & 0,7 & 9,0 & 0,1 \\
\hline & H8EBK7 & - & $\begin{array}{c}\text { Endo- } \beta-1,4 \text {-glucanase, } \\
\text { Doquerina tipo I, CenC-like }\end{array}$ & $\begin{array}{l}\text { Catabolismo de } \\
\text { Polissacarídeos }\end{array}$ & 63190,2 & 971,8 & 76,2 & 14,2 & 0,4 & 5,3 & 9,0 & 0,4 \\
\hline CelQ & C7HDM7 & 3 & $\begin{array}{l}\text { Endo- } \beta-1,4 \text {-glucanase, } \\
\text { Doquerina tipo I }\end{array}$ & $\begin{array}{l}\text { Catabolismo de } \\
\text { Polissacarídeos }\end{array}$ & 80224,8 & 36561,6 & 401,0 & 38,6 & 0,2 & 93,9 & 9,0 & 6,7 \\
\hline \multirow[t]{2}{*}{ CelR } & D1NM86 & 3 & $\begin{array}{l}\text { Endo- } \beta-1,4-\text { glucanase, } \\
\text { Celotetraose, Doquerina tipo }\end{array}$ & $\begin{array}{l}\text { Catabolismo de } \\
\text { Polissacarídeos }\end{array}$ & 82834,8 & 10326,8 & 373,1 & 45,1 & 1,2 & 17,3 & 9,0 & 1,2 \\
\hline & H8EB72 & 3 & $\begin{array}{c}\text { Endo- } \beta-1,4-\text { glucanase, } \\
\text { Celotetraose, Doquerina tipo } \\
\text { I }\end{array}$ & $\begin{array}{l}\text { Catabolismo de } \\
\text { Polissacarídeos }\end{array}$ & 82735,7 & 10314,1 & 370,4 & 44,4 & 1,0 & 23,5 & 9,0 & 1,7 \\
\hline \multirow{2}{*}{ CelT } & D1NQQ3 & - & $\begin{array}{l}\text { Endo- } \beta-1,4 \text {-glucanase, } \\
\text { Doquerina tipo I }\end{array}$ & $\begin{array}{l}\text { Catabolismo de } \\
\text { Polissacarídeos }\end{array}$ & 69154,8 & 5267,6 & 211,8 & 28,4 & 1,2 & 5,7 & 9,0 & 0,4 \\
\hline & Q8V773 & - & $\begin{array}{l}\text { Endo- } \beta-1,4-\text { glucanase, } \\
\text { Doquerina tipo I }\end{array}$ & $\begin{array}{l}\text { Catabolismo de } \\
\text { Polissacarídeos }\end{array}$ & 69024,6 & 5192,1 & 208,6 & 27,8 & 1,0 & 6,1 & 9,0 & 0,4 \\
\hline \multirow{2}{*}{ CelU } & A3DHY3 & 3 & $\begin{array}{c}\text { Endo- } \beta-1,4-\text { glucanase, } \\
\text { Doquerina tipo I }\end{array}$ & $\begin{array}{l}\text { Catabolismo de } \\
\text { Polissacarídeos }\end{array}$ & 105277,5 & 1439,3 & 148,4 & 29,8 & 0,6 & 5,9 & 9,0 & 0,4 \\
\hline & H8EAD5 & 3 & Endo- $\beta-1,4$-glucanase, & Catabolismo de & 107498,4 & 1441,9 & 148,9 & 30,0 & 2,0 & 1,9 & 9,0 & 0,1 \\
\hline
\end{tabular}




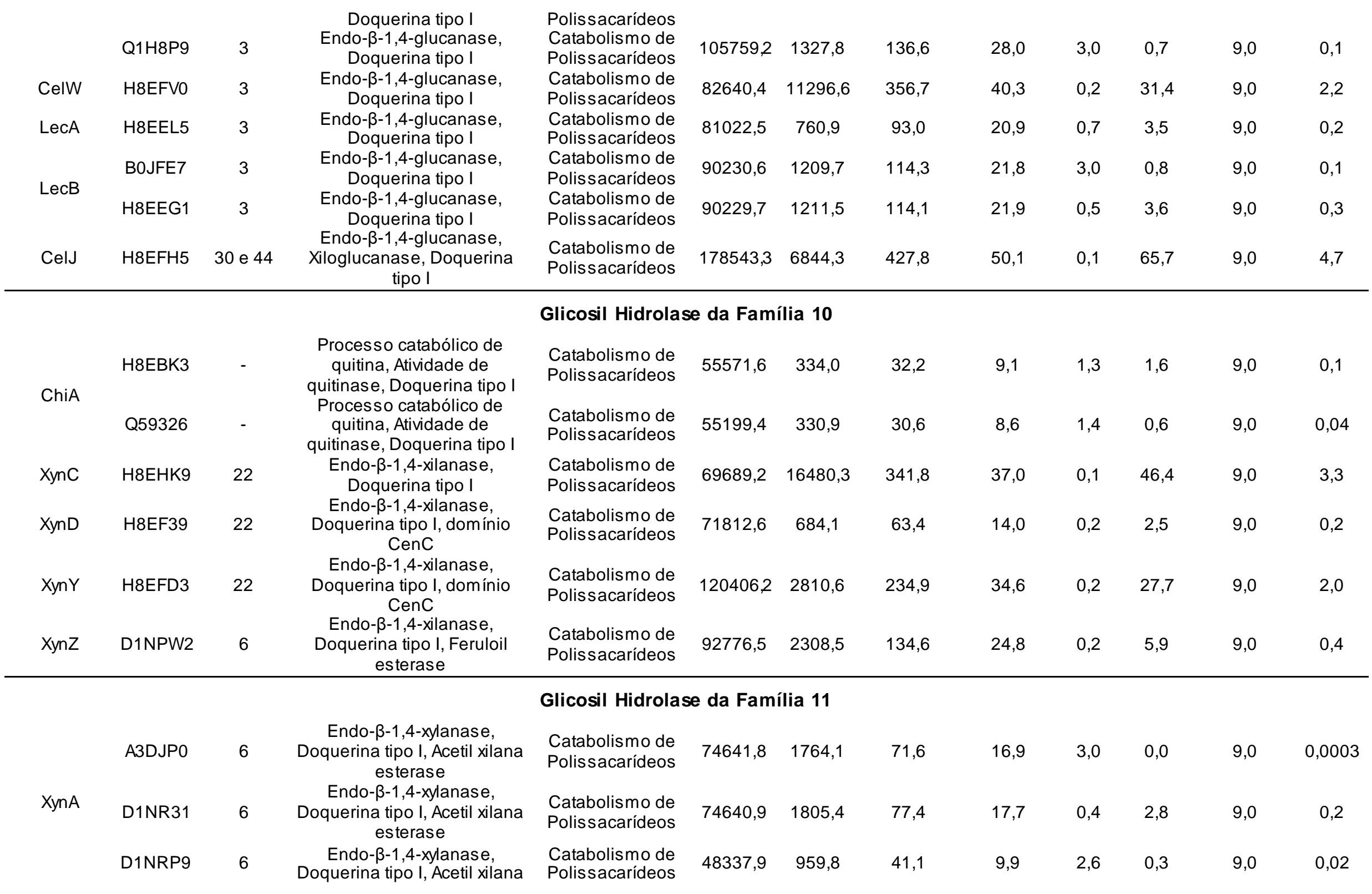




\begin{tabular}{|c|c|c|c|c|c|c|c|c|c|c|c|c|}
\hline & O52780 & 6 & $\begin{array}{c}\text { esterase } \\
\text { Endo- } \beta-1,4-x y l a n a s e, \\
\text { Doquerina tipo I, Acetil xilana } \\
\text { esterase }\end{array}$ & $\begin{array}{l}\text { Catabolismo de } \\
\text { Polissacarídeos }\end{array}$ & 74700,9 & 1713,2 & 69,6 & 16,3 & 2,6 & 0,4 & 9,0 & 0,03 \\
\hline \multicolumn{13}{|c|}{ Glicosil Hidrolase da Família 26} \\
\hline \multirow[b]{2}{*}{ ManA/ManB } & H8EGS1 & 35 & $\beta$-mananase, Doquerina tipo I & $\begin{array}{l}\text { Catabolismo de } \\
\text { Polissacarídeos }\end{array}$ & 67551,0 & 1605,9 & 99,6 & 18,4 & 0,8 & 3,2 & 9,0 & 0,2 \\
\hline & Q9REC7 & 35 & $\beta$-mananase, Doquerina tipo I & $\begin{array}{l}\text { Catabolismo de } \\
\text { Polissacarídeos }\end{array}$ & 67443,8 & 1208,0 & 90,6 & 17,3 & 1,6 & 1,2 & 9,0 & 0,1 \\
\hline \multicolumn{13}{|c|}{ Glicosil Hidrolase da Família 30} \\
\hline CtXyn & $\mathrm{H} 8 \mathrm{ECH} 6$ & 6 & $\begin{array}{c}\text { Glucuronoxilano } \\
\text { xilanohidrolase, Doquerina } \\
\text { tipo I }\end{array}$ & $\begin{array}{l}\text { Catabolismo de } \\
\text { Polissacarídeos }\end{array}$ & 70556,4 & 549,2 & 54,4 & 13,6 & 0,4 & 2,1 & 8,0 & 0,2 \\
\hline \multicolumn{13}{|c|}{ Glicosil Hidrolase da Família 43} \\
\hline Ct43Araf & H8ED90 & 6 & $\begin{array}{c}\alpha-L-a r a b i n o f u r a n o s i d a s e \\
\text { Doquerina tipo I }\end{array}$ & $\begin{array}{l}\text { Catabolismo de } \\
\text { Polissacarídeos }\end{array}$ & 75017,2 & 646,8 & 76,3 & 20,4 & 0,5 & 1,8 & 9,0 & 0,1 \\
\hline \multirow{2}{*}{ Gal43A } & A3DD67 & 13 & $\begin{array}{c}\text { Exo- } \beta-1,3-\text { galactanase, } \\
\text { Ricina B - lectina, Doquerina } \\
\text { tipo I }\end{array}$ & $\begin{array}{l}\text { Catabolismo de } \\
\text { Polissacarídeos }\end{array}$ & 64237,1 & 615,7 & 64,4 & 17,0 & 3,0 & 0,2 & 9,0 & 0,01 \\
\hline & H8EFL6 & 13 & $\begin{array}{c}\text { Exo- } \beta-1,3-g a l a c t a n a s e, \\
\text { Ricina B - lectina, Doquerina } \\
\text { tipo I }\end{array}$ & $\begin{array}{l}\text { Catabolismo de } \\
\text { Polissacarídeos }\end{array}$ & 64249,1 & 615,4 & 64,2 & 17,1 & 0,4 & 2,3 & 9,0 & 0,2 \\
\hline \multicolumn{13}{|c|}{ Glicosil Hidrolase da Família 48} \\
\hline \multirow{2}{*}{ CelS } & C7HDZ8 & - & $\begin{array}{c}\text { Exo- } \beta-1,4-\text { glucanase, } \\
\text { Doquerina tipo I }\end{array}$ & $\begin{array}{l}\text { Catabolismo de } \\
\text { Polissacarídeos }\end{array}$ & 83702,6 & 35973,6 & 685,3 & 59,7 & 1,2 & 0,3 & 9,0 & 0,02 \\
\hline & D1NQ73 & - & $\begin{array}{c}\text { Exo- } \beta-1,4 \text {-glucanase } \\
\text { Doquerina tipo I }\end{array}$ & $\begin{array}{l}\text { Catabolismo de } \\
\text { Polissacarídeos }\end{array}$ & 84105,1 & 36154,0 & 709,2 & 61,7 & 0,2 & 354,6 & 9,0 & 25,4 \\
\hline \multicolumn{13}{|c|}{ Glicosil Hidrolase da Família 53} \\
\hline- & H8EIB0 & - & $\begin{array}{c}\text { Endo- } \beta-1,4-\text { galactanase, } \\
\text { Arabinogalactano, Doquerina } \\
\text { tipo I }\end{array}$ & $\begin{array}{l}\text { Catabolismo de } \\
\text { Polissacarídeos }\end{array}$ & 47466,2 & 447,4 & 41,1 & 12,8 & 0,3 & 0,9 & 8,0 & 0,1 \\
\hline \multicolumn{13}{|c|}{ Outras Proteínas } \\
\hline- & D1NNL6 & - & V-ATP sintase, cadeia alfa & Matabolismo de & 65535,0 & 305,3 & 46,7 & 17,5 & 0,6 & 2,5 & 6,0 & 0,2 \\
\hline
\end{tabular}




\begin{tabular}{|c|c|c|c|c|c|c|c|c|c|c|c|}
\hline & & & ATP & & & & & & & & \\
\hline H8EEF2 & - & $\begin{array}{l}\text { Aminoglicosídeo } \\
\text { fosfotransferase }\end{array}$ & Fosforilação & 28701,0 & 1266,7 & 33,9 & 8,0 & 0,3 & 0,8 & 7,0 & 0,1 \\
\hline H8ED52 & - & Piruvato Fosfato Diquinase & Fosforilação & 99363,7 & 280,5 & 55,0 & 19,8 & 0,2 & 1,6 & 6,0 & 0,06 \\
\hline D1NKI2 & - & $\begin{array}{l}\text { Proteína da família Csh2 } \\
\text { associada à CRISPR }\end{array}$ & $\begin{array}{l}\text { Sistema imune } \\
\text { adaptativo }\end{array}$ & 34882,8 & 329,5 & 20,2 & 6,5 & 0,2 & 0,4 & 6,0 & 0,03 \\
\hline D1NLU9 & - & $\begin{array}{l}\text { Alcool desidrogenase íons } \\
\qquad \mathrm{Fe} 2+\end{array}$ & $\begin{array}{l}\text { Metabolismo de } \\
\text { Álcool }\end{array}$ & 96537,3 & 839,3 & 109,7 & 24,3 & 1,6 & 1,4 & 9,0 & 0,1 \\
\hline H8EEF1 & - & $\begin{array}{l}\text { Alcool desidrogenase íons } \\
\mathrm{Fe} 2+\end{array}$ & $\begin{array}{l}\text { Metabolismo de } \\
\text { Álcool }\end{array}$ & 96523,3 & 833,2 & 108,6 & 24,0 & 0,8 & 2,7 & 9,0 & 0,2 \\
\hline A3DHK9 & - & $\begin{array}{c}\text { Domínio de proteína } \\
\text { Flagelina }\end{array}$ & Motilidade celular & 29567,3 & 562,2 & 17,3 & 3,7 & 3,0 & 0,1 & 9,0 & 0,01 \\
\hline D1NNP7 & - & $\begin{array}{c}\text { Domínio de proteína } \\
\text { Flagelina }\end{array}$ & Motilidade celular & 29595,4 & 616,6 & 19,8 & 4,4 & 2,3 & 0,0 & 8,0 & 0,004 \\
\hline H8ECD9 & - & $\begin{array}{c}\text { Domínio de proteína } \\
\text { Flagelina }\end{array}$ & Motilidade celular & 26368,7 & 667,6 & 19,3 & 4,0 & 1,3 & 0,1 & 7,0 & 0,004 \\
\hline D1NNP6 & - & $\begin{array}{l}\text { Domínio de proteína } \\
\text { Flagelina }\end{array}$ & Motilidade celular & 29431,5 & 654,8 & 22,8 & 5,0 & 1,5 & 0,2 & 9,0 & 0,02 \\
\hline H8El41 & - & $\begin{array}{c}\text { Domínio de proteína } \\
\text { Flagelina }\end{array}$ & Motilidade celular & 26204,8 & 643,9 & 21,6 & 4,6 & 0,8 & 0,4 & 9,0 & 0,03 \\
\hline H8EGl8 & - & Histona & $\begin{array}{l}\text { Condensação do } \\
\text { cromossomo }\end{array}$ & 9728,3 & 5267,4 & 43,9 & 5,6 & 0,4 & 0,8 & 9,0 & 0,05 \\
\hline H8EEX1 & - & Histona & $\begin{array}{l}\text { Condensação do } \\
\text { cromossomo }\end{array}$ & 10087,7 & 982,7 & 18,0 & 4,9 & 0,4 & 0,3 & 7,0 & 0,02 \\
\hline H8ECAO & - & Enolase & $\begin{array}{l}\text { Processo } \\
\text { Glicolítico }\end{array}$ & 47159,7 & 728,7 & 45,9 & 9,9 & 0,4 & 1,9 & 8,0 & 0,1 \\
\hline H8ECN7 & - & $\begin{array}{l}\text { Frutose-1,6-bifosfato- } \\
\text { aldolase classe II }\end{array}$ & $\begin{array}{l}\text { Processo } \\
\text { Glicolítico }\end{array}$ & 33917,8 & 308,9 & 25,0 & 9,8 & 0,8 & 0,7 & 9,0 & 0,05 \\
\hline H8ECN6 & - & Fosfofrutoquinase & $\begin{array}{l}\text { Processo } \\
\text { Glicolítico }\end{array}$ & 46023,3 & 714,8 & 44,2 & 11,0 & 0,3 & 1,8 & 6,0 & 0,1 \\
\hline H8EC96 & - & Fosfofrutoquinase & $\begin{array}{l}\text { Processo } \\
\text { Glicolítico }\end{array}$ & 42876,6 & 289,6 & 23,1 & 8,6 & 0,3 & 0,6 & 9,0 & 0,04 \\
\hline D1NRJ8 & - & Esterase putativa & $\begin{array}{l}\text { Splicing proteína } \\
\text { inteína mediada }\end{array}$ & 64157,5 & 967,9 & 34,4 & 5,9 & 1,6 & 0,9 & 9,0 & 0,07 \\
\hline H8EAA3 & - & $\begin{array}{c}\text { Domínio da proteína tiamina } \\
\text { pirofosfato (TPP) }\end{array}$ & $\begin{array}{l}\text { Processo } \\
\text { Metabólico }\end{array}$ & 34991,4 & 1097,5 & 42,3 & 8,5 & 0,4 & 1,4 & 8,0 & 0,1 \\
\hline H8EGU7 & - & $\begin{array}{l}\text { Transportadores do tipo ABC } \\
\text { envolvido com a ligação ao } \\
\text { substrato }\end{array}$ & $\begin{array}{l}\text { Transporte } \\
\text { molecular }\end{array}$ & 34182,3 & 3814,6 & 63,6 & 9,4 & 0,6 & 3,1 & 9,0 & 0,2 \\
\hline H8EH05 & - & $\begin{array}{l}\text { Transportadores do tipo ABC } \\
\text { envolvido com a ligação ao } \\
\text { substrato }\end{array}$ & $\begin{array}{l}\text { Transporte } \\
\text { molecular }\end{array}$ & 50085,7 & 23636,1 & 426,0 & 43,2 & 0,4 & 44,5 & 9,0 & 3,2 \\
\hline H8EGV2 & - & Domínio da proteína álcool & Processo & 38508,2 & 554,3 & 40,5 & 13,8 & 0,4 & 1,0 & 6,0 & 0,07 \\
\hline
\end{tabular}




\begin{tabular}{|c|c|c|c|c|c|c|c|c|c|c|c|}
\hline D1NKK8 & - & $\begin{array}{c}\text { desidrogenase GroES } \\
\text { Domínio de amina oxidase } \\
\text { contendo cobre }\end{array}$ & $\begin{array}{l}\text { oxirredução } \\
\text { Processo } \\
\text { oxirredução }\end{array}$ & 30261,7 & 371,2 & 30,0 & 8,5 & 0,5 & 0,6 & 8,0 & 0,04 \\
\hline H8EAB3 & - & $\begin{array}{l}\text { Domínio de amina oxidase } \\
\text { contendo cobre }\end{array}$ & $\begin{array}{l}\text { Processo } \\
\text { oxirredução }\end{array}$ & 33203,5 & 395,9 & 30,4 & 8,9 & 0,4 & 0,5 & 7,0 & 0,03 \\
\hline H8EGG2 & - & $\begin{array}{l}\text { Domínio de amina oxidase } \\
\text { contendo cobre }\end{array}$ & $\begin{array}{l}\text { Processo } \\
\text { oxirredução }\end{array}$ & 59309,6 & 697,0 & 35,9 & 9,3 & 0,2 & 2,4 & 9,0 & 0,2 \\
\hline H8ECJ9 & - & $\begin{array}{l}\text { D-2-hidroxi ácido } \\
\text { desidrogenase }\end{array}$ & $\begin{array}{l}\text { Processo } \\
\text { oxirredução }\end{array}$ & 43147,8 & 323,3 & 22,3 & 8,2 & 0,3 & 0,7 & 6,0 & 0,05 \\
\hline H8EHS4 & - & $\begin{array}{l}\text { Enoil-(Proteína } \\
\text { Transportadora de Acil) } \\
\text { Redutase (NADH) }\end{array}$ & $\begin{array}{l}\text { Processo } \\
\text { oxirredução }\end{array}$ & 27101,0 & 508,5 & 22,9 & 5,1 & 0,5 & 0,5 & 7,0 & 0,03 \\
\hline H8EC95 & - & $\begin{array}{l}\text { Gliceraldeído-3-fosfato } \\
\text { desidrogenase tipo I }\end{array}$ & $\begin{array}{l}\text { Processo } \\
\text { oxirredução }\end{array}$ & 36367,4 & 6048,2 & 125,0 & 17,1 & 0,4 & 7,4 & 9,0 & 0,5 \\
\hline H8EAA4 & - & $\begin{array}{l}\text { Piruvato-ferredoxina } \\
\text { oxidorredutase (PFOR) }\end{array}$ & $\begin{array}{l}\text { Processo } \\
\text { oxirredução }\end{array}$ & 43632,8 & 701,6 & 55,0 & 13,6 & 0,3 & 1,6 & 7,0 & 0,1 \\
\hline H8EAA6 & - & $\begin{array}{c}\text { Piruvato ceto-isovalerato } \\
\text { oxidorredutase Subunidade } \\
\text { gama }\end{array}$ & $\begin{array}{l}\text { Processo } \\
\text { oxirredução }\end{array}$ & 21260,5 & 1758,4 & 30,8 & 5,6 & 0,4 & 0,5 & 8,0 & 0,04 \\
\hline H8EFJ2 & - & Proteína doquerina tipo I & $\begin{array}{l}\text { Catabolismo de } \\
\text { Polissacarídeos }\end{array}$ & 64784,5 & 282,6 & 39,5 & 13,3 & 0,4 & 0,9 & 8,0 & 0,07 \\
\hline H8EIA8 & - & Proteína doquerina tipo I & $\begin{array}{l}\text { Catabolismo de } \\
\text { Polissacarídeos }\end{array}$ & 92707,5 & 966,0 & 108,1 & 24,7 & 0,2 & 6,9 & 9,0 & 0,5 \\
\hline D1NPP3 & - & Proteína doquerina tipo I & $\begin{array}{l}\text { Catabolismo de } \\
\text { Polissacarídeos }\end{array}$ & 71820,2 & 3264,1 & 90,7 & 20,6 & 0,3 & 6,1 & 9,0 & 0,4 \\
\hline H8EHE5 & - & Proteína doquerina tipo I & $\begin{array}{l}\text { Catabolismo de } \\
\text { Polissacarídeos }\end{array}$ & 93232,5 & 858,8 & 111,6 & 27,2 & 0,1 & 3,8 & 9,0 & 0,3 \\
\hline H8EEA5 & - & Proteinase inibidor 14 serpina & $\begin{array}{l}\text { Catabolismo de } \\
\text { Polissacarídeos }\end{array}$ & 68045,4 & 366,2 & 40,0 & 12,3 & 0,2 & 1,2 & 9,0 & 0,09 \\
\hline H8EA87 & - & $\begin{array}{l}\text { Proteína da família } \\
\text { PspAlM30 }\end{array}$ & $\begin{array}{l}\text { Catabolismo de } \\
\text { Polissacarídeos }\end{array}$ & 27756,6 & 675,0 & 27,0 & 8,6 & 0,2 & 0,7 & 8,0 & 0,05 \\
\hline A3DGN2 & - & $\begin{array}{l}\text { Proteína putativa não } \\
\text { caracterizada }\end{array}$ & $\begin{array}{l}\text { Catabolismo de } \\
\text { Polissacarídeos }\end{array}$ & 80490,5 & 3083,1 & 84,1 & 19,6 & 3,0 & 0,0 & 9,0 & 0,0004 \\
\hline D1NNV1 & 6 e 35 & Pectato liase Amb alérgeno & $\begin{array}{l}\text { Catabolismo de } \\
\text { Polissacarídeos }\end{array}$ & 100782,7 & 4522,4 & 256,9 & 42,9 & 0,2 & 12,1 & 9,0 & 0,9 \\
\hline H8EB28 & 6 e 35 & Pectato liase Amb alérgeno & $\begin{array}{l}\text { Catabolismo de } \\
\text { Polissacarídeos }\end{array}$ & 62099,6 & 2633,4 & 146,0 & 21,4 & 2,1 & 0,0 & 9,0 & 0,001 \\
\hline H8EEP5 & - & Fator de alongamento EF-Tu & $\begin{array}{l}\text { Biossíntese de } \\
\text { proteínas }\end{array}$ & 44276,5 & 435,7 & 41,0 & 12,4 & 0,2 & 0,8 & 9,0 & 0,06 \\
\hline H8EI52 & - & Chaperonina $60 \mathrm{kDa}$ & $\begin{array}{l}\text { Enovelamento de } \\
\text { Proteínas }\end{array}$ & 57531,2 & 3076,6 & 134,8 & 21,5 & 0,5 & 5,7 & 8,0 & 0,4 \\
\hline H8ECT1 & & Peroxirredoxina & $\begin{array}{c}\text { Resposta ao } \\
\text { estresse oxidativo }\end{array}$ & 20918,6 & 1655,5 & 31,3 & 5,8 & 0,5 & 0,7 & 9,0 & 0,05 \\
\hline
\end{tabular}




\begin{tabular}{|c|c|c|c|c|c|c|c|c|c|c|c|c|}
\hline- & H8EEQ2 & - & Proteína ribossomal 50S & Tradução & 13295,4 & 1992,6 & 32,4 & 5,6 & 0,6 & 0,4 & 9,0 & 0,03 \\
\hline- & H8EDW1 & - & Domínio da proteína lg & $\begin{array}{c}\text { Função } \\
\text { desconhecida }\end{array}$ & 113214,2 & 309,4 & 73,0 & 23,3 & 1,5 & 1,1 & 6,0 & 0,08 \\
\hline - & D1NIC8 & - & $\begin{array}{l}\text { Proteína putativa não } \\
\text { caracterizada }\end{array}$ & $\begin{array}{c}\text { Função } \\
\text { desconhecida }\end{array}$ & 14884,1 & 2520,4 & 42,2 & 6,7 & 0,3 & 0,8 & 9,0 & 0,06 \\
\hline- & D1NMR1 & - & $\begin{array}{l}\text { Proteína putativa não } \\
\text { caracterizada }\end{array}$ & $\begin{array}{l}\text { Função } \\
\text { desconhecida }\end{array}$ & 19049,6 & 607,6 & 21,1 & 6,1 & 0,4 & 0,3 & 8,0 & 0,02 \\
\hline- & H8ERX6 & - & Domínio da proteína S-layer & $\begin{array}{c}\text { Função } \\
\text { desconhecida }\end{array}$ & 33738,1 & 820,7 & 25,6 & 4,6 & 2,8 & 0,0 & 8,0 & 0,0003 \\
\hline - & О86999 & - & Proteína S-layer & $\begin{array}{c}\text { Função } \\
\text { desconhecida }\end{array}$ & 113387,4 & 300,5 & 69,9 & 23,1 & 0,7 & 1,9 & 7,0 & 0,1 \\
\hline- & H8EGN3 & - & Proteína não caracterizada & $\begin{array}{c}\text { Função } \\
\text { desconhecida }\end{array}$ & 13231,1 & 646,5 & 13,9 & 3,6 & 0,4 & 0,2 & 7,0 & 0,01 \\
\hline- & H8EAT4 & - & Proteína não caracterizada & $\begin{array}{c}\text { Função } \\
\text { desconhecida }\end{array}$ & 22050,4 & 374,4 & 29,3 & 7,6 & 0,2 & 0,3 & 8,0 & 0,01 \\
\hline
\end{tabular}

CMB é referente à família de CBM presente na proteína, quando for o caso. MW é o peso molecular. O Score AVG é a média do score obtido pelo programa ProteinLynx Global Server (PLGS) para cada hit. Produtos AVG é média dos fragmentos de produtos ionizados de um hit de proteína. Peptídeos AVG é a média do hit de peptídeos por proteína identificada. FmolCV é a covariância ao nível de detecção de femtomol para cada proteína nas análises de replicatas. NgramAVG é a média em nanogramas de cada carga de proteína injetada na coluna. A taxa de repetição é a repetibilidade de cada proteína nas replicatas. \% de TSP é a porcentagem de cada proteína na mistura total solúvel, em relação à carga de proteína total (em nanogramas) sobre a coluna. 
Tabela 4. Proteínas identificadas da amostra CPP por nanoUPLC-MS(E).

\begin{tabular}{|c|c|c|c|c|c|c|c|c|c|c|c|c|}
\hline Gene & $\begin{array}{l}\text { Código } \\
\text { Uniprote }\end{array}$ & CBM & Descrição das proteínas & Função & MW & $\begin{array}{l}\text { Score } \\
\text { AVG }\end{array}$ & $\begin{array}{l}\text { Produtos } \\
\text { AVG }\end{array}$ & $\begin{array}{l}\text { Peptídeos } \\
\text { AVG }\end{array}$ & $\begin{array}{l}\text { Fmol } \\
\text { CV }\end{array}$ & $\underset{\text { AVG }}{\text { ngram }}$ & $\begin{array}{l}\text { Taxa de } \\
\text { repetição }\end{array}$ & $\begin{array}{l}\% \text { de } \\
\text { TSP }\end{array}$ \\
\hline \multicolumn{13}{|c|}{ CipA } \\
\hline \multirow{4}{*}{ CipA } & E6UU82 & 3 & Coesina tipo I & $\begin{array}{l}\text { Catabolismo de } \\
\text { Polissacarídeos }\end{array}$ & 143945,2 & 61133,1 & 411,3 & 34,3 & 0,9 & 53,6 & 3,0 & 13,8 \\
\hline & D1NHZ0 & 3 & Coesina tipo I & $\begin{array}{l}\text { Catabolismo de } \\
\text { Polissacarídeos }\end{array}$ & 178367,9 & 61133,5 & 413,0 & 35,3 & 1,7 & 32,1 & 3,0 & 8,3 \\
\hline & H8EAE8 & 3 & Coesina tipo I & $\begin{array}{l}\text { Catabolismo de } \\
\text { Polissacarídeos }\end{array}$ & 36765,6 & 16756,9 & 112,3 & 10,0 & 0,0 & 16,4 & 3,0 & 4,2 \\
\hline & D1NHZ1 & - & Coesina tipo I & $\begin{array}{l}\text { Catabolismo de } \\
\text { Polissacarídeos }\end{array}$ & 192072,7 & 8034,5 & 62,0 & 15,0 & 0,0 & 14,1 & 3,0 & 3,6 \\
\hline \multicolumn{13}{|c|}{ Glicosil hidrolase da família 5} \\
\hline CelB & H8EBB4 & - & $\begin{array}{c}\text { Endo- } \beta-1,4-g l u c a n a s e, \text { Doquerina } \\
\text { tipo I }\end{array}$ & $\begin{array}{l}\text { Catabolismo de } \\
\text { Polissacarídeos }\end{array}$ & 64157,2 & 601,2 & 35,7 & 10,7 & 0,0 & 3,2 & 3,0 & 0,8 \\
\hline \multirow{2}{*}{ CelG } & D1NQT1 & - & $\begin{array}{c}\text { Endo- } \beta-1,4-g l u c a n a s e, \text { Doquerina } \\
\text { tipo I }\end{array}$ & $\begin{array}{l}\text { Catabolismo de } \\
\text { Polissacarídeos }\end{array}$ & 63655,5 & 2801,8 & 60,7 & 11,0 & 0,9 & 3,9 & 3,0 & 1,0 \\
\hline & H8El72 & - & $\begin{array}{c}\text { Endo- } \beta-1,4-\text { glucanase, Doquerina } \\
\text { tipo I }\end{array}$ & $\begin{array}{l}\text { Catabolismo de } \\
\text { Polissacarídeos }\end{array}$ & 63641,5 & 2761,5 & 57,0 & 10,0 & 1,7 & 1,8 & 3,0 & 0,5 \\
\hline \multicolumn{13}{|c|}{ Glicosil hidrolase da família 8} \\
\hline CelA & C7HGK4 & - & $\begin{array}{c}\text { Endo- } \beta-1,4-\text { glucanase, Doquerina } \\
\text { tipo I }\end{array}$ & $\begin{array}{l}\text { Catabolismo de } \\
\text { Polissacarídeos }\end{array}$ & 51657,5 & 4985,5 & 85,7 & 12,7 & 0,0 & 7,7 & 3,0 & 2,0 \\
\hline \multicolumn{13}{|c|}{ Glicosil hidrolase da família 9} \\
\hline CbhA & D1NLS3 & 3 e 4 & $\begin{array}{c}\text { Celobiohidrolase, Doquerina tipo I, } \\
\text { domínio CenC }\end{array}$ & $\begin{array}{l}\text { Catabolismo de } \\
\text { Polissacarídeos }\end{array}$ & 137914,9 & 17768,1 & 232,0 & 41,0 & 0,1 & 8,3 & 3,0 & 2,1 \\
\hline CelF & H8EBA7 & 3 & $\begin{array}{c}\text { Endo- } \beta-1,4-\text { glucanase, Doquerina } \\
\text { tipo I }\end{array}$ & $\begin{array}{l}\text { Catabolismo de } \\
\text { Polissacarídeos }\end{array}$ & 82431,2 & 634,2 & 28,0 & 9,0 & 0,1 & 0,9 & 3,0 & 0,2 \\
\hline \multirow{2}{*}{ CelK } & C7HHU0 & 4 & $\begin{array}{l}\text { Celobiohidrolase, Doquerina tipo I, } \\
\text { CenC-like }\end{array}$ & $\begin{array}{l}\text { Catabolismo de } \\
\text { Polissacarídeos }\end{array}$ & 101249,4 & 39152,2 & 329,0 & 38,7 & 1,0 & 0,5 & 3,0 & 0,1 \\
\hline & D1NLS2 & 4 & $\begin{array}{c}\text { Celobiohidrolase, Doquerina tipo I, } \\
\text { CenC-like }\end{array}$ & $\begin{array}{l}\text { Catabolismo de } \\
\text { Polissacarídeos }\end{array}$ & 101339,4 & 47941,3 & 407,3 & 46,0 & 0,0 & 40,4 & 3,0 & 10,4 \\
\hline CelN & H8El14 & 3 & $\begin{array}{c}\text { Endo- } \beta-1,4-\text { glucanase, Doquerina } \\
\text { tipo I }\end{array}$ & $\begin{array}{l}\text { Catabolismo de } \\
\text { Polissacarídeos }\end{array}$ & 82538,4 & 316,3 & 19,3 & 10,3 & 0,2 & 1,0 & 3,0 & 0,3 \\
\hline CelQ & C7HDM7 & 3 & $\begin{array}{c}\text { Endo- } \beta-1,4 \text {-glucanase, Doquerina } \\
\text { tipo I }\end{array}$ & $\begin{array}{l}\text { Catabolismo de } \\
\text { Polissacarídeos }\end{array}$ & 80224,8 & 17837,3 & 220,0 & 31,0 & 0,1 & 16,6 & 3,0 & 4,3 \\
\hline CelR & H8EB72 & 3 & $\begin{array}{c}\text { Endo- } \beta-1,4-\text { glucanase, Celotetraose, } \\
\text { Doquerina tipo I }\end{array}$ & $\begin{array}{l}\text { Catabolismo de } \\
\text { Polissacarídeos }\end{array}$ & 82735,7 & 2335,7 & 107,7 & 22,7 & 0,1 & 7,2 & 3,0 & 1,8 \\
\hline
\end{tabular}




\begin{tabular}{|c|c|c|c|c|c|c|c|c|c|c|c|c|}
\hline \multirow{2}{*}{ CelT } & Q8VV73 & - & $\begin{array}{c}\text { Endo- } \beta-1,4 \text {-glucanase, Doquerina } \\
\text { tipo I }\end{array}$ & $\begin{array}{l}\text { Catabolismo de } \\
\text { Polissacarídeos }\end{array}$ & 69024,6 & 762,2 & 61,0 & 16,7 & 0,9 & 2,9 & 3,0 & 0,7 \\
\hline & D1NQQ3 & - & $\begin{array}{l}\text { Endo- } \beta-1,4-\text { glucanase, Doquerina } \\
\text { tipo I }\end{array}$ & $\begin{array}{l}\text { Catabolis mo de } \\
\text { Poliss acarídeos }\end{array}$ & 69154,8 & 776,1 & 60,3 & 16,7 & 1,7 & 1,1 & 3,0 & 0,3 \\
\hline CelU & A3DHY3 & 3 & $\begin{array}{l}\text { Endo- } \beta-1,4-\text { glucanase, Doquerina } \\
\text { tipo I }\end{array}$ & $\begin{array}{l}\text { Catabolis mo de } \\
\text { Polissacarídeos }\end{array}$ & 105277,5 & 231,0 & 33,0 & 15,7 & 0,1 & 2,2 & 3,0 & 0,6 \\
\hline CelW & H8EFV0 & 3 & $\begin{array}{c}\text { Endo- } \beta-1,4-\text { glucanase, Doquerina } \\
\text { tipo I }\end{array}$ & $\begin{array}{l}\text { Catabolis mo de } \\
\text { Polissacarídeos }\end{array}$ & 82640,4 & 3927,6 & 135,3 & 23,3 & 0,0 & 7,3 & 3,0 & 1,9 \\
\hline \multicolumn{13}{|c|}{ Glicosil hidrolase da família 10} \\
\hline XynC & H8ЕНК9 & 22 & \multirow{2}{*}{$\begin{array}{c}\text { Endo- } \beta-1,4-x i l a n a s e, \text { Doquerina tipo } \\
\text { I, domínio CenC } \\
\text { Endo- } \beta-1,4-x i l a n a s e, \text { Doquerina tipo } \\
\text { I, domínio CenC, Carboidratos } \\
\text { Esterase Família I }\end{array}$} & $\begin{array}{l}\text { Catabolismo de } \\
\text { Polissacarídeos }\end{array}$ & 69689,2 & 3158,5 & 119,7 & 19,7 & 0,1 & 8,4 & 3,0 & 2,2 \\
\hline XynY & H8EFD3 & 22 & & $\begin{array}{l}\text { Catabolismo de } \\
\text { Polissacarídeos }\end{array}$ & 120406,2 & 193,2 & 41,3 & 19,7 & 0,1 & 3,9 & 3,0 & 1,0 \\
\hline \multicolumn{13}{|c|}{ Glicosil hidrolase da família 48} \\
\hline CelS & D1NQ73 & - & $\begin{array}{c}\text { Exo- } \beta-1,4 \text {-glucanase, Doquerina tipo } \\
\text { I }\end{array}$ & $\begin{array}{l}\text { Catabolismo de } \\
\text { Polissacarídeos }\end{array}$ & 84105,1 & 35289,0 & 390,0 & 44,0 & 0,1 & 135,5 & 3,0 & 34,9 \\
\hline \multicolumn{13}{|c|}{ Glicosil hidrolase da família 9 e 44} \\
\hline CelJ & H8EFH5 & $\begin{array}{c}30 \text { e } \\
44\end{array}$ & $\begin{array}{c}\text { Endo- } \beta-1,4-\text { glucanase, } \\
\text { Xiloglucanase, Doquerina tipo I, } \\
\text { domínio PKD }\end{array}$ & $\begin{array}{l}\text { Catabolismo de } \\
\text { Polissacarídeos }\end{array}$ & 178543,3 & 1890,7 & 181,7 & 40,0 & 0,0 & 16,2 & 3,0 & 4,2 \\
\hline \multicolumn{13}{|c|}{ Outras proteínas } \\
\hline- & H8EH05 & - & $\begin{array}{l}\text { Transportadores do tipo ABC } \\
\text { envolvido com a ligação ao substrato }\end{array}$ & $\begin{array}{l}\text { Transporte } \\
\text { molecular }\end{array}$ & 50085,7 & 1253,9 & 51,0 & 11,0 & 0,0 & 2,9 & 3,0 & 0,7 \\
\hline
\end{tabular}

CMB é referente à família de CBM presente na proteína, quando for o caso. MW é o peso molecular. O Score AVG é a média do score obtido pelo programa ProteinLynx Global Server (PLGS) para cada hit. Produtos AVG é média dos fragmentos de produtos ionizados de um hit de proteína. Peptídeos AVG é a média do hit de peptídeos por proteína identificada. FmolCV é a covariância ao nível de detecção de femtomol para cada proteína nas análises de replicatas. NgramAVG é a média em nanogramas de cada carga de proteína injetada na coluna. A taxa de repetição é a repetibilidade de cada proteína nas replicatas. \% de TSP é a porcentagem de cada proteína na mistura total solúvel, em relação à carga de proteína total (em nanogramas) sobre a coluna. 


\subsection{Efeito de $\mathrm{pH}$ e temperatura nas amostras de PLC e CPP}

As amostras PLC e CPP apresentaram atividades de CMCase e xilanase nas temperaturas entre $40^{\circ} \mathrm{C}$ e $80^{\circ} \mathrm{C}$, com atividade máxima entre $60^{\circ} \mathrm{C}$ e $65^{\circ} \mathrm{C}$ para atividade de $\mathrm{CMCase}$ e entre $60^{\circ} \mathrm{C}$ e $70^{\circ} \mathrm{C}$ para a atividade de xilanase (Figura 13A). Entretanto, há uma diferença estatística entre as amostras quando observado especificamente as temperaturas de $40^{\circ} \mathrm{C}, 60^{\circ} \mathrm{C} \mathrm{e}$ $65^{\circ} \mathrm{C}$ para atividade de $\mathrm{CMCase}$, e para atividade de xilanase essa diferença ocorre a $40^{\circ} \mathrm{C}$ e $70^{\circ} \mathrm{C}$ (Figura $\left.13 \mathrm{~A}\right)$.

Ambas as amostras apresentaram valores significativos de atividades de CMCase e xilanase nos $\mathrm{pHs} 3,4,5,6,7,8$ e 9, com atividade máxima no pH 5,0 (Figura 13B). Foi observado diferença estatística entre as amostras nos $\mathrm{pH}$ 3, 4 e 7 para xilanase, e nos $\mathrm{pH} 3,7,8$ e 9 para CMCase $(P<0,05)$. A atividade de xilanase é evidentemente mais baixa em $\mathrm{pH}$ mais ácido, sendo detectada atividade relativa entre $20 \%$ e $30 \%$ em pH 3, para CPP e PLC, respectivamente, enquanto que em $\mathrm{pH}$ alcalino, a atividade é mantida em torno de $60 \%$ para ambas as amostras. Para a atividade de CMCase, no entanto, $50 \%$ de atividade foi mantida nos $\mathrm{pH}$ extremos, tanto ácido quanto alcalino, para ambas as amostras (Figura 13B). Outro ponto, é que o tampão Citrato de Sódio influenciou em 12,6\% a mais na atividade de xilanase de PLC, do que o tampão acetado de sódio para o pH 5,0. Houve também, diferença de atividade de xilanase da amostra PLC no pH 7,0, em que o tampão citrato de sódio contribui com $13,3 \%$ a mais de atividade do que o tampão tris- $\mathrm{HCl}$. 


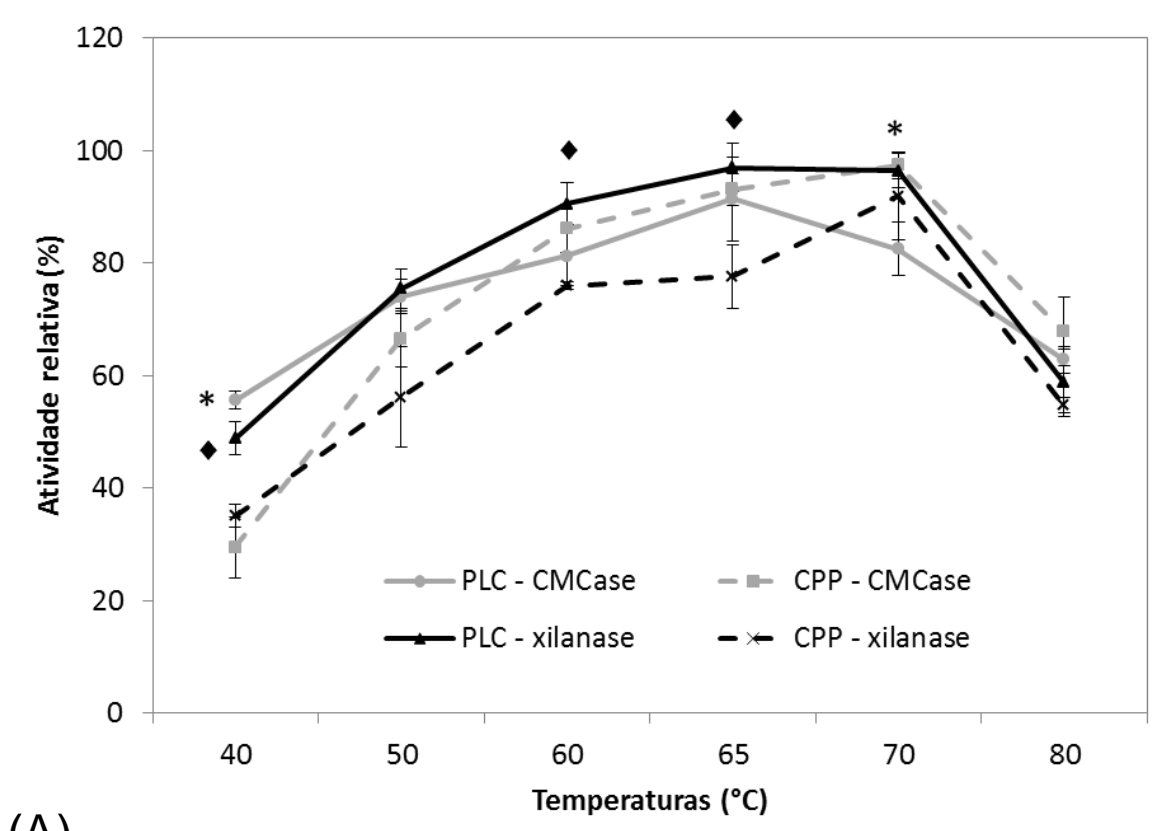

(A)

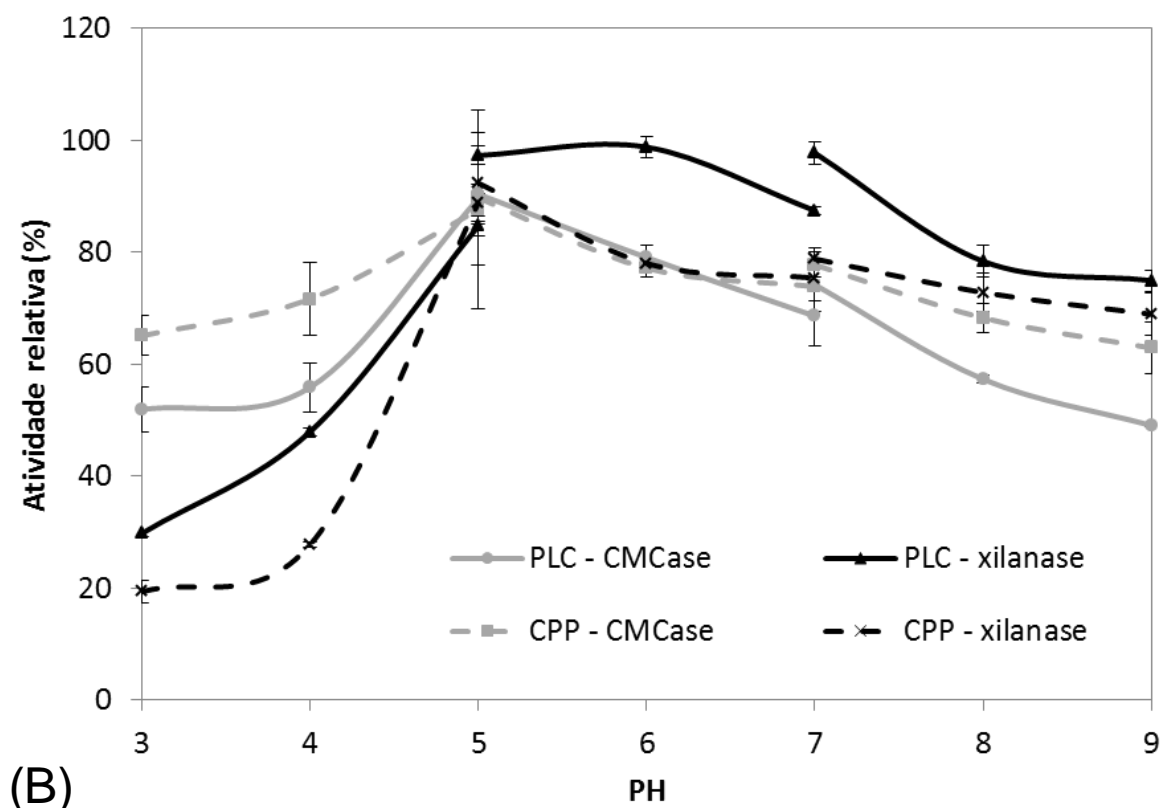

Figura 13. Efeito de temperatura (A) e $\mathrm{pH}(\mathrm{B})$ sob as atividades de CMCase e xilanase nas amostras PLC e CPP. (A) Teste da temperatura sob as atividades de CMCase e xilanase das amostras de PLC e CPP, no intervalo de temperaturas de $40^{\circ} \mathrm{C}, 50^{\circ} \mathrm{C}$, $60^{\circ} \mathrm{C}, 65^{\circ} \mathrm{C}, 70^{\circ} \mathrm{C}, 80^{\circ} \mathrm{C}$. Na figura $13 \mathrm{~A},\left(^{*}\right) \mathrm{P} \leq 0,05$ entre PLC e CPP para a atividade de CMCase ( $\bullet$ e $p \leq 0,05$ entre PLC e CPP para atividade de xilanase. (B) Efeito do $\mathrm{pH}$ sob as atividades de CMCase e xilanase das amostras de PLC e CPP para os pH $3,4,5,6,7,8$ e 9 . A barra de erro representa o desvio padrão de replicatas técnicas. 
A atividade de CMCase da amostra PLC foi mantida no valor máximo mesmo após 15 e 10 dias a $50^{\circ} \mathrm{C}$ e $60^{\circ} \mathrm{C}$, respectivamente, atingindo a sua meia-vida após 20 dias de pré-incubação nestas temperaturas. A atividade de xilanase de PLC foi mantida em retenção de $70 \%$ após 20 dias de incubação a $50^{\circ} \mathrm{C}$ e $60^{\circ} \mathrm{C}$ (Figura 14A). Apesar de a amostra PLC ter demonstrado atividades de $\mathrm{CMCase}$ e xilanase a $70^{\circ} \mathrm{C}$, estas atividades apresentaram uma diminuição de $17 \%$ após 120 horas (5 dias) e 96 horas (4 dias) de incubação a $70^{\circ} \mathrm{C}$, respectivamente (Figura $14 \mathrm{C}$ ).

Com relação à atividade de CMCase, a amostra CPP apresentou 76,6\% de atividade remanescente após 10 dias incubados a $50^{\circ} \mathrm{C}$, em contrapartida, quando incubada a $60^{\circ} \mathrm{C}$ sua meia-vida é atingida já no décimo dia. A atividade de xilanase de CPP a $60^{\circ} \mathrm{C}$ também alcança sua meia-vida após 10 dias de experimento, e a $50^{\circ} \mathrm{C}$ essa atividade diminuiu somente $35 \%$ nesse mesmo período (Figura 14B). A $70^{\circ} \mathrm{C}$, a meia vida de CPP foi atingida após 12 horas de incubação, para ambas as atividades (Figura 14D).
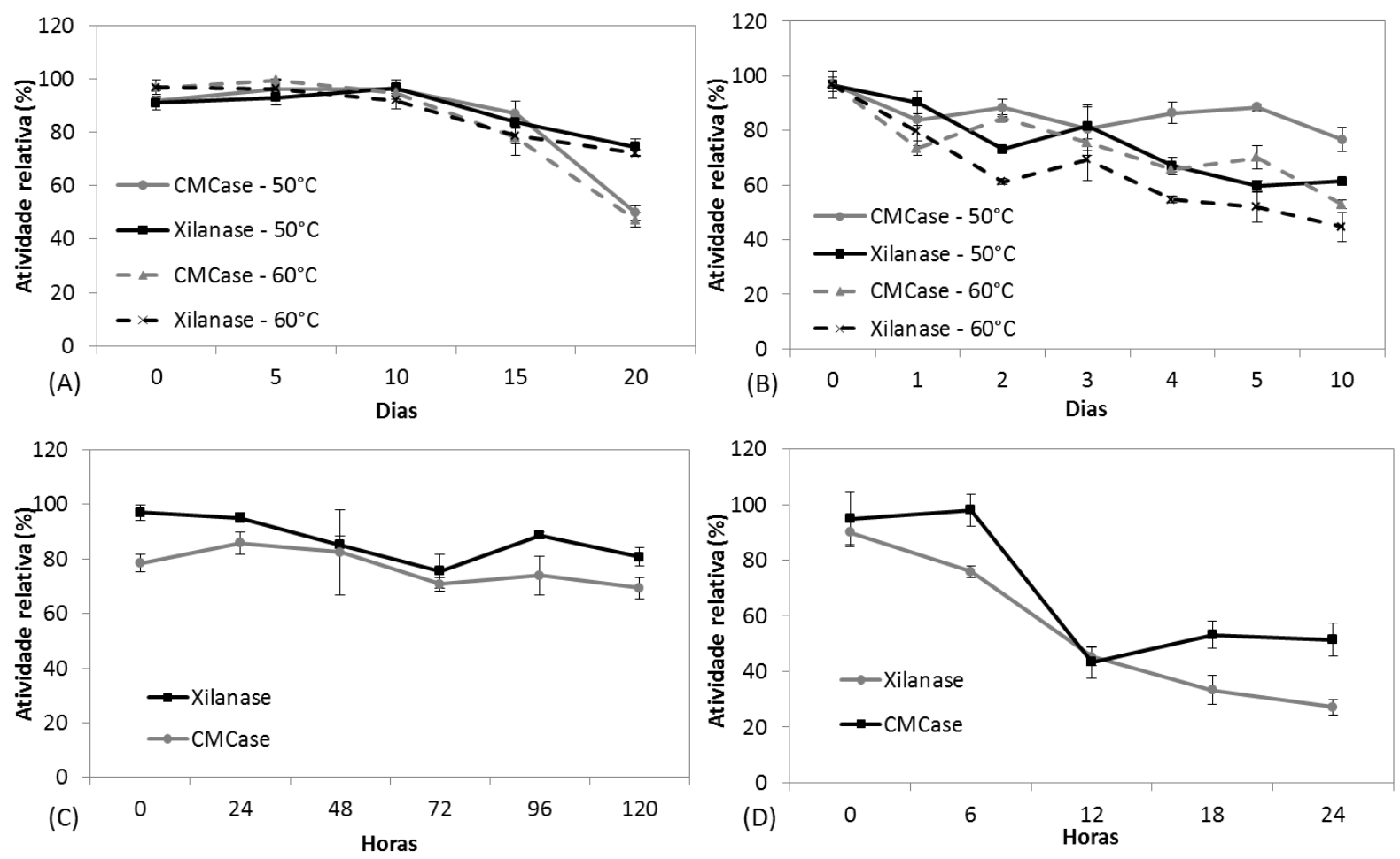

Figura 14. Avaliação da termoestabilidade com relação às atividades de $C M C a s e ~ e$ xilanase da amostra PLC a $50^{\circ} \mathrm{C}$ e $60^{\circ} \mathrm{C}(\mathrm{A}), \mathrm{CPP}$ a $50^{\circ} \mathrm{C}$ e $60^{\circ} \mathrm{C}(\mathrm{B}), \mathrm{PLC}$ a $70^{\circ} \mathrm{C}$ (C) e CPP a $70^{\circ} \mathrm{C}(\mathrm{D})$. A barra de erro representa o desvio padrão de replicatas técnicas. 


\subsection{Efeito dos compostos fenólicos nas atividades de CMCases e xilanases das amostras PLC e CPP}

A atividade de xilanase da amostra CPP não foi influenciada pela presença dos compostos fenólicos vanilina, ácido p-cumárico e 4-hidroxibenzóico, no entanto, decréscimo de 79,1\% e 16,8\% nesta atividade foram detectados na presença de ácido tânico e cinâmico, respectivamente, e aumento de $44,3 \%$ na presença do ácido ferúlico. Ao contrário, esta atividade para a amostra PLC foi inibida pelo ácido tânico em 95,3\%, ferúlico (52,1\%), cinâmico (75\%), p-cumárico (78\%) e 4-hidroxi-benzóico (67\%).

Foi detectado aumento em torno de $187 \%$ na atividade de CMCase de CPP na presença do ácido ferúlico e de pelo menos $70 \%$, na presença dos ácidos cinâmico, p-cumárico e 4-hidroxi-benzóico. Ainda com relação à atividade de CMCase, para ambas as amostras, foi detectada inibição completa pelo ácido tânico e nenhuma alteração na presença de vanilina. Porém, para a amostra PLC a atividade de CMCase foi inibida pelo ácido ferúlico (34,4\%), ácido cinâmico (36,4\%), ácido p-cumárico (57,2\%) e 4-hidroxi-benzóico (44,9\%), ao contrário do observado para CPP. 


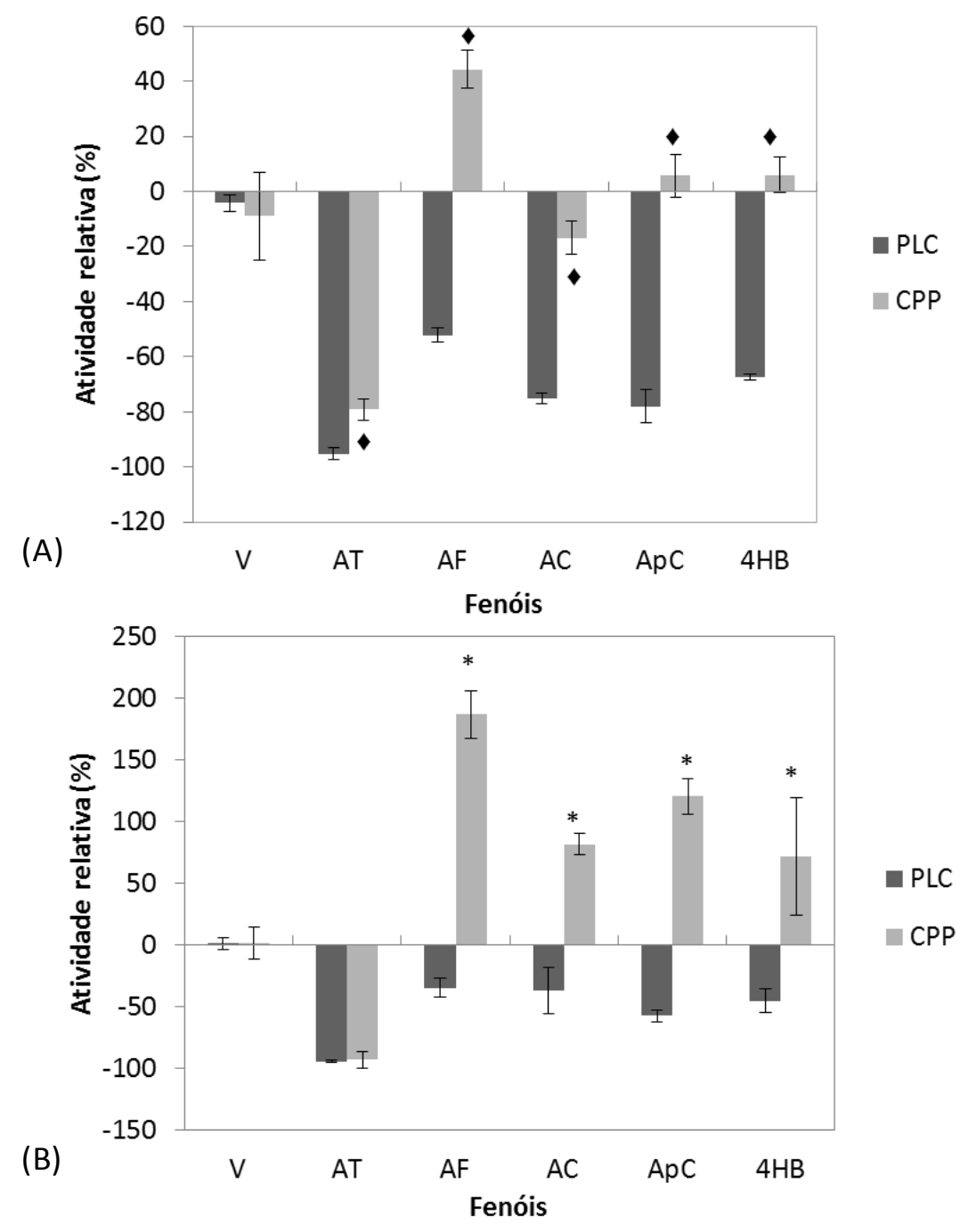

Figura 15. Efeito dos compostos fenólicos (vanilina (V), ácido tânico (AT), ácido ferúlico (AF), ácido cinâmico (AC), ácido p-cumárico (APC) e 4-hidroxi-benzóico (4HB)) nas atividades de CMCase e xilanase das amostras PLC e CPP. Atividade de xilanase das amostras PLC e CPP durante a presença de fenóis (A). (\$) p $\leq 0,05$ para comparação entre PLC e CPP com relação à atividade de xilanase com adição de fenóis. Atividade de CMCase das amostras PLC e CPP durante a presença de fenóis (B). $\left({ }^{*}\right) \mathrm{P} \leq 0,05$ para comparação entre PLC e CPP com relação à atividade de CMCase com adição de fenóis. $p \leq 0,05$ entre os padrões (atividade enzimática sem fenóis) quando comparado as amostras PLC e CPP na presença de AT, AF, AC, a APC e 4HB, para xilanase e atividades CMCase. A barra de erro representa o desvio padrão de replicatas técnicas. 


\subsection{Sacarificação de materiais lignocelulósicos por PLC e CPP}

As amostras PLC e CPP foram capazes de hidrolisar desde materiais com uma composição mais simples como a celulose cristalina, até materiais mais complexos, tais como a palha de cana e o piolho de algodão (Figura 10). A maior quantidade de açúcares redutores liberados foi detectada para os experimentos de sacarificação realizados a $50^{\circ} \mathrm{C}$ para ambas as amostras, com valores comparáveis de açúcar redutor liberado, enquanto PLC hidrolisa no total $0,37 \mathrm{mg} / \mathrm{mL}$ de açúcar redutor em celulose, $0,21 \mathrm{mg} / \mathrm{mL}$ em palha de cana e $0,21 \mathrm{mg} / \mathrm{mL}$ em piolho de algodão, a amostra CPP libera $0,44 \mathrm{mg} / \mathrm{mL}$ da celulose, $0,29 \mathrm{mg} / \mathrm{mL}$ da palha e $0,31 \mathrm{mg} / \mathrm{mL}$ do piolho de algodão.

De acordo com dados da cinética de sacarificação das biomassas pelas amostras PLC e CPP, a quantidade de açúcar liberado por hora é consideravelmente maior no segundo dia de incubação, com uma tendência de diminuição da velocidade de hidrólise até o décimo dia para ambas as amostras e nas duas condições de temperatura (Figura 17 A e B). Foi constatado em todos os experimentos de sacarificação a $60^{\circ} \mathrm{C}$, que não houve um aumento substancial do segundo dia para o décimo dia. Entretanto, ao mudar para a temperatura de $50^{\circ} \mathrm{C}$, pôde-se considerar um aumento de açúcares liberados pela hidrólise das biomassas até o décimo dia, quando comparado com o segundo dia de sacarificação. Em geral, a amostra CPP liberou uma maior quantidade de açúcar $(\mathrm{mg} / \mathrm{mL})$ do que PLC para quase todas as condições experimentais testadas.

A diferença na taxa de hidrólise destes substratos nas temperaturas de $50^{\circ} \mathrm{C}$ e $60^{\circ} \mathrm{C}$ pode ser visualizada principalmente nos resultados dos experimentos de sacarificação do piolho de algodão. Para a amostra PLC a $60^{\circ} \mathrm{C}$ foi detectada a produção de $0,01 \mathrm{mg}$ de açúcar redutor após 10 dias de incubação, e para esta mesma amostra a $50^{\circ} \mathrm{C}$, a quantidade de açúcar redutor liberado foi 12 vezes maior no mesmo período de experimento (Figura 16A). A maior taxa de sacarificação a $50^{\circ} \mathrm{C}$ também foi observada para amostra CPP (Figura 16B), neste caso foi detectado aumento de 38,5 vezes na concentração de açúcar redutor liberado em comparação com o valor obtido a $60^{\circ} \mathrm{C}$, atingindo $0,31 \mathrm{mg} / \mathrm{mL}$ de açúcar redutor liberado após 10 dias de incubação. 
A degradação de palha de cana também foi mais severa na temperatura de $50^{\circ} \mathrm{C}$ em comparação a $60^{\circ} \mathrm{C}$, praticamente dobrando a concentração de açúcar redutor liberado para ambos os experimentos que utilizaram PLC e CPP como fonte de enzimas. Outro dado observado foi que a $50^{\circ} \mathrm{C}$, a celulose foi $\mathrm{o}$ substrato que teve maior quantidade de açúcar liberado pela atuação das amostras PLC e CPP, quando comparado com outros substratos sacarificados. Já a $60^{\circ} \mathrm{C}$, a sacarificação da palha de cana, por ambas as amostra, liberou a maior quantidade de açúcar, quando comparado com os outros substratos hidrolisados nessa mesma condição.

$(A)$

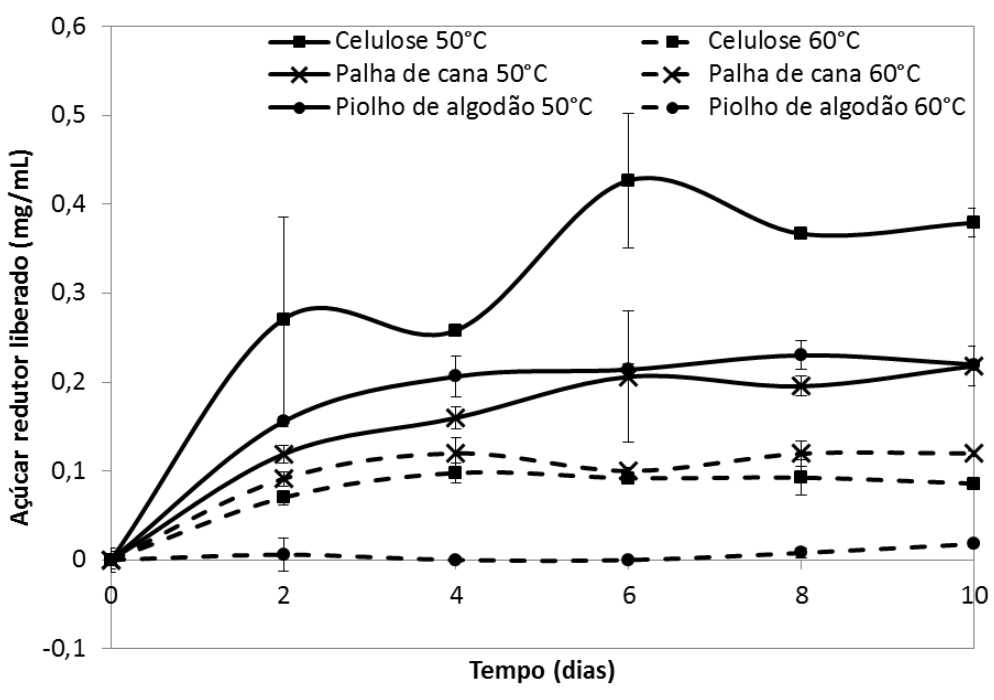

(B)

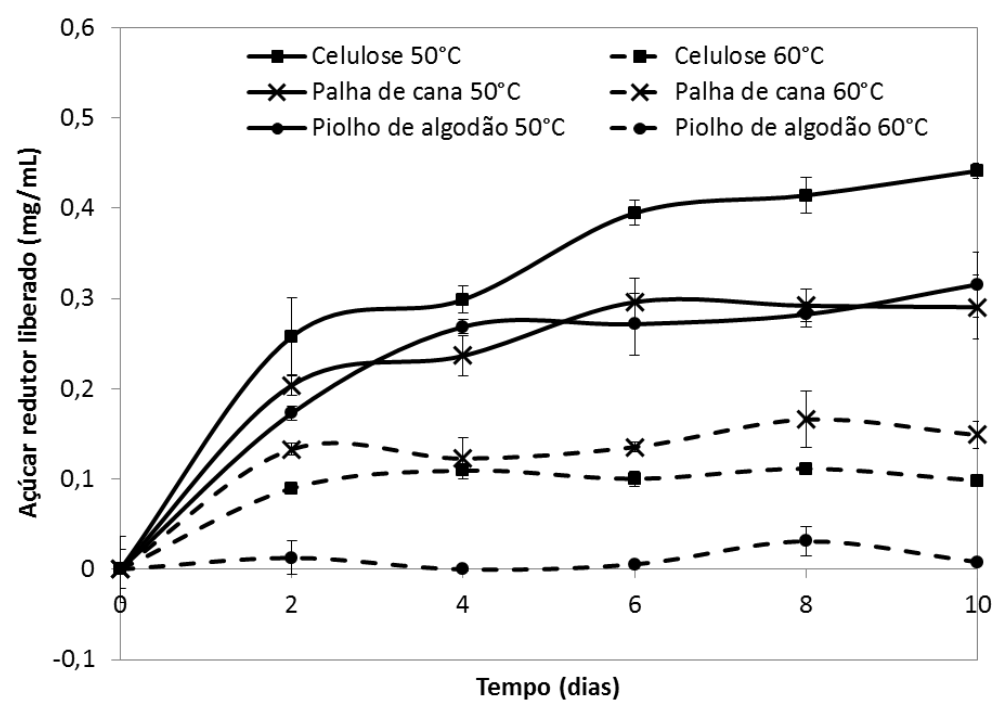

Figura 16. Quantidade de açúcar liberado durante a sacarificação por PLC (A) e CPP (B) dos substratos de celulose, palha de cana-de-açúcar e piolho algodão a $50^{\circ} \mathrm{C}$ e $60^{\circ} \mathrm{C}$, com agitação a $180 \mathrm{rpm}$ durante 10 dias. Os açúcares redutores liberados foram detectados por meio de um ensaio colorimétrico (DNS). 

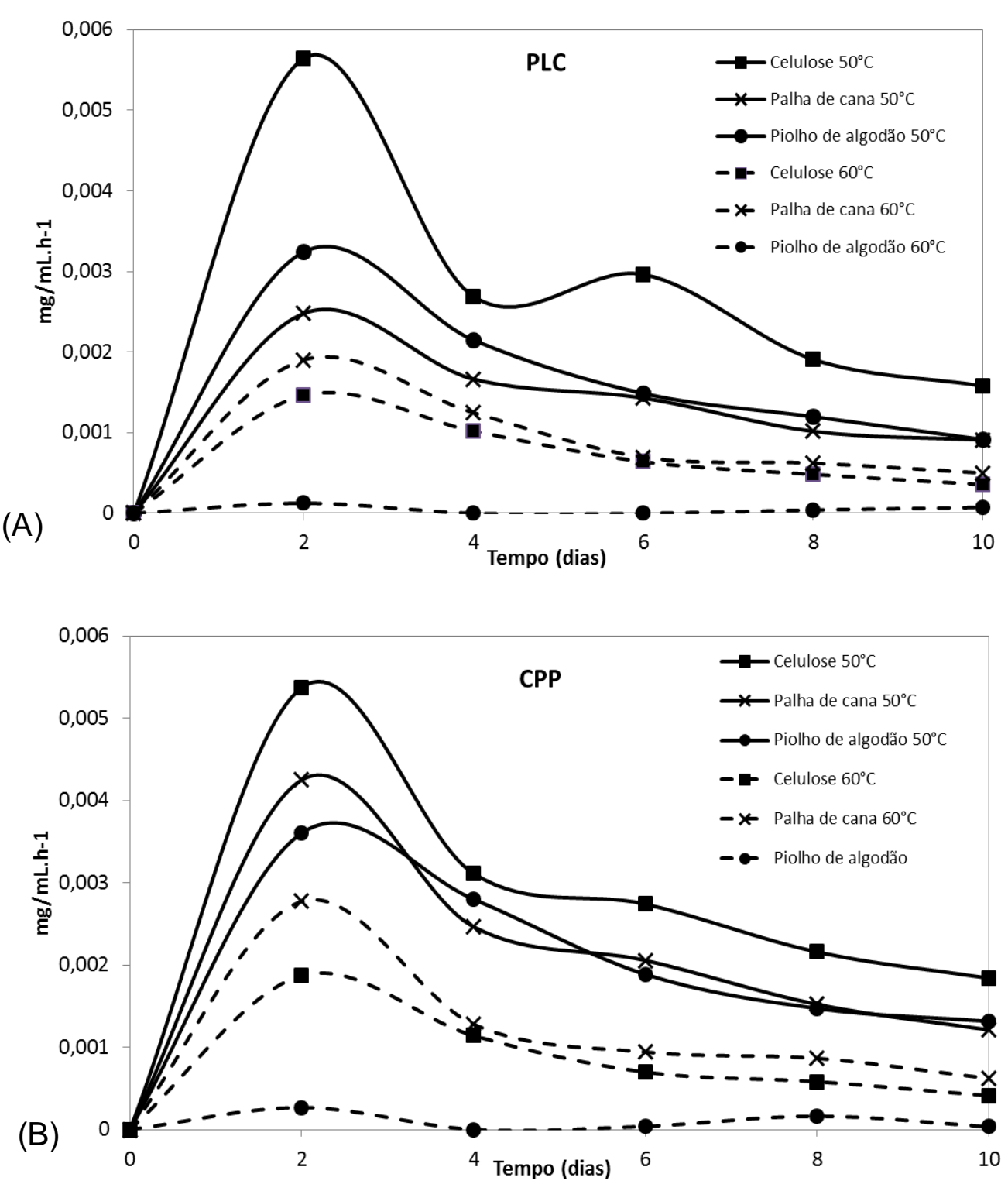

Figura 17. Cinética da sacarificação. Quantidade de açúcar liberado durante a sacarificação por tempo de incubação pelas amostras de PLC (A) e CPP (B) a partir dos substratos de celulose, palha de cana-de-açúcar e piolho algodão a $50^{\circ} \mathrm{C}$ e $60^{\circ} \mathrm{C}$.

\subsection{Identificação de açúcares liberados no processo de sacarificação por HPLC}

Glicose e dois oligossacarídeos com tempo de retenção de 5.2 minutos e 7.5 minutos, que correspondem ao tempo de retenção da manotriose e manopentaose, respectivamente, foram produzidos pela hidrólise de celulose a $50^{\circ} \mathrm{C}$ pelas amostras PLC e CPP (Tabela 5). Para o experimento realizado a $60^{\circ} \mathrm{C}$, foi liberado apenas a glicose e o oligossacarídeo com tempo de retenção 
de 7.5 minutos, com a concentração predominante do oligossacarídeo de 7.5 minutos.

Dentre os açúcares obtidos pela sacarificação de piolho de algodão utilizando as amostras PLC e CPP para hidrólise dessa biomassa a $50^{\circ} \mathrm{C}$, tiveram como predominância, oligossacarídeos derivados de manose. Os açúcares: manose, manotriose e manopentaose foram detectados tanto na condição de $50^{\circ} \mathrm{C}$, quanto na de $60^{\circ} \mathrm{C}$, tendo como diferença, a identificação de xilotriose somente na temperatura de $50^{\circ} \mathrm{C}$ para ambas as amostras (Tabela 6). O açúcar que teve maior concentração em todas as condições foi manopentaose, e o único que teve detecção inicial. Em dois dias de sacarificação, foi possível identificar a presença de todos os açúcares em alta concentração, aumentando cerca de $200 \mathrm{ng} / \mathrm{mL}$ do segundo ao décimo dia de experimento a $50^{\circ} \mathrm{C}$, e menos de $90 \mathrm{ng} / \mathrm{mL}$ na condição de $60^{\circ} \mathrm{C}$.

Os sacarídeos referentes a celotriose, celopentaose, manose, manotriose, manopentaose, xilotriose, xilohexaose foram os açúcares identificados a partir da sacarificação da palha de cana por PLC e CPP, nas temperaturas de $50^{\circ} \mathrm{C}$ e $60^{\circ} \mathrm{C}$ em 2 dias de hidrólise. O açúcar de manopentaose foi encontrado em maior concentração entre os açúcares redutores liberados (Tabela 7). Para ambas as amostras, a $50^{\circ} \mathrm{C}$, foram observadas um aumento de cerca de $100 \mathrm{ng} / \mathrm{mL}$, ao comparar o segundo dia com o décimo dia de sacarificação, e um aumento na concentração de menos de $40 \mathrm{ng} / \mathrm{mL}$ para $60^{\circ} \mathrm{C}$.

O processo de sacarificação com a etapa do pré-tratamento alcalino seguido da hidrólise enzimática pelas amostras PLC e CPP, obteve maior quantidade de açúcar redutor, do que a sacarificação enzimática sem o prétratamento, principalmente com relação a biomassas lignocelulósicas, que possuem uma estrutura mais complexa do que a celulose microcristalina (dado não mostrado). 
Tabela 5. Análise de açúcares obtidos durante a hidrólise enzimática da celulose a $50^{\circ} \mathrm{C}$ e $60^{\circ} \mathrm{C}$.

\begin{tabular}{|c|c|c|c|c|c|c|c|}
\hline \multicolumn{8}{|c|}{ Celulose } \\
\hline & & \multicolumn{3}{|c|}{ PLC } & \multicolumn{3}{|c|}{ CPP } \\
\hline \multirow{2}{*}{$\begin{array}{c}\text { Temperatura } \\
\text { da } \\
\text { Sacarificação }\end{array}$} & \multirow[b]{2}{*}{ Açúcares } & \multicolumn{3}{|c|}{ [] de açúcar (ng/mL) } & \multicolumn{3}{|c|}{ [] de açúcar (ng/mL) } \\
\hline & & $\begin{array}{c}0 \\
\text { dias }\end{array}$ & $\begin{array}{c}2 \\
\text { dias }\end{array}$ & $\begin{array}{c}10 \\
\text { dias }\end{array}$ & $\begin{array}{c}0 \\
\text { dias }\end{array}$ & $\begin{array}{c}2 \\
\text { dias }\end{array}$ & $\begin{array}{c}10 \\
\text { dias }\end{array}$ \\
\hline \multirow{4}{*}{$50^{\circ} \mathrm{C}$} & Glicose & 0 & 10 & 15 & 0 & 15 & 16,5 \\
\hline & *Oligossacarídeo 5.2' & 0 & 0 & 5 & 0 & 0 & 1,5 \\
\hline & *Oligossacarídeo 7,5' & 30 & 646,5 & 868 & 35 & 705 & 1005 \\
\hline & Total & 30 & 656,5 & 888 & 35 & 720 & 1023 \\
\hline \multirow{3}{*}{$60^{\circ} \mathrm{C}$} & Glicose & 0 & 6,5 & 10 & 0 & 5 & 5 \\
\hline & *Oligossacarídeo 7,5' & 15 & 315 & 320 & 23 & 366,5 & 438 \\
\hline & Total & 15 & 321,5 & 330 & 23 & 371,5 & 443 \\
\hline
\end{tabular}

*Oligossacarídeos com tempo de retenção de 5,2 e 7,5 minutos.

Tabela 6. Análise de açúcares obtidos durante a hidrólise enzimática de piolho de algodão a $50^{\circ} \mathrm{C}$ e $60^{\circ} \mathrm{C}$.

\begin{tabular}{|c|c|c|c|c|c|c|c|}
\hline \multicolumn{8}{|c|}{ Piolho de algodão } \\
\hline \multirow{3}{*}{$\begin{array}{l}\text { Temperatura da } \\
\text { Sacarificação }\end{array}$} & \multirow[b]{3}{*}{ Açúcares } & \multicolumn{3}{|c|}{ PLC } & \multicolumn{3}{|c|}{ CPP } \\
\hline & & \multicolumn{3}{|c|}{ [ ] de açúcar (ng/mL) } & \multicolumn{3}{|c|}{ [ ] de açúcar (ng/mL) } \\
\hline & & $\begin{array}{c}0 \\
\text { dias }\end{array}$ & $\begin{array}{c}2 \\
\text { dias }\end{array}$ & $\begin{array}{c}10 \\
\text { dias }\end{array}$ & $\begin{array}{c}0 \\
\text { dias }\end{array}$ & $\begin{array}{c}2 \\
\text { dias }\end{array}$ & $\begin{array}{c}10 \\
\text { dias }\end{array}$ \\
\hline \multirow{5}{*}{$50^{\circ} \mathrm{C}$} & Manose & 0 & 15 & 20 & 0 & 16,5 & 25 \\
\hline & Manotriose & 0 & 5 & 10 & 0 & 6,5 & 13 \\
\hline & Manopentaose & 5 & 541,5 & 665 & 5 & 628 & 801,5 \\
\hline & Xilotriose & 0 & 1,5 & 5 & 0 & 1,5 & 5 \\
\hline & Total & 5 & 563 & 700 & 5 & 652,5 & 844,5 \\
\hline \multirow{4}{*}{$60^{\circ} \mathrm{C}$} & Manose & 0 & 5 & 8 & 0 & 5 & 6,5 \\
\hline & Manotriose & 0 & 3 & 5 & 0 & 5 & 6,5 \\
\hline & Manopentaose & 5 & 165 & 183 & 5 & 121,5 & 208 \\
\hline & Total & 5 & 173 & 196 & 5 & 131,5 & 221 \\
\hline
\end{tabular}


Tabela 7. Análise dos açúcares obtidos durante a hidrólise enzimática da palha de cana de açúcar a $50^{\circ} \mathrm{C}$ e $60^{\circ} \mathrm{C}$.

\begin{tabular}{|c|c|c|c|c|c|c|c|}
\hline \multicolumn{8}{|c|}{ Palha de cana } \\
\hline \multirow{3}{*}{$\begin{array}{c}\text { Temperatura de } \\
\text { Sacarificação }\end{array}$} & \multirow[b]{3}{*}{ Açúcares } & \multicolumn{3}{|c|}{ PLC } & \multicolumn{3}{|c|}{ CPP } \\
\hline & & \multicolumn{3}{|c|}{ [ ] de açúcar (ng/mL) } & \multicolumn{3}{|c|}{ [ ] de açúcar (ng/mL) } \\
\hline & & $\begin{array}{c}0 \\
\text { dias }\end{array}$ & $\begin{array}{c}2 \\
\text { dias }\end{array}$ & $\begin{array}{c}10 \\
\text { dias }\end{array}$ & $\begin{array}{c}0 \\
\text { dias }\end{array}$ & $\begin{array}{c}2 \\
\text { dias }\end{array}$ & $\begin{array}{c}10 \\
\text { dias }\end{array}$ \\
\hline \multirow{8}{*}{$50^{\circ} \mathrm{C}$} & Celotriose & 0 & 5 & 1,5 & 0 & 5 & 0 \\
\hline & Celopentaose & 0 & 3 & 6,5 & 0 & 3 & 13 \\
\hline & Manose & 0 & 13 & 20 & 0 & 15 & 23 \\
\hline & Manotriose & 0 & 30 & 51,5 & 0 & 33 & 61,5 \\
\hline & Manopentaose & 1,5 & 460 & 520 & 0 & 590 & 670 \\
\hline & Xilotriose & 0 & 13 & 18 & 0 & 15 & 20 \\
\hline & Xilohexaose & 0 & 6,5 & 11,5 & 0 & 5 & 3 \\
\hline & Total & 1,5 & 530,5 & 629 & 0 & 666 & 790,5 \\
\hline \multirow{8}{*}{$60^{\circ} \mathrm{C}$} & Celotriose & 0 & 5 & 5 & 0 & 5 & 5 \\
\hline & Celopentaose & 0 & 3 & 10 & 0 & 8 & 15 \\
\hline & Manose & 0 & 8 & 10 & 0 & 11,5 & 13 \\
\hline & Manotriose & 0 & 13 & 20 & 0 & 18 & 28 \\
\hline & Manopentose & 0 & 266,5 & 271,5 & 0 & 371,5 & 385 \\
\hline & Xilotriose & 0 & 8 & 10 & 0 & 11,5 & 13 \\
\hline & Xilohexaose & 0 & 1,5 & 8 & 0 & 3 & 5 \\
\hline & Total & 0 & 305 & 334,5 & 0 & 428,5 & 464 \\
\hline
\end{tabular}




\section{DISCUSSÃO}

A grande disponibilidade de resíduos agroindustriais e a complexa estrutura lignocelulósica dessas biomassas fazem dessas matérias primas potenciais fontes energéticas, além de precursores para o desenvolvimento de vários produtos químicos de interesse biotecnológico. Para chegar a uma prática viável de biorrefinaria, que tem por objetivo o aproveitamento máximo de biomassas para gerar produtos de alto valor agregado, como acontece de forma paralela na refinaria de petróleo, é necessária a sua desconstrução completa.

De fato, a desconstrução completa desta biomassa em um processo com bom custo-benefício ainda é um limitante para o sucesso destas biorefinarias. Desta forma, uma maior compreensão dos microrganismos capazes de utilizar essas fontes de carbono, bem como a identificação e caracterização de enzimas promissoras na degradação de biomassa lignocelulósica são necessárias. Este conhecimento pode contribuir para o melhoramento do processo de sacarificação desses substratos, assim como, para o sucesso de biorefinarias. Neste contexto, o presente trabalho foi realizado com o objetivo de caracterizar um novo isolado de $C$. thermocellum de rúmen de caprino, visando a sua utilização como fonte de enzimas e complexos enzimáticos aplicados à degradação de resíduos agroindustriais e desta forma sua utilização para obtenção de compostos de maior valor agregado.

Embora a $C$. thermocellum seja bem reconhecida por sua capacidade de aproveitamento de materiais lignocelulósicos como fonte de carbono, e tenha o celulossoma descrito na literatura, foi demonstrado que há diferença entre as atividades enzimáticas de bactérias isoladas de biomas distintos, ainda que os isolados sejam cultivados e preparados sob as mesmas condições. Este fato foi reportado entres os isolados de $C$. thermocellum ISO 1, ISO 2 e JW20 (Blume et al., 2013) e também entre as linhagens ATCC 27405, CS7 e CS8 (Lv e Yu, 2013). 
Além de haver diferença entre as atividades dos isolados, estudos também apontaram diferenças filogenéticas em cepas de Ruminococcus flavefaciens, isoladas a partir de diferentes rúmens, sugerindo uma relação com 0 microbioma de ruminantes. Essa abordagem baseia-se pela identificação de alterações nas sequências de DNA dos genes Sca entre os isolados de $R$. flavefaciens, o que indica uma organização celulossomal específica de cada cepa. Portanto, é provável que exista uma maior variação de celulossomas no ambiente do rúmen, do que já se tem descrito até o momento, e ter um maior conhecimento dessa diversidade de celulossomas é fundamental para a degradação de diferentes tipos de substratos lignocelulósicos (Bayer et al., 2008). Resultados parciais (dado não mostrado) do alinhamento do genoma do isolado B8 com as linhagens que já possuem o genoma depositado no banco de dados do NCBI, ATCC 27405 e DSM 1313, demonstraram que há diferença entre algumas regiões destas cepas, verificando maior proximidade genética entre a B8 e a DSM 1313.

A maior atividade xilanolítica do que celulolítica apresentada pelo isolado B8 (Tabela 1 e Figura 10), está de acordo com o padrão de atividades enzimáticas já descritas para outras cepas de $\mathrm{C}$. thermocellum, tais como ATCC 27405, JW20 e S14 (Morag, Bayer e Lamed, 1990; Tachaapaikoon et al., 2012). Assim como, o valor inferior da atividade de avicelase em amostras proteicas eluídas do substrato, quando comparado com o sobrenadante (Blume et al., 2013), conforme mostrado para as amostras PLC e CPP de C. thermocellum B8. Desta forma, sugere-se uma maior eficiência de degradação das xilanases, pelo fato de ambas as amostras do isolado B8 possuírem alta atividade xilanolítica, apesar de estarem em menor quantidade (nanogramas) do que as celulases (Tabela 2). Há hipóteses de que a maior atividade específica das xilanases, em magnitude de 2 a 3 vezes maior que as atividades específicas das celulases, sejam decorrentes da maior recalcitrância do substrato de xilana com relação à celulose (Gilbert e Hazlewo, 1993). O mesmo já foi observado entre as atividades de celulases, as exoglucanases representam uma fração maior de proteínas identificadas tanto em PLC quanto em CPP, mas apresentaram valores de atividade inferiores (avicelase) aos obtidos para as endoglucanases (CMCase) (Tabela 1). Evidenciando, assim, 
que as características cinéticas das enzimas tem um peso maior para atividade detectada do que a quantidade das mesmas, assim como, deve ser considerada a natureza do substrato.

O padrão de proteínas detectada na amostra CPP em SDS-PAGE corresponde ao padrão observado para celulosomas de outros isolados de $C$. thermocellum, tendo como referência a CipA de 210 kDa (Bayer, Shimon, et al., 1998) e as enzimas hidrolíticas do complexo, variando de 40 a $180 \mathrm{kDa}$ (Lamed, Setter e Bayer, 1983; Morag, Bayer e Lamed, 1990; Bayer, Shimon, et al., 1998). Desta forma, conclui-se que o isolado B8 secreta enzimas celulolíticas e xilanolíticas e que estas provavelmente estão organizadas na forma de celulossomas.

Pode-se afirmar que a amostra CPP é um complexo ou um agregado proteico, pois as múltiplas formas de proteínas visualizadas no gel de poliacrilamida foram representadas por apenas duas populações polidispersas, pi1 e pi2 nas análises de DLS, sendo que a população detectada no pi1 (11,3MDa $\pm 4,4 \mathrm{MDa})$ possui massa molecular estimada semelhante aos celulossomas já descritos para outros isolados de C. thermocellum (JW20, YS e ATCC 27405) que possuem massa molecular de 2,0 a 6,5 MDa (Lamed, Setter e Bayer, 1983; Felix e Ljungdahl, 1993; Choi e Ljungdahl, 1996). Além disso, o tratamento da amostra CPP com o detergente tween 80 levou à dissociação das subunidades, que fazem parte dos complexos protéicos detectados em pi1 e pi2. Sendo, neste caso, observada na análise por DLS uma terceira população de proteínas (pi3), com massa molecular correspondente às subunidades celulossomais $(68,2 \mathrm{kDa} \pm 75,8 \mathrm{kDa})$.

A população de proteínas detectada no pi2 com massa molecular estimada de $1260 \mathrm{MDa} \pm 375 \mathrm{MDa}$ corresponde aos policelulossomas. Contudo, geralmente os policelulossomas descritos na literatura têm massa molecular estimada entre 50 a 100 MDa (Mayer et al., 1987; Felix e Ljungdahl, 1993). Deve ser levado em conta que diferentes métodos foram utilizados para determinar a massa molecular dos celulossomas e policelulossomas nestes trabalhos, desde gel filtração, microscopia eletrônica, velocidade de sedimentação e no caso deste trabalho, a técnica de DLS. Desta forma, é difícil 
determinar se a diferença entre as massas dos celulossomas é devido aos diferentes métodos utilizados ou em consequência à particularidade de constituição de cada celulossoma (Béguin e Lemaire, 1996). Conclui-se, portanto que a $C$. thermocellum $\mathrm{B} 8$, como outros isolados já descritos para esta espécie, também secreta celulossomas quando cultivada em celulose e estes foram purificados em um passo de purificação em cromatografia de exclusão molecular.

O custo do processo de sacarificação de biomassa lignocelulósica por hidrólise enzimática, como mencionado acima, ainda é um limitante para o desenvolvimento de um processo competitivo de reaproveitamento deste tipo de biomassa. Desta forma, visando um processo menos oneroso na produção de complexos enzimáticos para aplicação na sacarificação de compostos lignocelulósicos, foi realizada neste trabalho, em paralelo à caracterização dos celulossomas, a caracterização da amostra originalmente utilizada como fonte de celulossomas, PLC.

A amostra CPP é constituída por proteínas celulossomais conforme mostrado na tabela 3, confirmando, portanto, os resultados da análise de DLS. Nesta amostra foram identificadas a proteína estrutural CipA e glicosil hidrolases contendo domínio doquerina. A proteína de ancoragem (CipA) é uma das principais características para identificar um complexo celulossomal, pois é a partir dessa estrutura que é feita a organização do complexo via a ligação dos domínios coesina e doqueria, além da interação com o substrato (CBM) e com a superfície da bactéria. (Bayer, Morag e Lamed, 1994; Morag et al., 1995; Bayer, Shimon, et al., 1998). Todas as glicosil hidrolases identificadas em PLC e CPP são enzimas celulossomais devido à presença do domínio doquerina tipo I, e estas enzimas já foram descritas por análise genômica e proteômica para outros isolados desta mesma espécie (Shoham, Lamed e Bayer, 1999; Zverlov, Kellermann e Schwarz, 2005; Gold e Martin, 2007; Zverlov e Schwarz, 2008; Raman et al., 2009).

A presença de diversas celulases (endoglucanases, celobiohidrolases) e hemicelulases (endoxilanases, endoxilanases com funções de feruloil esterase e de acetil xilana esterases, xiloglucanases, arabinoxilanases, xilanohidrolases, 
arabinofuranosidases, exogalactanases, endogalactanases) na amostra de PLC (Tabela 2), é interessante para processos de sacarificação de biomassas lignocelulósicas, visto que as xilanases facilitam o acesso e a atuação das celulases nas biomassas, sendo reportadas interações sinérgicas entre celulases e xilanases (GH10 e GH11) ou com xiloglucanases (GH5), apresentando um aumento significativo na degradação desses materiais, que pode variar de 10 a 100\%, dependendo da fonte de carbono (Hu et al., 2013).

Por isto as xilanases são reconhecidas como enzimas acessórias, auxiliando as celulases na hidrólise de seus substratos, principalmente a combinação de $\mathrm{GH} 10$ com $\mathrm{GH} 5$, que teve um forte sinergismo descrito por $\mathrm{Hu}$ e colaboradores. Portanto, a constituição da amostra PLC, com diferentes proteínas envolvidas no catabolismo de polissacarídeos, valoriza esta amostra não apenas pelo sinergismo entre as enzimas, mas como uma alternativa de redução no custo de produção de coquetéis enzimáticos, ao evitar muitas etapas de purificação para obter enzimas de interesse biotecnológico.

O presente trabalho identifica pela primeira vez a secreção de CelU (GH9) quando a $C$. themocellum foi cultivada em meio contendo celulose cristalina como fonte de carbono, sendo detectada nas amostras PLC e CPP (Tabelas 2 e 3). No caso de estudos anteriores, esta endoglucanase só foi detectada quando a $C$. thermocellum foi cultivada em celobiose como fonte de carbono (Zverlov e Schwarz, 2008). Além desta endoglucanase, também foi identificada, em ambas as amostras, a CelW, a expressão do gene que codifica esta proteína é aumentada por etanol e foi identificada quando a bactéria foi cultivada em meio contendo celulose como fonte de carbono (Raman et al., 2009; Yang et al., 2012).

As proteínas mais abundantes nas amostras PLC e CPP são: CelS, CipA e CelK, respectivamente. CelS é descrita como um dos principais componentes do celulossoma (Guimarães et al., 2002; Dror et al., 2003; Olson et al., 2010). A produção desta celobiohidrolase é relativa à taxa de crescimento bacteriano, sendo produzida principalmente na fase exponencial e principalmente quando a bactéria é crescida em celulose cristalina (Dror et al., 2003). Entretanto, por mais que esta enzima desempenhe um papel importante 
na atividade celulolítica, em sua ausência, o celulossoma ainda é capaz de degradar por completo a celulose (Olson et al., 2010). A CipA, como já foi mencionado anteriormente, é a proteína sobre a qual o celulossoma é montado (Bayer, Morag e Lamed, 1994).

Em relação à terceira proteína mais abundante, a CelK, esta possui um domínio catalítico muito similar à celobiohidrolase $A(C b h A)$. Kataeva e colaboradores, em 1999, propuseram que a origem desses domínios catalíticos foram decorrentes da duplicação de um gene de um ancestral comum, e pelo fato de terem sido selecionados favoravelmente, sugere a importância dessas celobiohidrolases para a hidrólise da celulose por $C$. thermocellum. Além disso, a CelK e a CbhA apresentam o CBM da família 4, que foi caracterizado por exibir afinidade por celulose microcristalina e também por outras glucanas também degradadas por CelK, tais como liquenina, glucomanana, cevada e $\beta$ glucana (Kataeva et al., 2001), diferente do CMB da família 3, comumente encontrado em outras enzimas celulossomais, que se liga apenas a celulose, região amorfa ou cristalina (Boraston et al., 2004). A existência de vários tipos CMBs com reconhecimento de múltiplos substratos, é reflexo da diversidade encontrada na composição desses polissacarídeos (Guillén, Sánchez e Rodríguez-Sanoja, 2010).

Apesar das diferenças descritas na composição de proteínas das amostras PLC e CPP, estas apresentam perfis semelhantes quanto à temperatura e $\mathrm{pH}$ ótimos. O pH ótimo para PLC e CPP ( $\mathrm{pH}$ entre 5 e 6) está de acordo com os obtidos em outros trabalhos de caracterização cinética de celulossomas (Johnson et al., 1982; Mori, 1992; Xu et al., 2010). Com relação à atividade em pHs mais ácidos, ao contrário do já descrito para celulossomas de outros isolados de $C$. thermocellum, as atividades celulolítica e xilanolítica das amostras PLC e CPP de B8 mantiveram esta atividade tanto em pHs ácidos quanto alcalinos (Figura 13). Já foi relatado perda total de atividade entre os pHs 3 e 4 em estudos de xilanases celulossomais e não celulossomais de $C$. thermocellum YS (Morag, Bayer e Lamed, 1990). Assim como, perda total da atividade em pHs 4 e 9, dos celulossomas de $C$. thermocellum YM4 e extrato bruto de C. thermocellum ATCC 27405 (Johnson et al., 1982; Mori, 1992). Essa diferença de estabilidade ao $\mathrm{pH}$ entre enzimas está relacionada com a 
estrutura e composição de aminoácidos de cada uma. Estudos apontam que a adaptação alcalina é influenciada pela diminuição de aminoácidos carregados negativamente e aumento no número de arginina e resíduos neutros hidroflicos (histidina, asparagina e glutamina), portanto, interações eletrostáticas entre resíduos, são fatores essenciais para ser tolerante à pHs extremos (Fushinobu et al., 1998; Suplatov et al., 2014).

Quanto à temperatura, as atividades xilanolíticas e celulolíticas das amostras PLC e CPP foram maiores nas temperaturas de $65^{\circ} \mathrm{C}$ e $70^{\circ} \mathrm{C}$, respectivamente, como já descrito para estas atividades de $C$. thermocellum (Johnson et al., 1982; Mori, 1992; Xu et al., 2010). Um dos fatores responsáveis para que estas enzimas mantenham suas atividades em altas temperaturas, é a interação entre as proteínas, visto que há uma forte correlação quanto à associação entre as proteínas e o melhoramento da estabilidade térmica (Ross e Subramanian, 1981; Dixit e Maslov, 2013). Deste modo, a diferença de termoestabildiade entre as enzimas das amostras PLC e CPP, é provavelmente ocasionado pela maior concentração de proteínas em PLC, dado que a concentração é 15 vezes maior do que o valor quantificado para CPP (dado não mostrado).

As CMCases e xilanases de PLC apresentaram maior estabilidade térmica, em comparação com os resultados das atividades de amostras da linhagem de $C$. thermocellum JYT01 e até mesmo de celulases comerciais de T. reesei. Para o celulossoma de JYT01 após 6 dias de incubação a 50, 65 e $70^{\circ} \mathrm{C}$, a atividade de celulase foi reduzida em $35 \%, 58 \%$ e $79 \%$, respectivamente. Já para celulases comerciais foi descrita a perda total de atividade a $65^{\circ} \mathrm{C}$, no mesmo período de incubação ( $X u$ et al., 2010). As amostras PLC e CPP apresentam desta forma, parâmetros cinéticos que as habilitam a aplicação em processos industriais. Pois, por serem termoestáveis, possuem maior resistência quanto ao armazenamento em temperaturas ambientes, têm menor perda de atividade durante a sacarificação, e em casos de pré-tratamentos que requisitem altas temperaturas, não se faz necessário um resfriamento total do processo para seguir com a etapa da hidrólise enzimática, evitando deste modo, maiores gastos na obtenção do etanol de segunda geração (Turner, Mamo e Karlsson, 2007). 
Apesar de ambas as amostras apresentarem maior atividade celulolítica e xilanolítica a $60^{\circ} \mathrm{C}$, foi constatado, principalmente pelo aumento de até 38 vezes na quantidade de açúcares liberados, proveniente da mudança de temperatura da hidrólise de piolho de algodão por $\mathrm{CPP}$, de $60^{\circ} \mathrm{C}$ para $50^{\circ} \mathrm{C}$, que a termoestabilidade enzimática é uma característica fundamental para ter uma eficiente sacarificação de biomassas. Em virtude da identificação e quantificação total $(\mathrm{ng} / \mathrm{mL})$ dos açúcares liberados pela sacarificação enzimática dos três substratos (celulose, piolho de algodão e palha de cana) por dois métodos distintos (DNS e HPLC), pôde-se verificar que os resultados da quantificação de açúcar por DNS foi corroborado pelos resultados obtidos pelas análises por HPLC, para ambas as técnicas foram detectadas maior quantidade de açúcar nos experimentos realizados a $50^{\circ} \mathrm{C}$, quando comparado a $60^{\circ} \mathrm{C}$.

A sacarificação enzimática de palha de trigo e utilizando enzimas comerciais Accellerase $\AA 1500$, fabricada pela Genencor Co., Ltd (Wuxi, China) e de celulose microcristalina por $\beta$-glucosidases de vários microrganismos termófilos, não apresentou um aumento considerável de açúcar redutor do segundo dia de hidrólise para o último dia, como obtido no presente trabalho (Zhang et al., 2011; Waeonukul et al., 2012). O decaimento da velocidade de hidrólise das enzimas de PLC e CPP a partir do segundo dia de experimento, observado por meio da cinética de sacarificação, é provavelmente motivado pela presença de oligossacarídeos liberados no processo, que podem influenciar de forma inibitória nas atividades enzimáticas. Portanto, mesmo que as amostras evidenciem uma alta termoestabilidade, não significa que 0 aumento de açúcar redutor será constante.

A alta atividade específica da amostra CPP (Tabela 1), auxiliou na sacarificação e maior produção de açúcares redutores, quando comparado com a amostra PLC. Já a estabilidade térmica de PLC por 20 dias, só demonstraria vantagem nesse processo, se esta amostra não fosse inibida pelos produtos gerados e evitasse o decaimento da velocidade de hidrólise após o segundo dia de sacarificação. Uma alternativa para essa situação seria a utilização da $C$. thermocellum no bioprocesso consolidado, como estratégia para evitar a inibição na hidrólise enzimática, pois, devido à proximidade da 
bactéria com substrato, por intermédio do celulossoma, facilita o consumo da celobiose e de outros oligossacarídeos identificados como inbidores (Leibovitz e Béguin, 1996; Shoham, Lamed e Bayer, 1999).

Além disso, concluiu-se a partir do experimento de sacarificação, que a etapa do pré-tratamento alcalino, também foi essencial para obtenção significativa de açúcares redutores por meio da hidrólise enzimática. Uma vez que os valores de sacarificação obtidos para as biomassas "in natura" foi muito inferior à taxa de hidrólise para as biomassas pré-tratadas (resultado não mostrado). A lignina é um dos componentes que confere a característica recalcitrante na parede celular lignocelulósica (Chen e Dixon, 2007; Ruiz-Dueñas e Martínez, 2009; Demartini e Wyman, 2011), e como não há relatos de enzimas de $C$. thermocellum capazes de hidrolisar esse composto, a lignina se torna uma barreira limitante, dificultando o acesso das enzimas nas frações hemicelulósica e celulósica da biomassa.

No entanto, o uso de alguns pré-tratamentos termoquímicos pode liberar compostos fenólicos derivados da estrutura da lignina, interferindo no processo de hidrólise enzimática e fermentação (Sun e Cheng, 2002; Himmel et al., 2007; Kumar, Singh e Singh, 2008; Canilha et al., 2011). Neste trabalho, a atividade de xilanases e CMCases da amostra CPP não foi inibida pela presença de compostos fenólicos como vanilina, ácido p-cumárico e 4-hidroxibenzóico para xilanase, e ácido ferúlico, ácidos cinâmico, p-cumárico e 4hidroxi-benzóico para CMCase, inclusive foi observado um aumento dessas atividades, principalmente pela presença do ácido ferúlico. Desta forma, a torna promissora para aplicação em processos de degradação de biomassa lignocelulósica que utilizem esses tipos de pré-tratamentos, evitando a etapa de neutralização, que visa a remoção desses compostos fenólicos (Brodeur et al., 2011).

A vanilina não afetou a atividade de holocelulases de CPP e foi o único fenol que não inibiu estas atividades na amostra PLC, ao contrário do que já foi descrito na literatura de seu efeito inibidor, nas atividades de celulases comerciais oriundas de diversos microrganismos (Ximenes, 2010; Ximenes et al., 2010a; Tejirian e Xu, 2011). O efeito inibitório do ácido tânico foi observado 
para ambas as amostras estando como o que já se tem descrito na literatura. Sendo este fenol reportado por inibir a atividade de celulases comerciais (Spezyme CP) e de $\beta$-glicosidases (Novozyme 188) (Ximenes et al., 2010a).

O ácido ferúlico já foi descrito como responsável tanto pelo aumento na atividade da xilanase (XylT2) de Aspergillus terreus (Moreira et al., 2013), quanto pela inibição de celulases comerciais da Novozyme que tem origem de diversos microrganismos (Tejirian e Xu, 2011). Mas no caso da amostra CPP, este fenol foi o que contribuiu para o maior incremento nas atividades de xilanase e CMCase.

Com relação ao ácido cinâmico, este apresenta diferentes efeitos, dependendo da atividade enzimática, sendo um inibidor da atividade xilanolítica e contribuindo para o incremento da atividade de CMCase. Pode ser sugerido que este fenol tenha uma influência inibitória sobre enzimas xilanolíticas, pois foi observado um efeito inibitório na xilanase XylT2 de Aspergillus terreus, descrito por Moreira et. al., em 2013.

O ácido p-cumárico aumentou a atividade de CMCase de CPP assim como a de xilanase da enzima XylT2 de Aspergillus terreus (Moreira et al., 2013), e não afetou a atividade de xilanase de CPP. Outra vantagem da amostra CPP, é que ela não teve alteração em suas atividades enzimáticas quando incubada com o ácido 4-hidroxibenzóico, enquanto que esse fenol só foi observado atuando de forma repressora em outras atividades celulolíticas de enzimas comerciais oriundas de diversos microrganismos, descritas anteriormente (Ximenes, 2010; Ximenes et al., 2010a; Tejirian e Xu, 2011). De uma forma geral as holocelulases secretadas por $C$. thermocellum B8, não foram inibidas pela maior parte dos compostos fenólicos, apresentando com resultado principal, o aumento da atividade de CPP pelos ácidos ferúlico, $\mathrm{p}$ cumárico e 4-hidroxi-benzóico.

A inibição enzimática por fenóis foi elucidada por Kim et. al., em 2011, sugerindo que a causa desta inibição, fosse decorrente da precipitação de proteínas na presença de alguns compostos. Entretanto, o resultado de aumento de certas atividades enzimáticas na presença de fenóis seria em virtude de que em baixas concentrações, os grupos hidroxilas e carboxilas, 
contidos nos compostos fenólicos, aumentariam a capacidade hidrofilica de domínios de ligação à celulose, além de proteger as proteínas contra a oxidação.

Além disso, estes fenóis que influenciam no aumento de atividade, modificaria a estrutura secundária das proteínas, causando uma redução de $\alpha$ hélices e um aumento significativo de folhas $\beta$, tendo por consequência uma estrutura proteica mais flexível, de forma a aumentar a afinidade pelo substrato, ou seja, a diminuição do Km (Tian, Jiang e Ou, 2013).

Nesse contexto, a partir da identificação e caracterização das holocelulases secretadas pela bactéria $C$. thermocellum B8 foi possível verificar as condições adequadas de $\mathrm{pH}$ e temperatura para realizar o processo de sacarificação de resíduos como a palha de cana e o piolho de algodão por PLC e CPP. Além disso, até o momento não havia o conhecimento sobre a atividade de complexos celulossomais e do secretoma de $C$. thermocellum na presença de fenóis, o que irá contribuir para o desenvolvimento de eficientes coquetéis enzimáticos, pois estes compostos fenólicos são relatados na literatura como interferentes na atividade de enzimas comerciais utilizadas para sacarificação de biomassas lignocelulósicas. 


\section{CONCLUSÕES}

- Por meio deste estudo, foi possível compreender a composição e caracterização de amostras oriundas de um novo isolado de $C$. thermocellum B8, revelando diferença na expressão de enzimas com relação a outras cepas, na detecção de CelU, em cultivo de celulose.

- $O$ isolado B8, mesmo sendo crescido em celulose microcristalina, conseguiu hidrolisar materiais complexos como palha de cana e o piolho de algodão.

- Foi observado que após o segundo dia de sacarificação, os produtos obtidos pela desconstrução de materiais lignocelulósicos, acabam por interferir na velocidade de hidrólise das enzimas de $C$. thermocellum B8.

- Conclui-se também, que é interessante a etapa de purificação para obtenção da amostra de CPP, pois esta demonstrou maior atividade específica, celulossomas capazes de sacarificar biomassas complexas e apresentou um aumento de atividade na presença de diversos fenóis, que na maioria das vezes, são relatados como inibidores enzimáticos. Portanto, esta amostra é promissora em aplicações industriais que utilizem pré-tratamentos que possam liberar compostos fenólicos. 


\section{PERSPECTIVAS}

Uma perspectiva desse projeto é a expressão heteróloga e montagem de celulossomas, visando o aumento da escala de produção desse complexo, a partir dos resultados da identificação das amostras PLC e CPP obtidos nessa pesquisa. A continuidade com o teste de sacarificação em outras fontes de carbono e pré-tratamentos, bem como a análise da sacarificação das amostras na presença dos fenóis que influenciaram no aumento das atividades celulolíticas e xilanolíticas, permitirão o melhoramento na produção de açúcar redutor por meio da hidrólise enzimática. Outra perspectiva é com relação ao uso do isolado B8 de $C$. thermocellum aplicado ao bioprocesso consolidado. Entretanto, para esta última etapa, é necessário, diversos outros estudos para conciliar uma alta produção de celulossomas com o aumento da tolerância e produtividade de etanol. 


\section{REFERÊNCIAS BIBLIOGRÁFICAS}

ABDEL-BANAT, B. M. A. et al. High-temperature fermentation: how can processes for ethanol production at high temperatures become superior to the traditional process using mesophilic yeast? Applied microbiology and biotechnology, v. 85, n. 4, p. 861867, 2010. ISSN 0175-7598. Disponível em: < http://dx.doi.org/10.1007/s00253-009$\underline{2248-5}>$.

AGBLEVOR, F. A.; BATZ, S.; TRUMBO, J. Composition and Ethanol Production Potential of Cotton Gin Residues. Applied Biochemistry and Biotechnology, v. 105, n. 1-3, p. 219230, 2003. ISSN 0273-2289. Disponível em: < http://dx.doi.org/10.1385/ABAB:105:1-3:219 >.

AKINOSHO, $\mathrm{H}$. et al. The emergence of Clostridium thermocellum as a high utility candidate for consolidated bioprocessing applications. Frontiers in Chemistry, v. 2, 2014. Disponível em: < http://dx.doi.org/10.3389/fchem.2014.00066 >.

ALVIRA, P. et al. Pretreatment technologies for an efficient bioethanol production process based on enzymatic hydrolysis: A review. Bioresource technology, v. 101, n. 13, p. 4851-4861, 2010. ISSN 0960-8524. Disponível em: < http://dx.doi.org/10.1016/j.biortech.2009.11.093 >.

BALAT, M. Production of bioethanol from lignocellulosic materials via the biochemical pathway: A review. Energy Conversion and Management, v. 52, 2011. ISSN 01968904. Disponível em: < http://dx.doi.org/10.1016/i.enconman.2010.08.013 >.

BALAT, M.; BALAT, H.; ÖZ, C. Progress in bioethanol processing. Progress in Energy and Combustion Science, v. 34, 2008. ISSN 0360-1285. Disponível em: < http://dx.doi.org/10.1016/i.pecs.2007.11.001 >.

BALLESTEROS, I. et al. Optimization of the simultaneous saccharification and fermentation process using thermotolerant yeasts. Applied Biochemistry and Biotechnology, v. 39-40, n. 1, p. 201-211, 1993. ISSN 0273-2289. Disponível em: < http://dx.doi.org/10.1007/BF02918990 >.

BAYER, E. A. et al. Cellulose, cellulases and cellulosomes. Current Opinion in Structural Biology, v. 8, n. 5, p. 548557, 1998. ISSN 0959-440X. Disponível em: < http://dx.doi.org/10.1016/S0959-440X(98)80143-7 >. 
BAYER, E. A. et al. From cellulosomes to cellulosomics. Chemical record (New York, N.Y.), v. 8, n. 6, p. 364-377, 2007. ISSN 1528-0691. Disponível em: < http://dx.doi.org/10.1002/tcr.20160 >.

BAYER, E. A.; MORAG, E.; LAMED, R. The cellulosome - A treasure-trove for biotechnology. Trends in Biotechnology, v. 12, n. 9, p. 379-386, 1994. ISSN 0167-7799. Disponível em: < http://dx.doi.org/10.1016/0167-7799(94)90039-6 >.

BAYER, E. A. et al. Cellulosomes-Structure and Ultrastructure. Journal of Structural Biology, v. 124, n. 2-3, p. 221234, 1998. ISSN 1047-8477. Disponível em: < http://dx.doi.org/10.1006/jsbi.1998.4065 >.

BEG, Q. K. et al. Microbial xylanases and their industrial applications: a review. Applied microbiology and biotechnology, v. 56, n. 3-4, p. 326-338, 2001. ISSN 0175-7598. Disponível em: < http://dx.doi.org/10.1007/s002530100704 >.

BÉGUIN, P.; LEMAIRE, M. The cellulosome: an exocellular, multiprotein complex specialized in cellulose degradation. Critical reviews in biochemistry and molecular biology, v. 31, n. 3, p. 201-236, 1996. ISSN 1040-9238. Disponível em: < http://dx.doi.org/10.3109/10409239609106584 >.

BLUM, H.; BEIER, H.; GROSS, H. J. Improved silver staining of plant proteins, RNA and DNA in polyacrylamide gels. Electrophoresis, v. 8, n. 2, p. 93-99, 1987. ISSN 15222683.

BLUME, L. R. et al. Characterization of Clostridium thermocellum Isolates Grown on Cellulose and Sugarcane Bagasse. BioEnergy Research, v. 6, n. 2, p. 763775, 2013. ISSN 1939-1234. Disponível em: < http://dx.doi.org/10.1007/s12155-013-9295-6 >.

BORASTON, A. B. et al. Carbohydrate-binding modules: fine-tuning polysaccharide recognition. Biochemical Journal, v. 382, n. 3, p. 769, 2004. ISSN 0264-6021. Disponível em: < http://dx.doi.org/10.1042/BJ20040892 >.

BRADFORD, M. A rapid and sensitive method for the quantitation of microgram quantities of protein utilizing the principle of protein-dye binding. Analytical biochemistry, v. 72 , p. 248-254, 1976. ISSN 0003-2697. Disponível em: < http://dx.doi.org/10.1016/0003-2697(76)90527-3 >. 
BRODEUR, G. et al. Chemical and Physicochemical Pretreatment of Lignocellulosic Biomass: A Review. Enzyme Research, v. 2011, 2011. Disponível em: < http://dx.doi.org/10.4061/2011/787532 >.

BROSSE, N.; M., I. M. N.; RAHIM, A. A. Biomass to Bioethanol: Initiatives of the Future for Lignin. ISRN Materials Science, v. 2011, p. 1-10, 2011. ISSN 2090-6080. Disponível em: < http://dx.doi.org/10.5402/2011/461482 >.

BROWN, S. D. et al. Construction and evaluation of a Clostridium thermocellum ATCC 27405 whole-genome oligonucleotide microarray. Applied biochemistry and biotechnology, v. 137-140, n. 1-12, p. 663-674, 2007. ISSN 0273-2289. Disponível em: < http://dx.doi.org/10.1007/s12010-007-9087-6 >.

CAI, S.; ZHENG, X.; DONG, X. CBM3d, a novel subfamily of family 3 carbohydratebinding modules identified in Cel48A exoglucanase of Cellulosilyticum ruminicola. Journal of bacteriology, v. 193, n. 19, p. 5199-5206, 2011. ISSN 0021-9193. Disponível em: < http://dx.doi.org/10.1128/jb.05227-11 >.

CANILHA, L. et al. Bioconversion of sugarcane biomass into ethanol: an overview about composition, pretreatment methods, detoxification of hydrolysates, enzymatic saccharification, and ethanol fermentation. Journal of biomedicine \& biotechnology, v. 2012, p. 989572, 2011. ISSN 1110-7243. Disponível em: < http://dx.doi.org/10.1155/2012/989572 >.

CARDONA, C. A.; SÁNCHEZ, Ó. J. Fuel ethanol production: Process design trends and integration opportunities. Bioresource Technology, v. 98, n. 12, p. 24152457, 2007. ISSN 0960-8524. Disponível em: < http://dx.doi.org/10.1016/j.biortech.2007.01.002 >.

CARLSSON, A. S. Plant oils as feedstock alternatives to petroleum - A short survey of potential oil crop platforms. Biochimie, v. 91, n. 6, p. 665-670, 2009. ISSN 0300-9084. Disponível em: < http://dx.doi.org/10.1016/i.biochi.2009.03.021 >.

CHEN, F.; DIXON, R. A. Lignin modification improves fermentable sugar yields for biofuel production. Nature Biotechnology, v. 25, n. 7, p. 759-761, 2007. ISSN 10870156. Disponível em: < http://dx.doi.org/10.1038/nbt1316 >.

CHEN, J. C. P.; CHOU, C. C. Cane Sugar Handbook: A Manual for Cane Sugar Manufacturers and Their Chemists. Wiley, 1993. ISBN 9780471530374. Disponível em: < http://books.google.com.br/books?id=bDlwg2UZ8sYC $>$. 
CHEN, M. et al. Understanding Lignin-Degrading Reactions of Ligninolytic Enzymes: Binding Affinity and Interactional Profile. PLoS ONE, v. 6, n. 9, 2011. Disponível em: < http://dx.doi.org/10.1371/journal.pone.0025647 >.

CHERUBINI, F. The biorefinery concept: Using biomass instead of oil for producing energy and chemicals. Energy Conversion and Management, v. 51, n. 7, p. 14121421, 2010. ISSN 0196-8904. Disponível em: < http://dx.doi.org/10.1016/j.enconman.2010.01.015 >.

CHOI, S. K.; LJUNGDAHL, L. G. Dissociation of the cellulosome of Clostridium thermocellum in the presence of ethylenediaminetetraacetic acid occurs with the formation of trucated polypeptides. Biochemistry, v. 35, n. 15, p. 4897-4905, 1996. ISSN 0006-2960. Disponível em: < http://dx.doi.org/10.1021/bi9524629 >.

CHUM, H. L. et al. Evaluation of pretreatments of biomass for enzymatic hydrolysis of cellulose.[Organosolv process, wet oxidation, and steam explosion of wood chips]. Solar Energy Research Institute (SERI), 1985. Disponível em: < http://www.osti.gov/scitech/biblio/6151401 >.

CONAB. A Geração Termoelétrica com a Queima do Bagaço de Cana-de-Açúcar no Brasil. Análise do Desempenho da Safra 2009-2010, 2011.

CONAB. Acompanhamento de safra brasileira : cana-de-açúcar - terceiro levantamento. Companhia Nacional de Abastecimento, 2012.

CONAB. Perfil do Setor do Açúcar e do Álcool no Brasil - Safra 2011/2012. Companhia Nacional de Abastecimento, 2013.

DALE, B. Biofuels: thinking clearly about the issues. Journal of agricultural and food chemistry, v. 56, n. 11 , p. 3885-3891, 2008. ISSN 0021-8561. Disponível em: < http://dx.doi.org/10.1021/jf800250u >.

DAMERVAL, C. et al. Technical improvements in two-dimensional electrophoresis increase the level of genetic variation detected in wheat-seedling proteins. Electrophoresis, v. 7, n. 1, p. 52-54, 1986. ISSN 1522-2683.

DASHTBAN, $M$. et al. Cellulase activities in biomass conversion: measurement methods and comparison. Critical reviews in biotechnology, v. 30, n. 4, p. 302-309, 2010. ISSN 0738-8551. Disponível em: < http://dx.doi.org/10.3109/07388551.2010.490938 $>$. 
DEMAIN, A. L.; NEWCOMB, M.; WU, J. H. Cellulase, clostridia, and ethanol. Microbiology and molecular biology reviews : MMBR, v. 69, n. 1, p. 124-154, 2005. ISSN 1092-2172. Disponível em: < http://dx.doi.org/10.1128/MMBR.69.1.124$\underline{154.2005}>$.

DEMARTINI, J. D.; WYMAN, C. E. Changes in composition and sugar release across the annual rings of Populus wood and implications on recalcitrance. Bioresource technology, v. 102, n. 2, p. 1352-1358, 2011. ISSN 0960-8524. Disponível em: < http://dx.doi.org/10.1016/j.biortech.2010.08.123 >.

DEVRIES, R. P.; VISSER, J. Aspergillus Enzymes Involved in Degradation of Plant Cell Wall Polysaccharides. Microbiology and Molecular Biology Reviews, v. 65, n. 4, p. 497522, 2001. ISSN 1092-2172. Disponível em: < http://dx.doi.org/10.1128/MMBR.65.4.497-522.2001 >.

DIAS, J. M. C. S. et al. Produção de briquetes e péletes a partir de resíduos agrícolas, agroindustrais e florestais. Brasília: Embrapa Agroenergia, p. 36, 2012.

DIXIT, P. D.; MASLOV, S. Evolutionary Capacitance and Control of Protein Stability in Protein-Protein Interaction Networks. PLoS Computational Biology, v. 9, n. 4, 2013. ISSN 1553-734X. Disponível em: < http://dx.doi.org/10.1371/journal.pcbi.1003023 >.

DROR, T. W. et al. Regulation of the cellulosomal CelS (cel48A) gene of Clostridium thermocellum is growth rate dependent. Journal of bacteriology, v. 185, n. 10, p. 3042-3048, 2003. ISSN 0021-9193. Disponível em: < http://dx.doi.org/10.1128/JB.185.10.3042-3048.2003 >.

EPE, E. D. P. E. Relatório Síntese do Balanço Energético Nacional 2014 - Ano base 2013. Ministério de Minas e Energia 2014.

FELIX, C.; LJUNGDAHL, L. The cellulosome: the exocellular organelle of Clostridium. Annual Reviews in Microbiology, 1993. Disponível em: < http://www.annualreviews.org/doi/pdf/10.1146/annurev.mi.47.100193.004043 >.

FONTES, C. M.; GILBERT, H. J. Cellulosomes: highly efficient nanomachines designed to deconstruct plant cell wall complex carbohydrates. Annual review of biochemistry, $v$. 79, p. 655-681, 2010. ISSN 0066-4154. Disponível em: < http://dx.doi.org/10.1146/annurev-biochem-091208-085603 >. 
FREIER, D.; MOTHERSHED, C.; WIEGEL, J. Characterization of Clostridium thermocellum JW20. Applied and environmental microbiology, v. 54, n. 1, p. 204-211, 1988. ISSN 0099-2240.

Disponível em:

http://aem.asm.org/cgi/pmidlookup?view=long\&pmid=16347527 >.

FREUDENBERG, K. Biosynthesis and constitution of lignin. Nature n. 0028-0836 (Print), 1959.

FUJINO, T.; BÉGUIN, P.; AUBERT, J. P. Organization of a Clostridium thermocellum gene cluster encoding the cellulosomal scaffolding protein CipA and a protein possibly involved in attachment of the .... Journal of bacteriology, 1993. Disponível em: < http://jb.asm.org/content/175/7/1891.short >.

FUSHINOBU, S. et al. Crystallographic and mutational analyses of an extremely acidophilic and acid-stable xylanase: biased distribution of acidic residues and importance of Asp37 for catalysis at low pH. Protein Engineering, v. 11, n. 12, p. 1121 1128, 1998.

GANNER, T. et al. Dissecting and Reconstructing Synergism - In Situ Visualization of Cooperativity Among Cellulases. Journal of Biological Chemistry, v. 287, n. 52, p. 43215-43222, 2012. ISSN 0021-9258. Disponível em: < http://dx.doi.org/10.1074/jbc.M112.419952 >.

GILBERT, H. J.; HAZLEWO, G. P. Bacterial cellulases and xylanases Journal of General Microbiology, 1993.

GNANSOUNOU, E. Production and use of lignocellulosic bioethanol in Europe: Current situation and perspectives. Bioresource technology, v. 101, n. 13, p. 4842-4850, 2010. ISSN 0960-8524. Disponível em: < http://dx.doi.org/10.1016/j.biortech.2010.02.002 >.

GOLD, N. D.; MARTIN, V. J. J. Global view of the Clostridium thermocellum cellulosome revealed by quantitative proteomic analysis. Journal of bacteriology, v. 189, n. 19, p. 6787-6795, 2007. ISSN 0021-9193. Disponível em: < http://dx.doi.org/10.1128/JB.00882-07 >.

GOLDEMBERG, J. The Brazilian biofuels industry. Biotechnology for biofuels, v. 1, n. 1, p. 6, 2007. ISSN 1754-6834. Disponível em: < http://dx.doi.org/10.1186/1754-6834-1$\underline{6}>$.

GREENE, N. Growing Energy: How Biofuels Can Help End America's Oil Dependence Natural Resources Defense Council, New York, 2004. 
GUILLÉN, D.; SÁNCHEZ, S.; RODRÍGUEZ-SANOJA, R. Carbohydrate-binding domains: multiplicity of biological roles. Appl Microbiol Biotechnol, 2010.

GUIMARÃES, B. G. et al. The crystal structure and catalytic mechanism of cellobiohydrolase CelS, the major enzymatic component of the Clostridium thermocellum Cellulosome. Journal of molecular biology, v. 320, n. 3, p. 587-596, 2002. ISSN 0022-2836. Disponível em: < http://dx.doi.org/10.1016/S00222836(02)00497-7 >.

HAHN-HÄGERDAL, B. et al. Metabolic Engineering for Pentose Utilization in Saccharomyces cerevisiae. In: OLSSON, L. (Ed.). Biofuels: Springer Berlin Heidelberg, v.108, 2007. cap. 62, p.147-177. (Advances in Biochemical Engineering/Biotechnology). ISBN 978-3-540-73650-9.

HELD, P. Enzymatic Digestion of Polysaccharides - Part II: Optimization of Polymer Digestion and Glucose Production in Microplates. BioTek Application note, 2012. Disponível em: $<$ www.biotek.com $>$.

HEREDIA, A.; JIMÉNEZ, A.; GUILLÉN, R. Composition of plant cell walls. Zeitschrift für Lebensmittel-Untersuchung und -Forschung, v. 200, n. 1, p. 24-31, 1994. ISSN 00443026. Disponível em: < http://www.ncbi.nlm.nih.gov/pubmed/7732730 >.

HIMMEL, M. E. et al. Biomass Recalcitrance: Engineering Plants and Enzymes for Biofuels Production. Science, v. 315, n. 5813, p. 804-807, 2007. ISSN 0036-8075. Disponível em: < http://dx.doi.org/10.1126/science.1137016 >.

HOLTZAPPLE, M. et al. Inhibition of Trichoderma reesei cellulase by sugars and solvents. Biotechnology and Bioengineering, v. 36, n. 3, p. 275-287, 1990. ISSN 10970290. Disponível em: < http://dx.doi.org/10.1002/bit.260360310 >.

HORN, S. J. et al. Novel enzymes for the degradation of cellulose. Biotechnology for Biofuels, v. 5, n. 1, p. 45, 2012. ISSN 1754-6834. Disponível em: < http://dx.doi.org/10.1186/1754-6834-5-45 >.

HU, F.; RAGAUSKAS, A. Pretreatment and Lignocellulosic Chemistry. BioEnergy Research, v. 5, n. 4, p. 1043-1066, 2012. ISSN 1939-1234. Disponível em: < http://dx.doi.org/10.1007/s12155-012-9208-0 >.

$\mathrm{HU}$, J. et al. The synergistic action of accessory enzymes enhances the hydrolytic potential of a "cellulase mixture" but is highly substrate specific. Biotechnology for 
Biofuels, v. 6, n. 1, p. 112, 2013. ISSN 1754-6834. Disponível em: < http://dx.doi.org/10.1186/1754-6834-6-112 >.

IMA, I. M. D. A. Define conceitos e características do algodão em caroço, algodão em pluma, caroço de algodão, linter e subprodutos do beneficiamento de algodão. Minas Gerais, Belo Horizonte, Portaria n 630, de 30 de Março de 2004.

JOHNSON, E. A. et al. Saccharification of Complex Cellulosic Substrates by the Cellulase System from Clostridium thermocellum. Applied and environmental microbiology, v. 43, n. 5, p. 1125-1132, 1982. ISSN 0099-2240. Disponível em: < http://aem.asm.org/content/43/5/1125.short >.

JUTURU , V.; WU, J. C. Insight into microbial hemicellulases other than xylanases: a review. Journal of Chemical Technology and Biotechnology, v. 88, n. 3, p. 353-363, 2013. ISSN 1097-4660. Disponível em: < http://dx.doi.org/10.1002/jctb.3969 >.

KÁDÁR, Z.; SZENGYEL, Z.; RÉCZEY, K. Simultaneous saccharification and fermentation (SSF) of industrial wastes for the production of ethanol. Industrial Crops and Products, v. 20 , n. 1 , p. 103110, 2004. ISSN 0926-6690. Disponível em: < http://dx.doi.org/10.1016/j.indcrop.2003.12.015 $>$.

KAMM, B.; KAMM, M. Principles of biorefineries. Applied Microbiology and Biotechnology, v. 64, n. 2, p. 137-145, 2004. ISSN 0175-7598. Disponível em: < http://dx.doi.org/10.1007/s00253-003-1537-7 >.

KATAEVA, I. et al. Cloning and Sequence Analysis of a New Cellulase Gene Encoding CelK, a Major Cellulosome Component of Clostridium thermocellum: Evidence for Gene Duplication and Recombination. Journal of Bacteriology, 1999 1999. Disponível em: < citeseerx.ist.psu.edu >.

KATAEVA, I. et al. Properties and Mutation Analysis of the CelK Cellulose-Binding Domain from the Clostridium thermocellum Cellulosome. Journal of Bacteriology, v. 183, n. 5, p. 15521559, 2001. ISSN 0021-9193. Disponível em: < http://dx.doi.org/10.1128/JB.183.5.1552-1559.2001 >.

KHAZRAJI, A. C.; ROBERT, S. Interaction Effects between Cellulose and Water in Nanocrystalline and Amorphous Regions: A Novel Approach Using Molecular Modeling. Journal of Nanomaterials, 2013. 
KIM, S.; DALE, B. E. Global potential bioethanol production from wasted crops and crop residues. Biomass and Bioenergy, v. 26, 2004. ISSN 0961-9534. Disponível em: < http://dx.doi.org/10.1016/j.biombioe.2003.08.002 >.

$\mathrm{KIM}, \mathrm{Y}$. et al. Soluble inhibitors/deactivators of cellulase enzymes from lignocellulosic biomass. Enzyme and microbial technology, v. 48, n. 4-5, p. 408-415, 2011. ISSN 01410229. Disponível em: < http://dx.doi.org/10.1016/j.enzmictec.2011.01.007 >.

KUMAR, R.; SINGH, S.; SINGH, O. V. Bioconversion of lignocellulosic biomass: biochemical and molecular perspectives. Journal of Industrial Microbiology \& Biotechnology, v. 35, n. 5, p. 377-391, 2008. ISSN 1367-5435. Disponível em: < http://dx.doi.org/10.1007/s10295-008-0327-8 >.

KUNG, Y.; RUNGUPHAN, W.; KEASLING, J. D. From fields to fuels: recent advances in the microbial production of biofuels. ACS synthetic biology, v. 1, n. 11, p. 498-513, 2012. ISSN 2161-5063. Disponível em: < http://dx.doi.org/10.1021/sb300074k >.

LAEMMLI, U. K. Cleavage of structural proteins during the assembly of the head of bacteriophage T4. Nature, v. 227, n. 5259, p. 680-5, Aug 15 1970. ISSN 0028-0836 (Print)

0028-0836 (Linking). Disponível em: < http://www.ncbi.nlm.nih.gov/pubmed/5432063 $>$.

LAMED, R.; SETTER, E.; BAYER, E. A. Characterization of a cellulose-binding, cellulasecontaining complex in Clostridium thermocellum. Journal of bacteriology, v. 156, n. 2, p. 828-836, 1983. ISSN 0021-9193. Disponível em: < http://jb.asm.org/content/156/2/828.short >.

LEIBOVITZ, E.; BÉGUIN, P. A new type of cohesin domain that specifically binds the dockerin domain of the Clostridium thermocellum cellulosome-integrating protein CipA. Journal of bacteriology, v. 178, n. 11, p. 3077-3084, 1996. ISSN 0021-9193. Disponível em: < http://www.ncbi.nlm.nih.gov/pmc/articles/PMC178055/ >.

LJUNGDAHL, L. G. et al. A yellow affinity substance involved in the cellulolytic system of Clostridium thermocellum. Current Microbiology, 1983. Disponível em: < http://dx.doi.org/10.1007/BF01567580 >.

LV, W.; YU, Z. Isolation and characterization of two thermophilic cellulolytic strains of Clostridium thermocellum from a compost sample. Journal of applied microbiology, $v$. 114, n. 4, p. 1001-1007, 2013. ISSN 1364-5072. Disponível em: < http://dx.doi.org/10.1111/jam.12112 >. 
LYND, L. R. Overview and evaluation of fuel ethanol from cellulosic biomass: technology, economics, the environment, and policy. Annual review of energy and the environment, $1996 . \quad$ Disponível em: < http://www.annualreviews.org/doi/abs/10.1146/annurev.energy.21.1.403 >.

LYND, L. R. et al. Consolidated bioprocessing of cellulosic biomass: an update. Current opinion in biotechnology, v. 16, n. 5, p. 577-583, 2005. ISSN 0958-1669. Disponível em: < http://dx.doi.org/10.1016/i.copbio.2005.08.009 >.

LYND, L. R.; WANG, M. Q. A Product-Nonspecific Framework for Evaluating the Potential of Biomass-Based Products to Displace Fossil Fuels. Journal of Industrial Ecology, v. 7, n. 3-4, p. 17-32, 2003. ISSN 1530-9290. Disponível em: < http://dx.doi.org/10.1162/108819803323059370 >.

LYND, L. R. et al. Microbial cellulose utilization: fundamentals and biotechnology. Microbiology and molecular biology reviews : MMBR, v. 66, n. 3, p. 506, 2002. ISSN 1092-2172. Disponível em: < http://dx.doi.org/10.1128/MMBR.66.3.506-577.2002 >.

MARTIN, M. A. First generation biofuels compete. New biotechnology, v. 27, n. 5, p. 596-608, 2010. ISSN 1871-6784. Disponível em: < http://dx.doi.org/10.1016/j.nbt.2010.06.010 >.

MAYER, F. et al. Macromolecular Organization of the Cellulolytic Enzyme Complex of Clostridium thermocellum as Revealed by Electron Microscopy. Applied and environmental microbiology, v. 53, n. 12, p. 2785-2792, 1987. ISSN 0099-2240. Disponível em: < http://www.ncbi.nlm.nih.gov/pubmed/16347495 >.

MCBEE, R. H. The Characteristics of Clostridium thermocellum. Journal of bacteriology, 1954.

MILLER, G. L. Use of Dinitrosalicylic Acid Reagent for Determination of Reducing Sugar. Analytical Chemistry, v. 31, 1959. ISSN 0003-2700. Disponível em: < http://dx.doi.org/10.1021/ac60147a030 >.

MOHNEN, D. Pectin structure and biosynthesis. Current opinion in plant biology, v. 11, n. 3, p. 266-277, 2008. ISSN 1369-5266. Disponível em: < http://dx.doi.org/10.1016/j.pbi.2008.03.006 >.

MORAG, E.; BAYER, E. A.; LAMED, R. Relationship of cellulosomal and noncellulosomal xylanases of Clostridium thermocellum to cellulose-degrading enzymes. Journal of 
bacteriology, v. 172, n. 10, p. 6098-6105, 1990. ISSN 0021-9193. Disponível em: < http://www.ncbi.nlm.nih.gov/pmc/articles/PMC526935/ >.

MORAG, E. et al. Expression, purification, and characterization of the cellulose-binding domain of the scaffoldin subunit from the cellulosome of Clostridium thermocellum. Applied and Environmental Microbiology, v. 61, n. 5, p. 1980-1986, 1995. ISSN 00992240

1098-5336. Disponível em: < http://www.ncbi.nlm.nih.gov/pmc/articles/PMC167460/ $>$.

MORAïs, S. et al. Deconstruction of lignocellulose into soluble sugars by native and designer cellulosomes. mBio, v. 3, n. 6, 2012. Disponível em: < http://dx.doi.org/10.1128/mBio.00508-12 >.

MOREIRA, L. R. S.; FILHO, E. X. F. An overview of mannan structure and mannandegrading enzyme systems. Applied microbiology and biotechnology, v. 79, n. 2, p. 165-178, 2008. ISSN 0175-7598. Disponível em: < http://dx.doi.org/10.1007/s00253$\underline{008-1423-4}>$.

MOREIRA, L. R. S. M. et al. Two $\beta$-xylanases from Aspergillus terreus: Characterization and influence of phenolic compounds on xylanase activity. Fungal Genetics and Biology, v. 60, p. 4652, 2013. ISSN 1087-1845. Disponível em: < http://dx.doi.org/10.1016/j.fgb.2013.07.006 >.

MORI, Y. Purification and Characterization of an Endoglucanase from the Cellulosomes (Multi-component Cellulase Complexes) of Clostridium thermocellum. Bioscience, Biotechnology and Biochemistry, v. 56, n. 8, p. 1198-1203, 1992. ISSN 0916-8451. Disponível em: < http://dx.doi.org/10.1271/bbb.56.1198 >.

MURAD, A. M.; RECH, E. L. NanoUPLC-MSE proteomic data assessment of soybean seeds using the Uniprot database. BMC biotechnology, v. 12, p. 82, 2012. ISSN 14726750. Disponível em: < http://dx.doi.org/10.1186/1472-6750-12-82 >.

MURAD, A. M. et al. Detection and expression analysis of recombinant proteins in plant-derived complex mixtures using nanoUPLC-MS(E). Journal of separation science, v. 34, n. 19, p. 2618-2630, 2011. ISSN 1615-9314. Disponível em: < http://dx.doi.org/10.1002/jssc.201100238 >.

NG, T. K.; WEIMER, P. J.; ZEIKUS, J. G. Cellulolytic and physiological properties of Clostridium thermocellum. Archives of Microbiology, v. 114, n. 1, p. 1-7, 1977. ISSN 0302-8933. Disponível em: < http://dx.doi.org/10.1007/BF00429622 >. 
OHARA, H. Biorefinery. Applied Microbiology and Biotechnology, v. 62, n. 5-6, p. 474477, 2003. ISSN 0175-7598. Disponível em: < http://dx.doi.org/10.1007/s00253003-1383-7 >.

OLSON, D. G. et al. Deletion of the Cel48S cellulase from Clostridium thermocellum. Proceedings of the National Academy of Sciences of the United States of America, v. 107, n. 41, p. 17727-17732, 2010. ISSN 0027-8424. Disponível em: < http://dx.doi.org/10.1073/pnas.1003584107 >.

PAULOVÁ, L. et al. Lignocellulosic ethanol: Technology design and its impact on process efficiency. Biotechnology Advances, 2014. ISSN 0734-9750. Disponível em: < http://dx.doi.org/10.1016/i.biotechadv.2014.12.002 >.

PRAWITWONG, P. et al. Direct glucose production from lignocellulose using Clostridium thermocellum cultures supplemented with a thermostable $\beta$-glucosidase. Biotechnology for Biofuels, v. 6, n. 1, p. 184, 2013. ISSN 1754-6834. Disponível em: < http://dx.doi.org/10.1186/1754-6834-6-184 >.

RAMAN, B. et al. Impact of pretreated Switchgrass and biomass carbohydrates on Clostridium thermocellum ATCC 27405 cellulosome composition: a quantitative proteomic analysis. PloS one, v. 4, n. 4, 2009. ISSN 1932-6203. Disponível em: < http://dx.doi.org/10.1371/journal.pone.0005271 >.

RIDLEY, B. L.; O'NEILL, M. A.; MOHNEN, D. Pectins: structure, biosynthesis, and oligogalacturonide-related signaling. Phytochemistry, v. 57, n. 6, p. 929967, 2001. ISSN 0031-9422. Disponível em: < http://dx.doi.org/10.1016/S0031-9422(01)00113-3 $>$.

ROSS, P. D.; SUBRAMANIAN, S. Thermodynamics of protein association reactions: forces contributing to stability. Biochemistry, v. 20, n. 11, p. 30963102, 1981. ISSN 0006-2960. Disponível em: < http://dx.doi.org/10.1021/bi00514a017 >.

RUDOLF, A. et al. Simultaneous saccharification and fermentation of steam-pretreated bagasse using Saccharomyces cerevisiae TMB3400 and Pichia stipitis CBS6054. Biotechnology and Bioengineering, v. 99, n. 4, p. 783-790, 2008. ISSN 1097-0290. Disponível em: < http://dx.doi.org/10.1002/bit.21636 $>$.

RUIZ-DUEÑAS, F. J.; MARTÍNEZ, A. T. Microbial degradation of lignin: how a bulky recalcitrant polymer is efficiently recycled in nature and how we can take advantage of this. Microbial Biotechnology, v. 2, n. 2, p. 164-177, 2009. ISSN 1751-7915. Disponível em: < http://dx.doi.org/10.1111/j.1751-7915.2008.00078.x >. 
SARKAR, N. et al. Bioethanol production from agricultural wastes: An overview. Renewable Energy, v. 37, 2012. ISSN 0960-1481. Disponível em: < http://dx.doi.org/10.1016/j.renene.2011.06.045 >.

SARROUH, B. et al. Up-To-Date Insight on Industrial Enzymes Applications and Global Market. Journal of Bioprocessing \& Biotechniques, 2012. ISSN 2155-9821. Disponível em: < http://dx.doi.org/10.4172/2155-9821.S4-002 >.

SCHELLER, H. V.; ULVSKOV, P. Hemicelluloses. Annual Review of Plant Biology, v. 61, n. 1) p. 263-289, 2010. ISSN 1543-5008. Disponível em: < http://dx.doi.org/10.1146/annurev-arplant-042809-112315 >.

SCHWARZ, W. H. The cellulosome and cellulose degradation by anaerobic bacteria. Applied microbiology and biotechnology, v. 56, n. 5-6, p. 634-649, 2001. ISSN 01757598. Disponível em: < http://dx.doi.org/10.1007/s002530100710 $>$.

SHALLOM, D.; SHOHAM, Y. Microbial hemicellulases. Current Opinion in Microbiology, v. $6, \quad$ n. 3, p. 219228, 2003. ISSN 1369-5274. Disponível em: < http://dx.doi.org/10.1016/S1369-5274(03)00056-0 $>$.

SHEN, J.; AGBLEVOR, F. A. Modeling semi-simultaneous saccharification and fermentation of ethanol production from cellulose. Biomass and Bioenergy, v. 34, n. 8, p. 1098-1107, 2010. ISSN 0961-9534. Disponível em: < http://dx.doi.org/10.1016/j.biombioe.2010.02.014 >.

SHOHAM, Y.; LAMED, R.; BAYER, E. The cellulosome concept as an efficient microbial strategy for the degradation of insoluble polysaccharides. Trends in microbiology, v. 7, n. 7 , p. 275-281, 1999. ISSN 0966-842X. Disponível em: < http://dx.doi.org/10.1016/S0966-842X(99)01533-4 >.

SKOOG, K.; HAHN-HÄGERDAL, B. Xylose fermentation. Enzyme Microb Technol, v. 10, p. 66-80, 1988.

SOCCOL, C. R. et al. Bioethanol from lignocelluloses: Status and perspectives in Brazil. Bioresource technology, v. 101, n. 13, p. 4820-4825, 2010. ISSN 0960-8524. Disponível em: < http://dx.doi.org/10.1016/j.biortech.2009.11.067 >.

SUN, Y.; CHENG, J. Hydrolysis of lignocellulosic materials for ethanol production: a review. Bioresource technology, v. 83, n. 1, p. 1-11, 2002. ISSN 0960-8524. Disponível em: < http://dx.doi.org/10.1016/S0960-8524(01)00212-7 >. 
SUPLATOV, D. et al. Computational Design of a pH Stable Enzyme: Understanding Molecular Mechanism of Penicillin Acylase's Adaptation to Alkaline Conditions. PloS one, v. 9, n. 6, 2014.

TACHAAPAIKOON, C. et al. Isolation and characterization of a new cellulosomeproducing Clostridium thermocellum strain. Biodegradation, v. 23, n. 1, p. 57-68, 2012. ISSN 0923-9820. Disponível em: < http://dx.doi.org/10.1007/s10532-011-9486-9 >.

TEJIRIAN, A.; XU, F. Inhibition of enzymatic cellulolysis by phenolic compounds. Enzyme and microbial technology, v. 48, n. 3, p. 239-247, 2011. ISSN 0141-0229. Disponível em: < http://dx.doi.org/10.1016/j.enzmictec.2010.11.004 >.

TIAN, Y.; JIANG, Y.; OU, S. Interaction of cellulase with three phenolic acids. Food chemistry, v. 138 , n. $2-3$, p. 1022-1027, 2013. ISSN 0308-8146. Disponível em: < http://dx.doi.org/10.1016/i.foodchem.2012.10.129 >.

TURNER, P.; MAMO, G.; KARLSSON, E. N. Potential and utilization of thermophiles and thermostable enzymes in biorefining. Microbial Cell Factories, v. 6, n. 1, p. 9, 2007. ISSN 1475-2859. Disponível em: < http://dx.doi.org/10.1186/1475-2859-6-9 >.

VERARDI, A. et al. Hydrolysis of Lignocellulosic Biomass: Current Status of Processes and Technologies and Future Perspectives. Bioethanol, p. Chapter 5, 2012. Disponível em: < http://www.intechopen.com/books/bioethanol/hydrolysis-of-lignocellulosicbiomass-current-status-of-processes-and-technologies-and-future-perspe $>$.

WAEONUKUL, R. et al. Efficient saccharification of ammonia soaked rice straw by combination of Clostridium thermocellum cellulosome and Thermoanaerobacter brockii $\beta$-glucosidase. Bioresource technology, v. 107, p. 352-357, 2012. ISSN 09608524. Disponível em: < http://dx.doi.org/10.1016/j.biortech.2011.12.126 >.

WILSON, W. Light scattering as a diagnostic for protein crystal growth--a practical approach. Journal of structural biology, v. 142, n. 1, p. 56-65, 2003. ISSN 1047-8477. Disponível em: < http://dx.doi.org/10.1016/S1047-8477(03)00038-8 >.

WINGREN, A.; GALBE, M.; ZACCHI, G. Techno-Economic Evaluation of Producing Ethanol from Softwood: Comparison of SSF and SHF and Identification of Bottlenecks. Biotechnology Progress, v. 19, n. 4, p. 1109-1117, 2003. ISSN 1520-6033. Disponível em: < http://dx.doi.org/10.1021/bp0340180 >. 
WOODWARD, J. Synergism in Cellulases Systems. Bioresource Technology, v. 36, 1991 1991. Disponível em: < http://dx.doi.org/10.1007/BF00414454 >.

XIMENES, E. et al. Deactivation of cellulases by phenols. Enzyme and microbial technology, v. 48, n. 1, p. 54-60, 2010a. ISSN 0141-0229. Disponível em: < http://dx.doi.org/10.1016/j.enzmictec.2010.09.006 >.

XIMENES, E. et al. Inhibition of cellulases by phenols. Enzyme and Microbial Technology, v. 46, n. 3-4, p. 170176, 2010b. ISSN 0141-0229. Disponível em: < http://dx.doi.org/10.1016/i.enzmictec.2009.11.001 >.

XIMENES, E., KIMA, Y., MOSIER, N., DIEND, B., LADISCH, M.,. Inhibition of cellulases by phenols. Enzyme and Microbial Technology, v. 46, n. 3-4, p. 170176, 2010. ISSN 01410229. Disponível em: < http://dx.doi.org/10.1016/j.enzmictec.2009.11.001 >.

$\mathrm{XU}, \mathrm{C}$. et al. Factors influencing cellulosome activity in consolidated bioprocessing of cellulosic ethanol. Bioresource technology, v. 101, n. 24, p. 9560-9569, 2010. ISSN 0960-8524. Disponível em: < http://dx.doi.org/10.1016/j.biortech.2010.07.065 >.

YANG, S. et al. Clostridium thermocellum ATCC27405 transcriptomic, metabolomic and proteomic profiles after ethanol stress. BMC Genomics, v. 13, n. 1, p. 336, 2012. ISSN 1471-2164. Disponível em: < http://dx.doi.org/10.1186/1471-2164-13-336 >.

ZHANG, Y. et al. High solid and low enzyme loading based saccharification of agricultural biomass. BioResources, 2011. Disponível em: < https://ojs.cnr.ncsu.edu/index.php/BioRes/article/view/BioRes_07_1_0345_Zhang_LX YZ_Hi_Solid_Lo_Enzyme_Saccharification_Ag >.

ZVERLOV, V. V.; KELLERMANN, J.; SCHWARZ, W. H. Functional subgenomics of Clostridium thermocellum cellulosomal genes: identification of the major catalytic components in the extracellular complex and detection of three new enzymes. Proteomics, v. 5, n. 14, p. 3646-3653, 2005. ISSN 1615-9853. Disponível em: < http://dx.doi.org/10.1002/pmic.200401199 >.

ZVERLOV, V. V.; SCHWARZ, W. H. Bacterial Cellulose Hydrolysis in Anaerobic Environmental Subsystems-Clostridium thermocellum and Clostridium stercorarium, Thermophilic Plant-fiber Degraders. Annals of the New York Academy of Sciences, v. 1125, n. 1, p. 298-307, 2008. ISSN 1749-6632. Disponível em: < http://dx.doi.org/10.1196/annals.1419.008 >. 


\section{Curso de Inverno de Bioquímica e Biologia Molecular}

eee

둘

\section{Certificado}

Certificamos que Karen Ofuji Osiro apresentou o trabalho na forma de pôster intitulado "Purificação e Caracterização de Complexos Celulolíticos de Clostridium thermocellum", de autoria de Osiro, K.O.; Camargo, B. R.; Pereira, J. L.; Felix, C. R.; Noronha, E.F., durante o XI Curso de Inverno de Bioquimica e Biologia Molecular, realizado pelo Departamento de Bioquimica e Imunologia da Faculdade de Medicina de Ribeirão Preto - USP no periodo de 09 a 20 de julho de 2012.

Ribeirão Preto, 20 de julho de 2012

$$
\text { Ref } 1 \text {-1. }
$$

Prof. Dr. Roberto do Nascimento Silva Comissão Organizadora Docente
Maban N.Luena

Malson Neilson de Lucena Comissão Organizadora Discente 

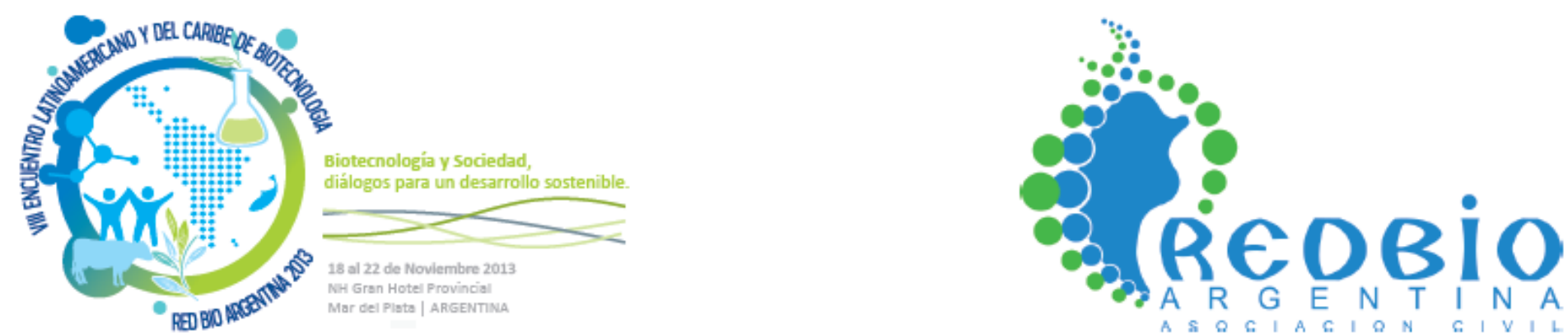

Se deja constancia que el trabajo

PURIFICATION AND CHARACTERIZATION OF CELLULOLYTIC COMPLEXS OF CLOSTRIDIUM THERMOCELLUM

de los autores

Karen Ofuji Osiro; Brenda Rabello de Camargo; Carlos Roberto Felix; Eliane Ferreira Noronha

ha sido presentado como poster

en el VIII Encuentro de Latinoamericano del Caribe de Biotecnología - REDBIO2013

$$
\text { Tuinom }
$$

PATRICIA BENAVIDES

Secretaria REDBIO Argentina

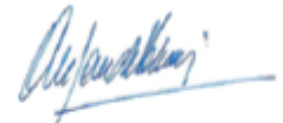

ALEJANDRO ESCANDON

Presidente
del VIII Encuentro REDBIO Argentina 2013 


\section{Simpósio de Biologia Molecular PPG-BIOMOL-UnB}

Certificamos que o trabalho

Purificação e caracterização do celulossoma do isolado de Clostridium thermocellum (B8) de rúmen de caprino.

com o autor

\section{Karen Ofuji Osiro}

foi apresentado como POSTER no

III SIMPÓSIO DE BIOLOGIA MOLECULAR DO PROGRAMA DE PÓS-GRADUAÇÃO EM BIOLOGIA MOLECULAR DA UNIVERSIDADE DE BRASÍLIA, realizado em Brasília no período de 27 a 29 de novembro de 2013.

KASVI

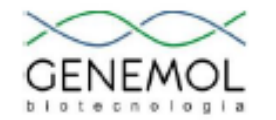

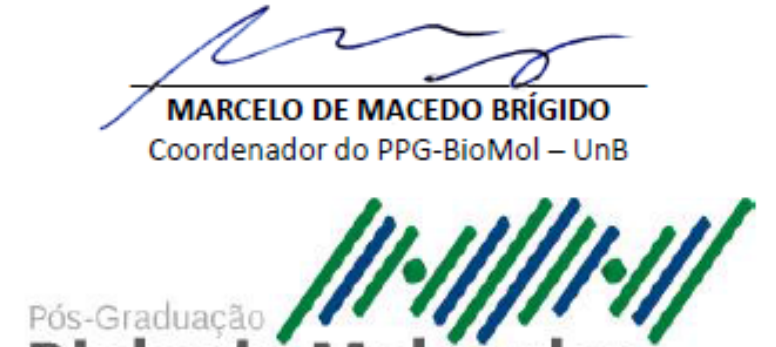

Biologia Molecular

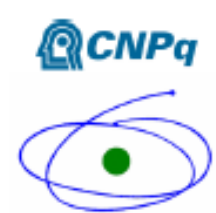

C A PE S

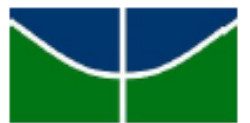

UnB 


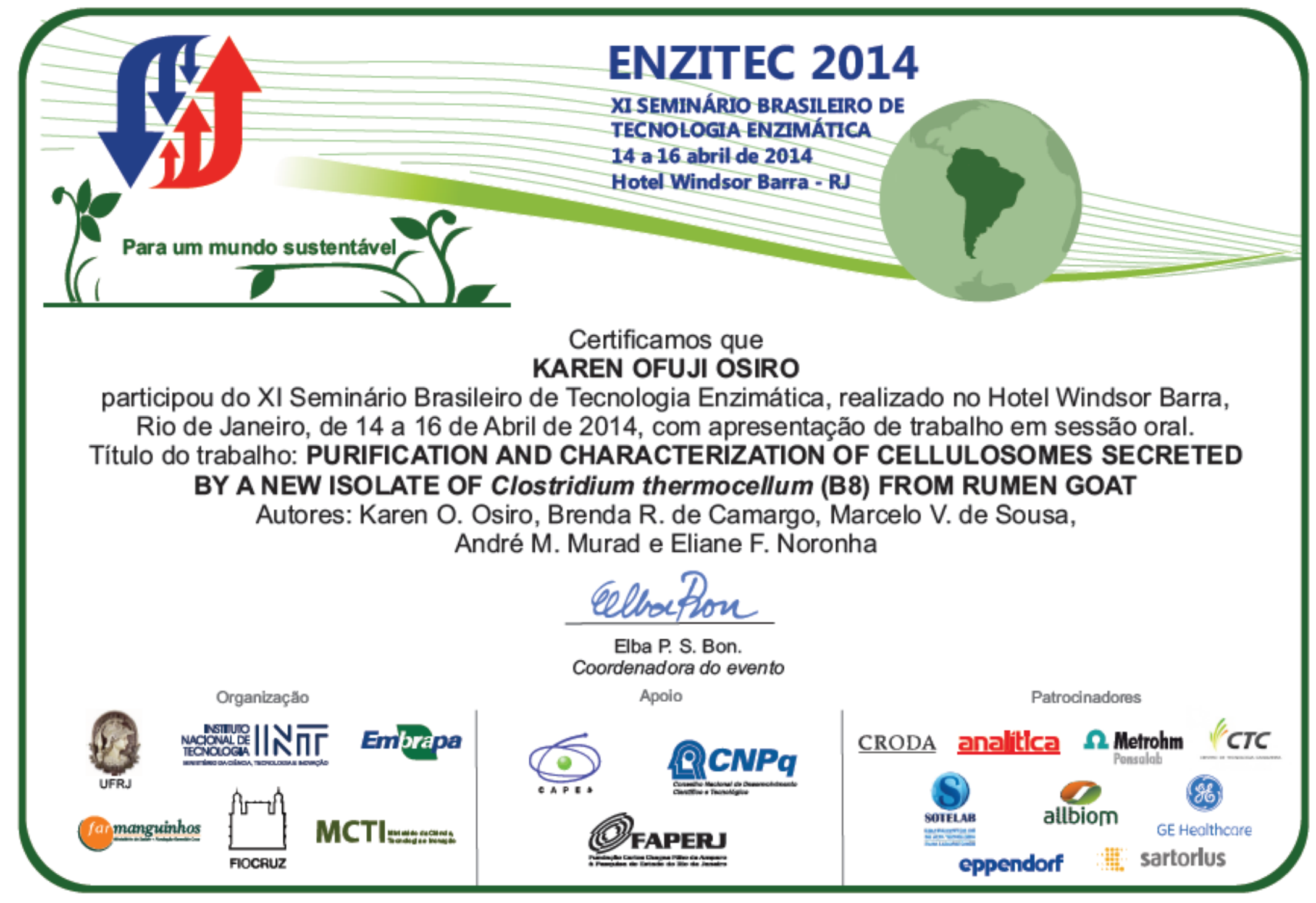




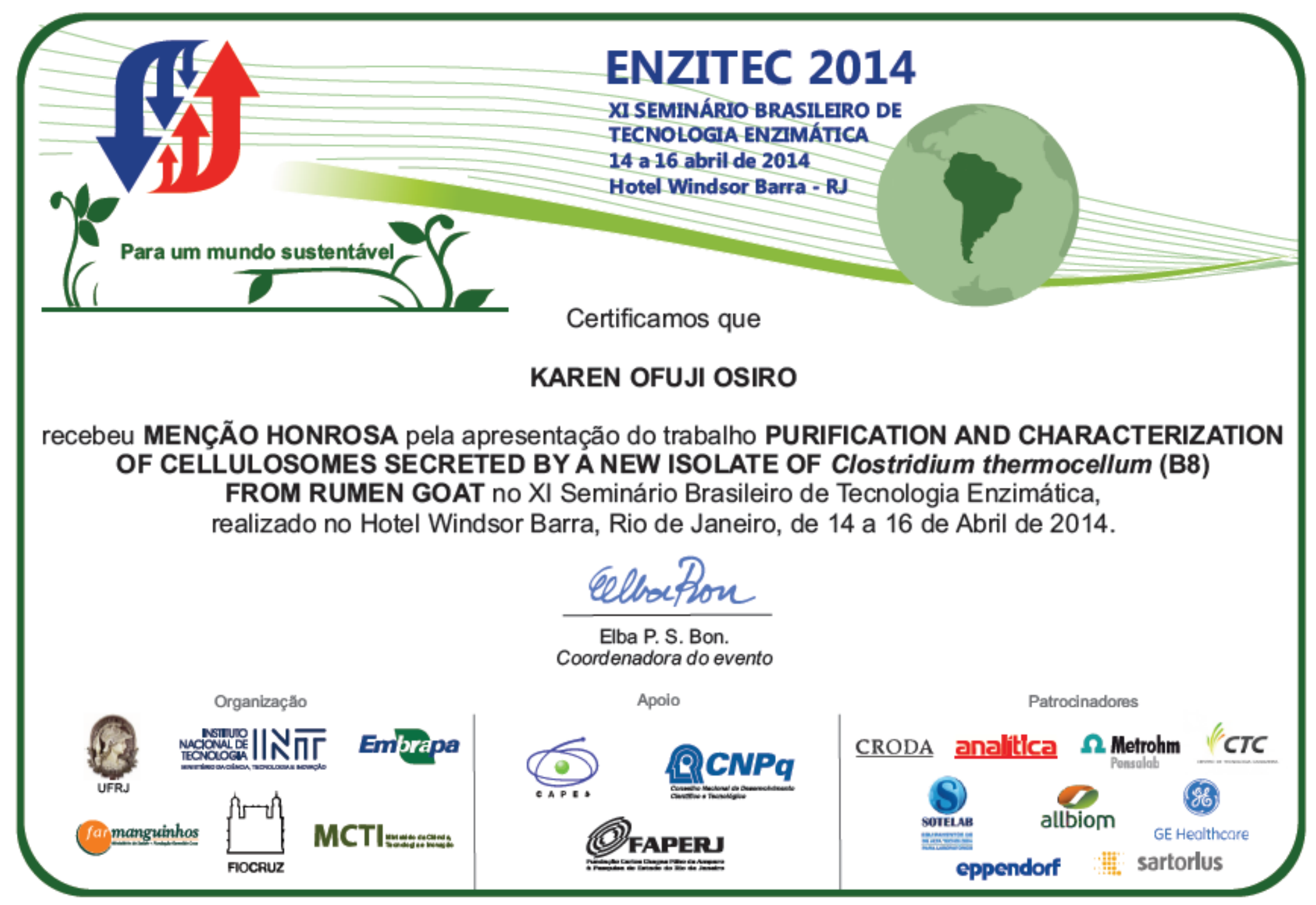




\section{Simpósio de Biologia Molecular PPG-BiolMol-UnB}

\section{Certificado}

A comissão organizadora e o PPG-BioMol-UnB reconhecem o presente certificado à

\section{Karen Ofuji Osiro}

ao trabalho apresentado na forma de PÔSTER com o título:

Characterization and comparison between the cellulosome and the crude extract produced by a new isolate of Clostridium thermocellum

durante o IV Simpósio de Biologia Molecular do Programa de Pós-graduação em Biologia Molecular da Universidade de Brasília, realizado no Instituto de Biologia no campus Darcy Ribeiro, em Brasília no período de 19 a 21 de novembro de 2014.

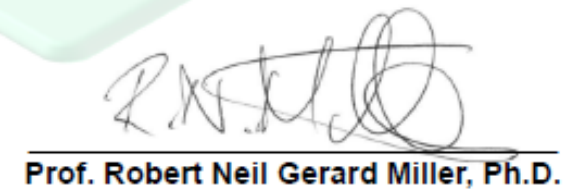
Coordenador do PPG-BioMol-UnB

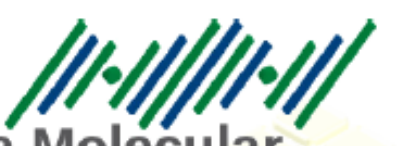

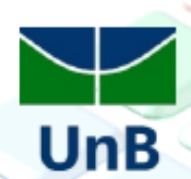

Q Q $C N P q$

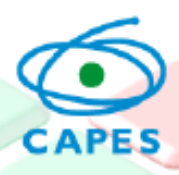




\section{Simpósio de Biologia Molecular PPG-BioMol-UnB}

\section{Certificado}

A comissão organizadora e o PPG-BioMol-UnB reconhecem o presente certificado à Sra. Karen Ofuji Osiro, como prêmio painel ao trabalho apresentado com o título: "Characterization and comparison between the cellulosome and the crude extract produced by a new isolate of Clostridium thermocellum " em colaboração com Camargo, Brenda Rabello; Inoue, Rachel Satomi; Sousa, Marcelo Valle; Murad, André Melro; Felix, Carlos Roberto; Noronha, Eliane Ferreira, durante o IV Simpósio de Biologia Molecular do Programa de Pós-graduação em Biologia Molecular da Universidade de Brasília, realizado no Instituto de Biologia no campus Darcy Ribeiro, em Brasília no período de 19 a 21 de novembro de 2014.

Brasília (DF), 21 de novembro de 2014.

Realização/Apoio
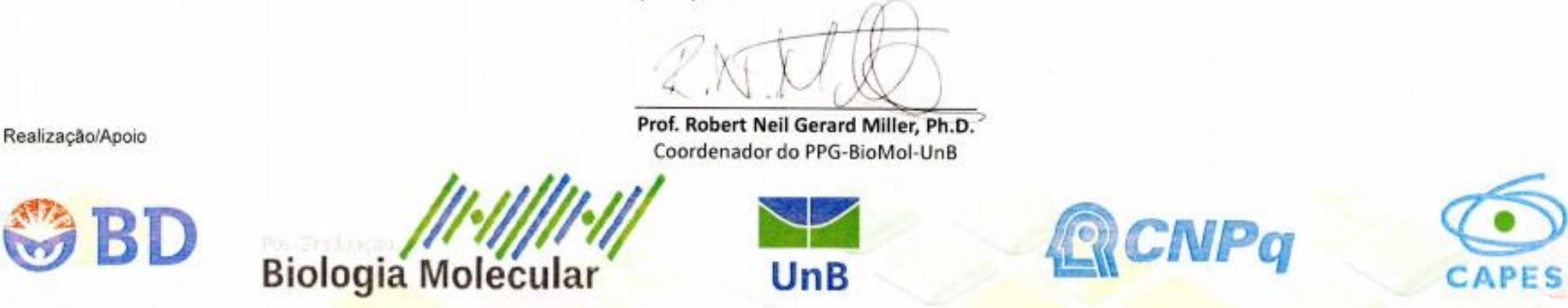
